\title{
Noninvasive diagnostic studies of arteriovenous fistulas for hemodialysis
}

Citation for published version (APA):

Tordoir, J. H. M. (1989). Noninvasive diagnostic studies of arteriovenous fistulas for hemodialysis.

[Doctoral Thesis, Maastricht University]. Rijksuniversiteit Limburg. https://doi.org/10.26481/dis.19891130jt

Document status and date:

Published: 01/01/1989

DOI:

10.26481/dis.19891130jt

Document Version:

Publisher's PDF, also known as Version of record

\section{Please check the document version of this publication:}

- A submitted manuscript is the version of the article upon submission and before peer-review. There can be important differences between the submitted version and the official published version of record.

People interested in the research are advised to contact the author for the final version of the publication, or visit the DOI to the publisher's website.

- The final author version and the galley proof are versions of the publication after peer review.

- The final published version features the final layout of the paper including the volume, issue and page numbers.

Link to publication

\footnotetext{
General rights rights.

- You may freely distribute the URL identifying the publication in the public portal. please follow below link for the End User Agreement:

www.umlib.nl/taverne-license

Take down policy

If you believe that this document breaches copyright please contact us at:

repository@maastrichtuniversity.nl

providing details and we will investigate your claim.
}

Copyright and moral rights for the publications made accessible in the public portal are retained by the authors and/or other copyright owners and it is a condition of accessing publications that users recognise and abide by the legal requirements associated with these

- Users may download and print one copy of any publication from the public portal for the purpose of private study or research.

- You may not further distribute the material or use it for any profit-making activity or commercial gain

If the publication is distributed under the terms of Article $25 \mathrm{fa}$ of the Dutch Copyright Act, indicated by the "Taverne" license above, 
Noninvasive diagnostic studies of arteriovenous fistulas for hemodialysis 



\section{Noninvasive diagnostic studies of arteriovenous fistulas for hemodialysis}

\section{PROEFSCHRIFT}

ter verkrijging van de graad van doctor

aan de Rijksuniversiteit Limburg te Maastricht, op gezag van de Rector Magnificus, Prof. Dr. F.I.M. Bonke, volgens het besluit van het College van Dekanen, in het openbaar te verdedigen op donderdag, 30 november 1989 om 14.00 uur

door

Johannes Hendrik Marie Tordoir geboren te Rotterdam in 1952 

Promotor:
Prof. Dr. G. Kootstra
Co-promotor:
Dr. P.J.E.H.M. Kitslaar

Beoordelingscommissie: Prof. Dr. B.K. Janevski (voorzitter)

Prof. Dr. R.H. Kuyten

Dr. T.J. Bast

Dr. P.J. Breslau

Dr. K.L.M. Leunissen

CIP-DATA KONINKLUKE BIBLIOTHEEK, DEN HAAG.

Tordoir, Johannes Hendrik Marie

Noninvasive diagnostic studies of arteriovenous

fistulas for hemodialysis / Johannes Hendrik

Marie Tordoir. - Maastricht : Datawyse. - III.

Thesis Maastricht. - With ref, - With summary

in Dutch.

ISBN 90-5291-008-1

SISO 605.19 UDC 616.1(043.3)

Subject headings: arteriovenous fistulas /

noninvasive investigation.

Produktie en layout: Datawyse Maastricht

Druk: Krips Repro Meppel

Uitgave van dit proefschrift werd financieel gesteund door ATL Nederland, Braun Medical, W.L. Gore \& Co, B.V, Stöpler en TD Medical. 
Aan alle dialyse patienten 



\section{Contents}

General Introduction $\ldots \ldots \ldots$

Chapter 1

Vascular Access

1-1 Types of vascular access $\ldots \ldots \ldots \ldots \ldots 13$

$1-2$ Fysiology of AV fistulas $\ldots \ldots \ldots \ldots \ldots, 17$

1-3 Fistula complications . . . . . . . . . 2 21

$1-4$ Methods of investigation . . . . . . . . 23

$1-5$ References . . . . . . . . . . . . 31

\section{Chapter 2}

Noninvasive evaluation of prosthetic arteriovenous fistulas in asymptomatic patients . . . . . . . . . 39

\section{Chapter 3}

Duplex ultrasound scanning in the assessment of

arteriovenous fistulas created for hemodialysis access:

comparison with Digital Subtraction Angiography . . . . . . 55

\section{Chapter 4}

The correlation between clinical and Duplex ultrasound

parameters and the development of complications in

arteriovenous fistulas for hemodialysis . . . . . . . . 71

\section{Chapter 5}

Hemodynamic sequelae of dialysis fistulas: A noninvasive

study with Duplex ultrasound scanning and digital

bloodpressure measurement . . . . . . . . . . . 85

\section{Chapter 6}

General Discussion . . . . . . . . . . . . . . . 101

\section{Chapter 7}

Summary $\ldots \ldots \ldots \ldots \ldots \ldots \ldots \ldots \ldots \ldots$

Chapter 8 *

Samenvatting ............... 115

Dankwoord . . . . . . . . . . . . . . . . . 119

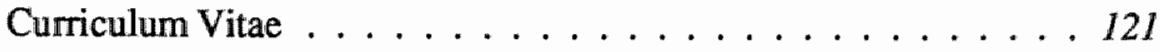





\section{General introduction}

The treatment of patients with end-stage renal failure plays a major role in modern health care. Since the development of the artificial kidney in 1943 by the Dutchman William Kolff, chronic intermittent hemodialysis can be applied to patients with failing kidneys. ${ }^{50}$ In 1985 in the USA, 85.000 patients were kept alive by dialysis. ${ }^{76}$ In 1987 in the Netherlands 2800 patients with end-stage renal failure were treated in 52 centers by means of hemodialysis or continuous ambulatory peritoneal dialysis (CAPD). ${ }^{63}$ Each year some 900 new patients are referred for dialysis and their number is still increasing such that a total of 3100 patients will be on dialysis treatment by 1990 .

In 1960 Quinton, Dillard and Scribner described the Teflon-Silastic indwelling external shunt that made chronic hemodialysis a practical method of treatment. ${ }^{67}$ The description of the Brescia/Cimino fistula in 1966 was the next step in the development of vascular access for chronic hemodialysis. ${ }^{15}$ Connection of the cephalic vein to the radial artery by a direct vascular anastomosis resulted in dilatation of the forearm veins with a high bloodflow, allowing repeated needle cannulation and withdrawal and reinfusion of blood. The final stage has evolved over the past 20 years with the use of various grafts to interpose between an artery and a vein when the patients own veins are lacking or not suitable for construction of a Brescia/Cimino arteriovenous fistula.

AV fistulas constructed for vascular access have a high rate of complications. Thrombotic occlusion and progressive vascular stenosis frequently lead to loss of the access and the need for operative revision or creation of a new access. Infection, either primary, at the time of operation, or secondary from contamination during needle puncture, is a major problem, especially in graft AV fistulas. ${ }^{12}$ False aneurysms may develop in prosthetic grafts after repeated traumatic needle punctures. The most common hemodynamic complications are excessive arteriovenous shunting and arterial insufficiency from a radial steal syndrome. Distal venous hypertension manifested by swelling, venous engorgement and ulcerations of the skin can also develop in these patients and is a sign of proximal venous outflow obstruction.

Early detection of fistula complications, followed by an elective revision, may possibly prevent fistula failure and improve the patency rate. 
For the diagnosis of fistula complications, contrast angiography has been used since $1968 .^{39}$ Indications for the performance of angiography have included reduced arterial inflow, increased venous resistance, difficulty in needle cannulation, oedema of the hand and suspected steal syndrome. More recently noninvasive techniques have been developed for the diagnosis of carotid and peripheral arterial disease. ${ }^{6,49}$ These methods can be used for the investigation of AV fistulas as well. Real-time sonography can visualize lesions within and outside bloodvessels (B-mode imaging). With Doppler examination disturbances in the bloodflow pattern induced by these lesions can be detected. In the Doppler examination high frequency ultrasound is reflected from moving red bloodcells and changed in frequency. The Doppler ultrasound can be emitted continuously (continuous-wave Doppler) or intermittently (pulsed Doppler). Duplex scanning combines the use of ultrasonic vessel imaging (B-mode imaging) and pulsed Doppler examination.

In this study several noninvasive diagnostic tests were used to investigate the typical complications occurring with hemodialysis fistulas and the results are compared with angiography.

The aim of the study was to answer the following specific questions:

- can continuous-wave Doppler analysis and real-time sonography detect stenotic lesions in Polytetrafluoroethylene (PTFE) graft AV fistulas?

- how accurate is Duplex ultrasound scanning for the diagnosis of stenotic lesions in AV fistulas?

- can fistulas complications be predicted by a regular follow- up of fistulas by means of Duplex scanning?

- what are the hemodynamic consequences of AV fistulas?

In chapter 1 the different types of vascular access, the fysiology and complications are described and methods of investigation discussed.

In chapter 2 a study on the reliability of continuous-wave Doppler spectral analysis and real-time sonography for the detection of stenoses in PTFE graft AV fistulas using fistula angiography as a reference method, is described.

In chapter 3 the results of Duplex scanning for the detection of stenoses in patients with Brescia/Cimino fistulas and graft AV fistulas are described. The results were compared to the outcome of digital subtraction angiography.

In chapter 4 a prospective study with Duplex scanning in the prediction of fistula complications is described.

In chapter 5 the hemodynamic consequences of AV fistulas, investigated by Duplex scanning and digital bloodpressure measurement are described. 
In chapter 6 the results of the different noninvasive tests are discussed. In chapter 7 a summary of the different subjects and chapters is given. In chapter 8 a summary in the Dutch language is provided. 


\section{Chapter 1}

\section{Vascular access}

\section{1-1 TYPES OF VASCULAR ACCESS}

\section{External AV shunts}

In 1960 Quinton, Dillard and Scribner described the technique of direct cannulation of arterial and venous vessels by a Teflon tip which is connected to Silastic tubing. ${ }^{67}$ The Silastic tubes are tunneled subcutaneously before they exit the skin. The arterial and venous ends are joined externally using a connector. Usual access sites include the radial artery and cephalic vein at the wrist and the posterior tibial artery and great saphenous vein at the ankle. The disadvantages of an external shunt are a high incidence of infection and thrombosis. Clotting of the shunt occurs primarily because of intimal damage at the vessel tip or by venous outflow stenosis due to intimal hyperplasia.

Although external AV shunts have been known to function for years, the average duration of functioning is usually less than 6 months. Nowadays external shunts are almost exclusively used for acute dialysis and temporarily in case of fistula failure before a new permanent access is established. An other alternative for temporary dialysis is the use of a double lumen catheter, inserted into the subclavian vein.

\section{Internal AV fistulas}

The preferred method for maintaining vascular access in chronic hemodialysis is the radial artery-to-cephalic vein Brescia/Cimino fistula at the wrist. ${ }^{15}$ Usually the anastomosis is created in a side-to-side or end of vein-to-side of artery fashion. However end-to-end types of fistulas and fistulas using the ulnar artery and basilic vein at the wrist are also performed. ${ }^{48}$ About 10 percent of all 
constructed Brescia/Cimino fistullas fail within the first month. ${ }^{83,85}$ Of the functioning fistulas the cumulative patency rate varies from 80 to $85 \%$ at one year and from 70 to $80 \%$ at 3 years. ${ }^{18,48}$ The most common cause for late failure of a Brescia/Cimino fistula is thrombosis due to a stenosis in the proximal vein at, or just above the anastomosis. The etiology of these stenoses is unclear but several causes have been proposed including trauma by repeated punctures or intimal hyperplasia from turbulent flow. Stenosis in the proximal artery or in the case of a side-to-side AV fistula, in the efferent vein is less common. Other complications include infection, formation of aneurysms, arterial insufficiency due to radial steal and venous hypertension.

\section{Secondary arteriovenous fistulas}

In case when a Brescia/Cimino fistula cannot be constructed or if it has failed, an alternative has to be offered to the patient. This alternative is usually an arteriovenous graft fistula: an interposition of a graft between any suitably sized artery and vein. The grafts are positioned in a loop or straight configuration and placed in a subcutaneous tunnel in the forearm, upper arm or upper leg. The graft can be anastomosed end-to-side to the artery and either end-to-side or end-to-end to the vein. For grafting, two types of materials are in use: biologic and synthetic. Examples of biologic grafts are autologous or homologous saphenous vein, bovine carotid artery and human umbilical cord vein. Synthetic grafts are made of Dacron or Polytetrafluoroethylene (PTFE).

A third group of secondary AV fistulas are fistulas between the brachial artery and the venous system at the level of the elbow.

\section{Biologic grafts}

May et.al. (1969) were the first authors reporting the use of the saphenous vein as a graft for AV fistulas. ${ }^{56}$ The incidence of complications with the saphenous vein AV fistula varies considerably with cumulative patency rates from 20 to $80 \%$ at one year and 10 to $60 \%$ at 3 years. ${ }^{35,52,55}$

In 1972 homologous saphenous veins were introduced as a graft for vascular access. ${ }^{82}$ After harvesting from a donor the saphenous veins are either used immediately or preserved at -50 degrees Celsius in plasma. ${ }^{1}$ At the present time 
homologous vein grafts are commercially available. The patency rate of this allograft varies from 70 to $90 \%$ at one year. Aneurysms and infection are encountered in respectively 7 and 5 percent of the cases. ${ }^{10,13}$

In 1972 Chinitz et.al. reported the use of the modified bovine carotid artery graft for access purpose. ${ }^{19}$ Fresh bovine carotid arteries are obtained from the slaughter house and subjected to enzymatic digestion in $1 \%$ ficin solution. The arteries are then drawn over stainless steel mandrels and tanned in a bath of dialdehyde starch. The modified bovine arteries appear to be collagen tubes compatible with the human vascular system. After initial enthousiasm with implantation on a large scale, these grafts were virtually abandonned, because of a high percentage of thrombotic occlusion and the risk of graft dilatation and rupture in case of infection.

Modified human umbilical vein grafts have been developed and used on a large scale for peripheral arterial reconstruction. ${ }^{21}$ In 1975 the first report was published about the modified umbilical vein as a graft for access surgery. ${ }^{58}$ The umbilical cords are obtained from normal infants at delivery and pretreated with ethanol and glutaraldehyde starch. Since the grafts are prone to aneurysm formation the umbilical vein is strengthened by surrounding it with a polyester mesh. Human umbilical vein grafts are supposed to have low thrombogenic properties due to the preservation of the intima. Publications concerning the use of umbilical vein grafts for AV fistulas are scarce and usually deal with a small group of patients. ${ }^{46,57,73}$ The patency rate achieved with umbilical vein grafts is $65 \%$ at one year and $60 \%$ at two years. Rubio reports excellent results of $93 \%$ of the grafts functioning without problems at 3 years. The incidence of graftinfection (6\%) and aneurysms (2\%) is low. ${ }^{73}$ Good results can be obtained with this material, but it is very expensive, and also rather difficult to handle because of the disparity in thickness between the umbilical vein and the forearm veins. Generally biologic grafts are susceptible to the formation of aneurysms and stenoses. The incorporation of this type of graft into the adjacent tissues is firm and makes revision difficult. Infected biologic grafts require removal with the exception of autologous saphenous vein grafts.

\section{Synthetic grafts}

Dacron grafts have been used for many years in vascular surgery. Flores et.al. reported the results of an experiment in which two different types of Dacron grafts were implanted in animals for vascular access. The patency rate of the Dacron velour graft was much better then the woven Dacron graft. ${ }^{24}$ Burdick 
et.al. reported the use of Dacron grafts in 16 patients on hemodialysis. Fifteen grafts could be used for dialysis. Two grafts were explanted because of infection and skin erosion. They had 5 late thrombotic occlusions of which in 4 instances succesful thrombectomy was accomplished. ${ }^{17}$

Of all the synthetic grafts the Polytetrafluoroethylene (PTFE) prosthesis is one of the most popular graft materials for secondary vascular access. Polytetrafluoroethylene is a polymer of tetrafluoroethylene called Teflon. When Teflon is stretched, fibrils develop and the material becomes porous, allowing ingrowth of tissue and formation of a viable neo-intima. Hanel et.al. demonstrated with the use of scanning electron microscopy the histological pattern of intimal healing in the PTFE graft. A thin pannus of endothelial cells extended across the anastomoses from the host artery into the graft. The neo-intima in the middle of the graft was however devoid of endothelial cells and consisted of a red cell-fibrin coagulum. ${ }^{37}$ In 1976 Baker et.al. were the first to report on the use of PTFE in access surgery. ${ }^{8}$ Numerous publications on its use have since appeared. The cumulative patency rates range from 60 to $87 \%$ at one year and from 50 to $69 \%$ at three years. $60,77,80,84$ Infection (10\%) and the occurrence of false aneurysms (6\%) are the major complications of PTFE grafts. Thrombotic events mostly occur as a result of stenosis due to intimal hyperplasia at the site of the graft-to-vein anastomosis. ${ }^{62}$

\section{Elbow AV fistulas}

In 1971 Tellis et.al. described the elbow fistula, a side-to-side anastomosis between the brachial artery and the cephalic vein with subsequent proximal arterialisation of the vein. ${ }^{81}$ The "reverse fistula" consists of a brachial arteryto-basilic vein anastomosis with narrowing of the proximal venous outflow by a suture. By mechanical damage to the valves in the distal basilic vein the bloodstream is forced to the forearm and the deep veins. ${ }^{26,29} \mathrm{Gracz}$ et.al. described an AV anastomosis between the brachial artery and the deep median vein. This vein connects the superficial and deep venous system. The segment of deep vein in which the median vein drains, is resected and used as a patch for the anastomosis to the artery. Through this fistula the superficial venous system of the whole arm can be arterialised. ${ }^{33}$ 


\section{1-2 FYSIOLOGY OF AV FISTULAS}

Most of the clinical symptoms and signs of AV fistulas are attributable to the low resistance leak between the high arterial pressure and low venous pressure of the circulation. The hemodynamic alterations can be divided into two groups: local circulatory changes and systemic effects.

\section{Local circulatory changes}

In a side-to-side Brescia/Cimino fistula, there is a proximal artery and vein and a distal artery and vein. The ulnar artery serves as a collateral artery, which supplies the hand (fig.1.1).

Beyond the fistula, there is the peripheral vascular bed which depends on blood supplied by the radial artery and ulnar artery for its inflow. Strandness and Sumner have described the hemodynamic changes in the forearm vessels, due to the presence of the AV fistula. ${ }^{79}$ The basic patterns of pressure and flow are

figure 1.1.: Intravenous Digital Subtraction Angiogram of the vessels in the forearm and hand of a patient with an end-to-side Brescia/Cimino arteriovenous fistula.

ra = radial artery; $c v=$ cephalic vein; $u a=$ ulnar artery; ia = interosseous artery; $\mathrm{pa}=$ palmar arch; an $=$ arteriovenous anastomosis.

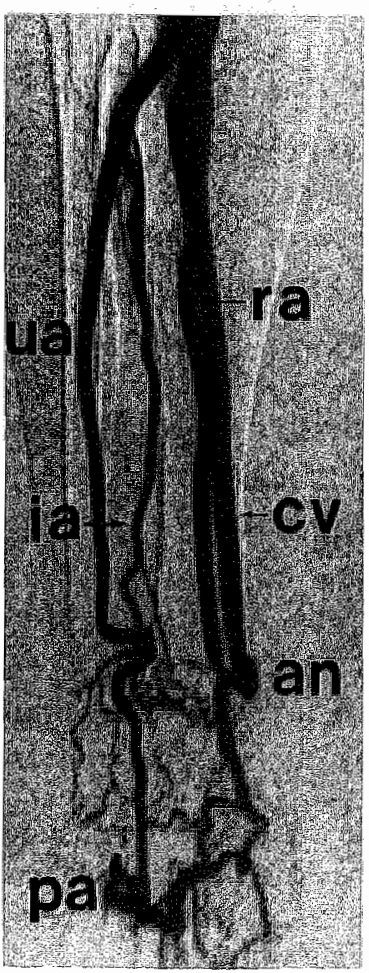


determined by the size of the fistula, the diameters of the component arteries and veins, the adequacy of the collateral circulation and the competence of the distal vein valves.

The direction of bloodflow in the proximal artery will always be toward the fistula and the flow in the proximal vein will be away from it. Prediction of the direction of flow in the distal artery and vein is more complex.

The direction and magnitude of bloodflow in the distal radial artery bears a complex relationship to the hemodynamic resistances of the fistula itself, the proximal artery, the ulnar artery and the peripheral vascular bed. This relationship can be explained with the aid of an electrical analoque in which the distal artery can be considered to be the crossarm of a Wheatstone bridge (fig.1.2). From this diagram it can be seen that the pressure in the artery at the level of the anastomosis depends on the ratio of the resistance of the proximal artery to the resistance of the fistula. The pressure in the distal radial artery depends upon the ratio of the resistance of the arterial collaterals to the resistance of the peripheral vascular bed. Since blood flows down an energy gradient (=pressure gradient), flow in the distal artery will be retrograde toward the fistula when the pressure in the distal artery exceeds that in the artery at the level of the anastomosis. On the other hand, when the arterial pressure at the level of the anastomosis exceeds

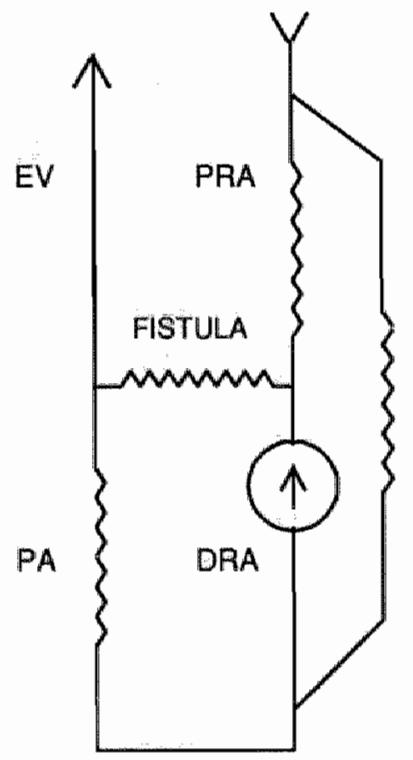

UA

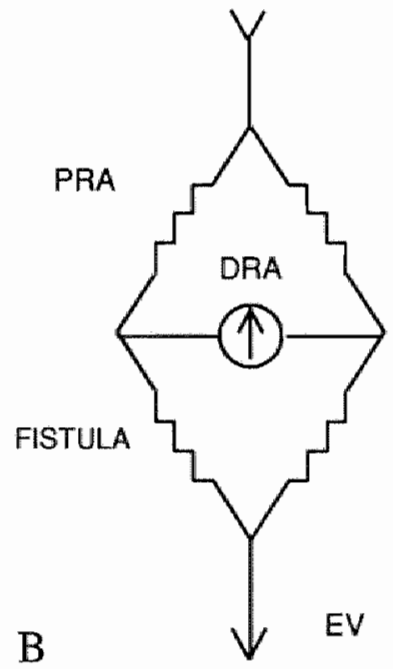

UA

A

B

PA

figure 1.2.: a. Electrical analogue of vessel resistances of a Brescia/Cimino arteriovenous fistula. b. The distal radial artery is comparable to the crossarm of a Wheatstone bridge.

PRA = proximal radial artery; $D R A=$ distal radial artery; $U A=$ ulnar artery; $P A=$ palmar arch; $\mathrm{EV}=$ efferent vein. 
Table 1.1: Direction of blood flow in the distal radial artery of Brescia/Cimino AV fistulas

Direction of flow

Resistance ratio

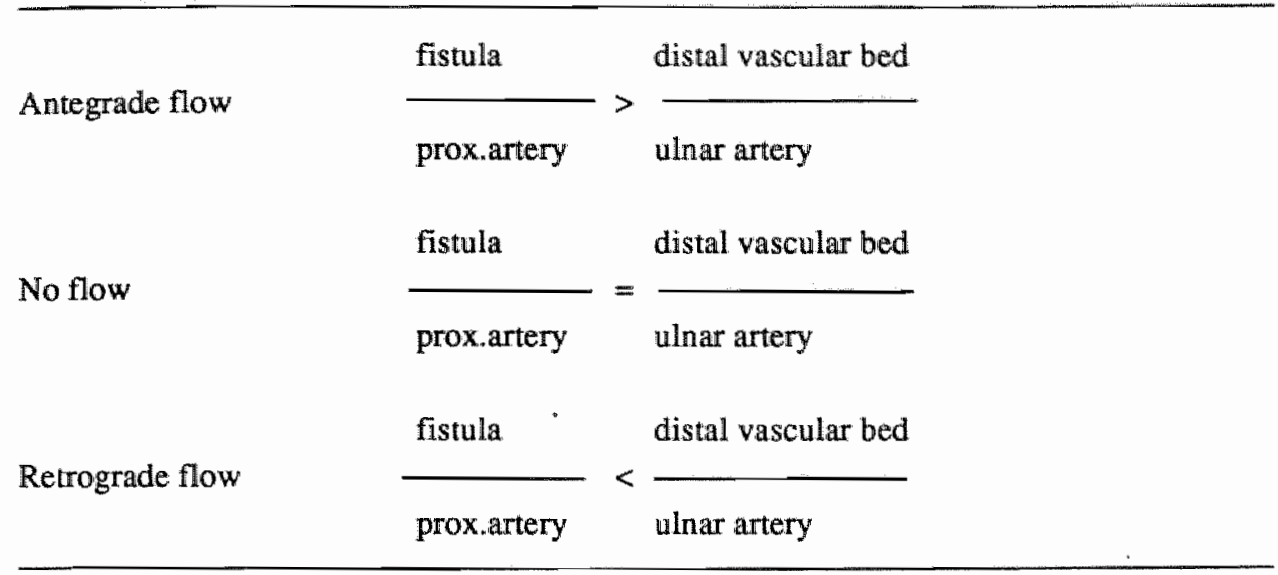

that in the distal artery, flow will proceed in normal direction to the hand. In Table 1.1 the three possible relationships based on the foregoing assumptions, are listed.

The presence of an AV fistula always jeopardizes the blood supply to the peripheral tissues. If the fistula is small and the collateral arteries are large, peripheral vasodilatation will maintain bloodflow at normal levels. However, when the fistula is large with small collateral arteries, peripheral dilatation will not be sufficient to maintain normal bloodflow. Elevation of venous pressure may result in local fluid retention and a further decrease in perfusion.

Symptoms of decreased peripheral circulation include weak pulses, decreased skin temperature and pallor. Cramps in the hand during exercise, comparable to the claudication in the lower extremity, can also occur. In severe cases, the extremity may become painful and develops necrosis.

In general, lowered digital bloodpressure can be found in extremities with AV fistulas. In case of a radial steal, compression of the distal radial artery and the fistula veins causes the arterial bloodpressure to rise and the bloodflow in the finger to increase. These changes indicate that the distal radial artery and fistula veins are part of the fistula circuit and do not contribute to the nutrition of the fingers. The blood supply to the fingers is provided by the ulnar artery. 
Occlusion of the ulnar artery or the proximal radial artery causes allso a decrease in finger bloodpressure. Collateral inflow is reduced by ulnar compression. Although this manoeuvre increases the collateral arterial resistance and leads to increased antegrade flow in the distal radial artery, so much of the blood flowing in the proximal artery is stolen by the fistula that a reduction in peripheral pressure and flow results. Generally in Brescia/Cimino fistulas, which have an excellent collateral circulation via the ulnar artery, occlusion by manual pressure on the fistula and associated vessels results in an increase in peripheral flow and bloodpressure.

In an in vitro resistance model representing the hemodynamics in the human arm of different types of $\mathrm{AV}$ fistulas, the finger bloodpressure and the chance on finger ischemia could be calculated. ${ }^{27,28}$ The model suggests that secondary access procedures in the elbow will cause finger ischemia, when the resistance of the fistula plus efferent vein is lower than the resistance of the afferent artery. Furthermore, finger ischemia in Brescia/Cimino fistulas has no direct relationship with the presence of retrograde flow in the distal radial artery. Finger ischemia is predicted never to occur in end(artery)-to-end(vein) AV fistulas. To avoid ischemia, the resistances of the fistula and efferent vein should be larger than the resistance of the afferent artery.

\section{Systemic effects}

The creation of an arteriovenous fistula for hemodialysis produces a drop in total peripheral resistance. This is the essential pathophysiologic change that institutes several compensatory adjustments aimed at maintaining arterial pressure and peripheral bloodflow. Initially the systemic arterial pressure drops, causing an increase in heart rate. In addition, circulating catecholamines increase the contractility of the heart and cause peripheral vasoconstriction. Arterial constriction helps to maintain central aortic pressure. With passage of time, cardiac output is increased, due to an increase in stroke volume. Cardiac reserve is decreased. Therefore some patients with AV fistulas may develop heart failure. Depending on the degree of fistula flow volume and the type of fistula, failing may become evident almost immediately. ${ }^{69}$ Whereas young patients may be able to sustain the increased circulatory load for a prolonged time without evident harm, older patients may develop severe heart failure. ${ }^{66}$ 


\section{1-3 FISTULA COMPLICATIONS}

Fistula complications can be divided into two categories: early complications, within 30 days of fistula creation and late complications.

\section{- Early complications}

Fistula thrombosis is one of the most frequent complications after creation of an AV fistula. Six to twelve percent of all Brescia/Cimino fistulas fails because of early thrombosis. ${ }^{47,48,85}$

Woundinfection occurs only in a few patients and does not usually lead to loss of the AV fistula. ${ }^{48}$

\section{- Late complications}

Late complications can be divided into three groups: flow-related, puncture-related and hemodynamic complications.

\section{- Flow-related complications}

Progressive vascular sclerosis in the area of the arteriovenous anastomosis, but also in the efferent vein is responsible for diminution of bloodflow and subsequently occlusion by thrombosis. In AV fistulas at the wrist and at the elbow, the stenosis develops in the region of the anastomosis. In graft AV fistulas, the stenosis is almost universally located at the graft-vein anastomosis. Different hypotheses for the development of vascular stenosis at the venous site are reported in the literature e.g. local surgical damage to the vein, mismatch of compliance between graft and vein, vein ischemia by extensive dissection or local trauma due to the repeated fistula punctures.

Histological examination of stenotic segments mostly shows thickening of the intimal layer with intimal hyperplasia. Kemkes et.al. demonstrated pannus-like intimal proliferation at the anastomotic site as well as the formation of fibrous pads in the area of puncturing. They concluded that intimal hyperplasia was the major cause for thrombosis and failure of the graft fistula. ${ }^{45}$ Clarke et.al. have implied that differences in the mechanical properties of the parent artery and various graft materials may result in anastomotic hyperplasia. They state that materials with different mechanical properties, when joined together and placed in a cyclical stress situation can result in considerable flexing at the anastomosis causing thrombosis or intimal thickening. ${ }^{20}$ Imperato et.al. documented intimal hyperplasia at sites of altered flow, either high or low flow. They experimentally found endothelial cell separation within 2 days of operation as a response to hemodynamic changes. Smooth muscle cells migrated through the 
internal elastic membrane and were modified to endothelial cells and fibroblasts. Through continuous proliferation of these cells, intimal thickening in the anastomotic area was observed. ${ }^{41}$

The frequency of late thrombosis of Brescia/Cimino fistulas is 20 to $30 \%{ }^{48,83}$ Secondary access procedures have a higher rate of thrombosis up to $68 \%$ of all fistulas. ${ }^{59}$ The results of thrombectomy and surgical revision are better in graft fistulas compared to Brescia/Cimino fistulas. ${ }^{23}$ However the cumulative patency rate of Brescia/Cimino fistulas exceeds the results of graft fistulas especially in the long run. ${ }^{47}$ In larger series, cumulative patency rates of Brescia/Cimino fistulas range from $76 \%$ at one year to $67 \%$ at three and $62 \%$ at five years of follow-up. ${ }^{71,74}$ Reported patency rates of the various graft materials (bovine carotid artery graft; saphenous vein graft; PTFE prosthesis) range from 59 to $74 \%$ at one year, 33 to $57 \%$ at three years and 20 to $43 \%$ at five years of follow-up. ${ }^{36,55,68}$

\section{- Puncture-related complications}

Depending on the frequency of dialysis and the method used (single versus double-needle puncture) every year 150 to 300 vessel punctures are performed in patients on maintenance hemodialysis. Penetration of the skinbarrier can cause infection due to an improper asepsis. Especially bovine grafts and PTFE grafts are prone to infection. ${ }^{61}$ In bovine grafts this will lead to graft desintegration and the need for graftexcision. Multiple punctures in a small traject of an AV fistula can cause weakening of the vessel wall with formation of aneurysms. Increased venous pressure due to efferent vein obstruction may cause abnormal vessel dilatation. False aneurysms develop due to inadequate compression of puncture holes after withdrawal of the needles.

\section{- Hemodynamic complications}

An AV fistula may cause a change in bloodflow volume and in flow direction in the forearm vessels. When there is insufficient collateral arterial bloodflow, ischemia of the hand may occur. The frequency of distal ischemia varies according to the kind of access: 0.2 to $2.4 \%$ in Brescia/Cimino fistulas; 3 to $6 \%$ in graft fistulas. Elbow fistulas have the greatest chance on peripheral ischemia $(25-33 \%) .{ }^{35,53,54}$ Irreversible ischemia necessitating limb amputation is very rare. Venous engorgement (Venous hypertension) with oedema of the hand can occur due to proximal venous obstruction with reversed venous bloodflow in the forearm.

Cardiac insufficiency with a high-output failure due to an excessive fistula flow is only seldomly encountered. Anderson et.al. reported on the development of 
cardiac failure in upper extremity fistulas. ${ }^{2}$ Rosenthal et.al. measured fistula flow in PTFE graft fistulas and found flows between 2 and 3 litres in patients with cardiac failure and distal ischemia. ${ }^{72}$ For the treatment of high-output failure banding of the fistula or the use of tapered grafts is advised. ${ }^{4}$

\section{1-4 METHODS OF INVESTIGATION}

\section{Physical examination}

After completion of the arteriovenous anastomosis of the fistula, a thrill is usually palpable and a loud bruit can be heard over the anastomosis and the efferent vein. Failing AV fistulas are often signaled by difficulties in dialysis with low flow rates or high venous resistances. There is a diminution of the thrill or bruit over the venous outflow. Some fistulas will thrombose after a period of hypotension during dialysis or major surgery. ${ }^{11}$

Evaluation of failing fistulas must begin with a careful analysis of clinical data. Important information can be obtained from the dialysis personnel. A high venous resistance on dialysis is suggestive of a proximal outflow obstruction. Poor arterial inflow is indicative of a stenosis in the afferent vessels, usually in the region of the anastomosis. Venous hypertension with swelling of the hand is a sign of proximal vein obstruction. In addition, if the thrill over the proximal vein is replaced by a prominent pulsation, venous runoff is probably compromised.

\section{Angiography}

The first report concerning angiography of AV fistulas was published by Hurwich in 1968. He used direct cannulation of the brachial artery for contrast injection and visualization of the vessels in Brescia/Cimino fistulas. ${ }^{39}$

In 1973 Staple introduced retrograde angiography for the diagnosis of malfunctioning fistulas. A needle is inserted into the venous draining limb of the fistula directed towards the anastomosis. A bloodpressure cuff is placed around the upper arm and inflated to $250 \mathrm{~mm} \mathrm{Hg}$ to occlude bloodflow in the arm. Contrast material is injected manually. Arterial and venous fistula limbs are visualized by contrast flowing distally in the artery and proximally in the veins. Venous runoff can be seen by gradually lowering the pressure in the upper arm 
cuff. $^{78}$ Anderson et.al. reported on the results of 256 angiograms performed because of low flow and increased venous resistance during dialysis, suspected high-output failure, aneurysms and hemodynamic complications. In $91 \%$ of the studies useful information was obtained and fistula revisions could be accomplished. Only one already poorly functioning fistula, thrombosed after angiography. ${ }^{5}$ Glanz et.al. reviewed 125 angiograms of AV fistulas. Direct brachial cannulation as well as retrograde angiography were performed with good diagnostic results. They prefer brachial cannulation, because this method allows a physiologic study of the fistula. There were no complications associated with the brachial cannulation. ${ }^{30}$ Transfemoral catheterisation using the Seldinger technique with selective contrast injection into the brachial artery for the study of AV fistulas, has been reported in $1979 . .^{42}$

Transvenous angiography with subtraction technique and Digital Subtraction Angiography (DSA) are today accepted methods of angiography. ${ }^{43}$ Based on digital image processing with subtraction and contrast enhancement, bloodvessels can be imaged by means of intravenous or intra-arterial injection of contrast medium.

Good results for the diagnosis of fistula complications with DSA have been reported by several authors. Picus et.al. use the conventional technique of contrast injection directly into the graft or venous limb of the fistula with a pressure cuff for proximal occlusion of the bloodvessels of the arm. They consider intravenous injection of large amounts of contrast and a good cardiac output mandatory for a good diagnostic study. ${ }^{64}$ Boomsma et.al. reported good results of intravenous DSA studies with several advantages versus conventional angiography: no arterial punctures and no pain for the patient. The osmotic loading however is substantial and overhydration may cause heart failure. Intravenous bolus injection in the contralateral extremity provides real information about fistula anatomy and flow characteristics. ${ }^{14}$

\section{Segmental bloodpressure measurement and plethysmography}

Segmental limb systolic bloodpressure measurement has been used for the diagnosis of congenital AV fistulas. ${ }^{75}$ It can also be applied to the study of dialysis fistulas. The reduced peripheral resistance associated with AV fistulas decreases mean arterial pressure in the arterial tree, but increases pulse pressure. Therefore, proximal to an AV fistula the systolic bloodpressure usually will be increased in comparison to the contralateral extremity, whereas distal to the fistula, the bloodpressure may be normal or in case of a steal, may be decreased. 
Limb plethysmography and pulse-volume recording can be used for monitoring of increased volume changes due to AV fistulas and detection of distal steal phenomena. ${ }^{40}$ Directly after placement of an AV fistula digital bloodpressure drops and flattening of plethysmographic traces can be expected distal to the fistula. However, the decrease in distal perfusion improves with time, because of the development of collateral circulation.

\section{B-mode imaging}

The B-mode imaging techniques are based on the concept that ultrasound traversing biologic tissue is reflected from interfaces between structures with different acoustic impedances. In AV fistulas the ultrasound is reflected from arterial and venous vessel walls. It presents anatomic information. Stenotic lesions are identified as echogenic material within the lumen of the vessel. In addition, B-mode imaging offers the potential of detection of vessel wall irregularities and lesions outside the vessel wall like hematoma and aneurysm formation. The limitations of the B-mode imager are related to the inability of ultrasound to differentiate between substances of the same acoustic impedance and therefore to distinguish soft fatty plaques from a recent thrombus. This implies that a significant stenosis may be underestimated and even a totally occluded vessel may appear normal on the image. Many of the problems of real-time B-mode imaging can be overcome by the combined use of pulsed Doppler analysis and B-mode imaging with the Duplex scanner.

\section{Doppler investigation}

In Doppler flowmeters a beam of ultrasonic waves is emitted from a piezoelectric crystal and directed towards bloodvessels. The ultrasound reflected from the moving red bloodcells is shifted in frequency by an amount proportional to the velocity of the bloodcells. This effect is known as the Doppler effect. In continuous-wave Doppler flowmeters the ultrasound is transmitted from one crystal and the reflected ultrasound received by another crystal. The pulsed Doppler system is transmitting the ultrasound intermittently from a piezoelectric crystal. Between the emissions of the burst of ultrasound the same crystal is used to receive the reflected ultrasound from the previous emission. An electronic gate allows the selection of ultrasound reflections from a certain distance from the transducer. The size of the sample volume depends on the 
duration of emission and the width of the ultrasonic beam. The size of the sample volume is small compared to the size of the insonated vessel and it can be positioned in the center of the vessel. This is the main advantage of pulsed Doppler systems over continuous-wave Doppler devices. In the continuouswave Doppler system, if flow is detected, it is present somewhere along the transducer axis, but its origin is unknown. The Doppler signal represents a composite of all velocity signals along the line of site.

Only recently Doppler systems have been used for the evaluation of arteriovenous fistulas. 7,31

\section{Duplex scanning}

In Duplex scanning, B-mode imaging and pulsed Doppler analysis are combined. The B-mode image serves as an anatomical roadmap for the identification of vessels and to recognize anatomic variations. Calcified plaques and narrowings of the vessel on the B-mode are important guides for correct placement of the sample volume in detecting flow patterns with the Doppler system. Moreover, the B-mode imager is a prerequisite for accurate placement of the sample volume in the center of the vessel and to ensure a constant angle of the Doppler beam with respect to the vessel axis. The displayed velocity or frequency of the Doppler signal is affected by the angle of insonation. A 60-degree Doppler angle provides the optimum Doppler spectrum and makes selection of this angle in every examination possible to compare the results of different investigations.

With the development of Duplex scanning, a method is available that combines anatomic information with physiologic data. The method permits a quantitative evaluation of the velocity changes at all levels of the arterial system in the human body. Especially the accuracy of Duplex scanning in the detection of carotid artery stenosis is well established. ${ }^{16}$

\section{Analy sis of the Doppler signal}

The Doppler ultrasound signal may be analysed by different techniques: acoustic interpretation, spectral analysis and quantitative signal analysis. 


\section{Acoustic interpretation}

In audible interpretation of the Doppler signal a subjective analysis is made of the characteristics of the signal. An experienced observer can distinguish the specific disturbances in bloodflow velocity of arterial and venous Doppler signals. In normal peripheral arteries the Doppler sounds are pulsatile and synchronous with the cardiac cycle. They consist of two high-pitched sounds followed by a pause. The first sound follows the systolic cardiac phase and the second represents the reversed flow. Arteries with an inflow obstruction have a damped signal without a second sound. In arteriovenous fistula a loud sound can be heard continuously during systole and diastole indicative of a low peripheral resistance. Recognition of a stenosis can be achieved by the detection of an increase in frequency shift, particularly during the systolic phase of the cardiac cycle.

\section{Spectral analysis}

A graphic display of the entire range of frequencies and amplitudes of the Doppler spectrum may be obtained with a real-time spectrum analyser. Under normal circumstances in peripheral and carotid arteries the distribution of frequencies has a maximum along the upper border of the velocity waveform. The resultant clear area below the outline of the upper velocity waveform is called the window. The Doppler frequency spectrum from a continuous-wave Doppler system is broader than that of a pulsed Doppler system because of the sample volume that encompasses the cross-section of the interrogated vessel. The backscattered continuous-wave Doppler spectrum will include the high frequencies associated with centerline bloodflow velocity as well as the lower frequencies associated with slower moving bloodcells near the vessel wall. In pulsed Doppler systems only a small area of the vessel is insonated with as result also a small spectrum. If a severe stenotic lesion is present in the vessel under investigation the Doppler spectrum will show disturbances as compared to the normal pattern. At the site of the stenosis the frequency shift will rise due to an increased bloodflow velocity. Distal to a stenosis broadening of the Doppler spectrum with disappearance of the window will occur, because of turbulence and eddy currents. As the flow velocity increases the laminar regularity of the flow may change to turbulent flow. In AV fistulas with large fistula flows, turbulence often occurs with subsequently spectral broadening of the Doppler signal. 


\section{Quantitative signal analysis}

Numerical parameters from the Doppler signal waveform can be measured and calculations made in a standard fashion. Fronek et.al, have characterised Doppler curves in a straight forward way. ${ }^{25}$ From the advancing and receding maximall curves a number of parameters can be derived which describe the shape of the curve (fig.1.3).

figure 1.3.: Quantitative parameters of the Doppler spectrum according to Fronek. Fmax=maximal systolic frequency; Fmin=minimal (reversed) frequency; Folias= enddiastolic frequency; mean $=$ mean frequency.

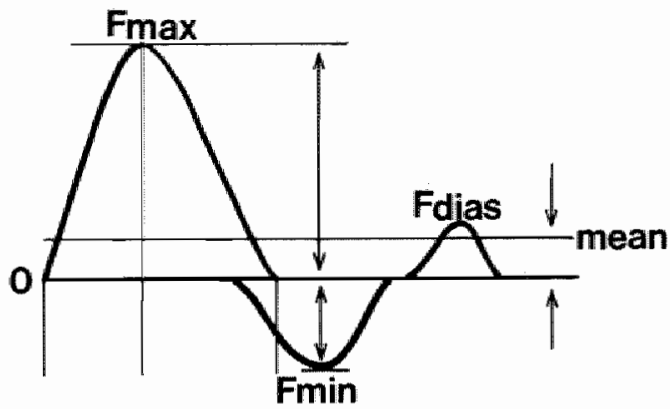

The maximum frequency waveform represents the velocity of the fastest moving bloodcells during the heart cycle. In normal peripheral arteries with a high peripheral resistance a relatively high peak and mean reversed flow velocity is found, whereas in distal obstruction a decrease in and even disappearance of reversed flow can be noticed. Also in arteriovenous fistulas enddiastolic frequencies (Fdias) and maximum advancing frequencies (Fmax) are markedly increased.

A numerical measurement of peripheral resistance can be obtained by calculation of the Resistance Index (RI).The Resistance Index is defined as:

$\mathrm{RI}=$ (Fmax-Fdias)/Fmax. ${ }^{65}$

The values of RI are between zero and one and will be lower in case of a decreased peripheral resistance, which in AV fistulas is usually the situation. It can be expected that in case of increased peripheral resistances, RI will show higher values. In AV fistulas this may occur in the presence of a significant outflow obstruction. 
Gosling et.al. introduced a method which characterises the shape of the Doppler waveform by a single parameter: the Pulsatility Index is defined as the sum of the maximum oscillatory energy of the Doppler waveform divided by the mean energy over a cycle (fig.1.4). ${ }^{32}$ Since PI is a ratio between frequencies derived from the same spectrum, it is a dimensionless number which indicates the shape of the maximal waveform curves independently of the angle of insonation. The PI is decreased in cases of proximal stenosis and in cases of decreased peripheral resistance. In arteries with a high peripheral resistance PI values are usually increased.

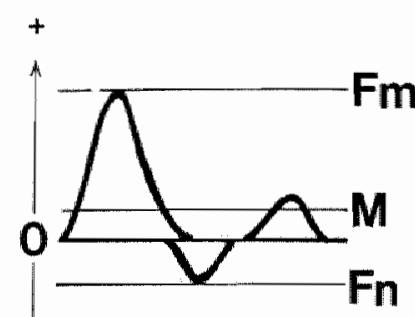

a

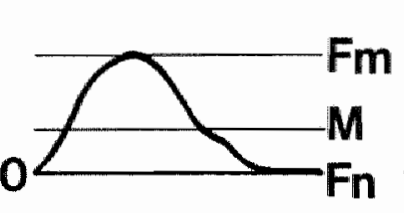

b

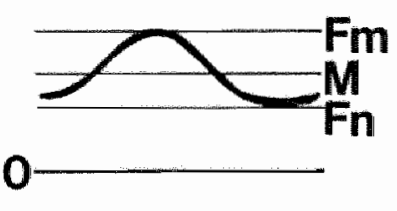

C

figure 1.4.: Determination of the Pulsatility Index (PI); PI= Fm-Fn/M.

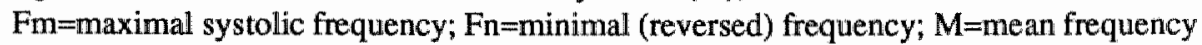
a. normal peripheral vessel; b. proximal stenosis; $c$. arteriovenous fistula.

\section{Flow measurements}

Bloodflow measurements during creation of an AV fistula have been used by several authors. Anderson et.al. reported the results of electromagnetic flow measurements of Brescia/Cimino fistulas and bovine grafts. In the grafts the flow was almost twice the flow in Brescia/Cimino fistulas. ${ }^{3}$ Hart et.al. also used electromagnetic measurement of flow in bovine grafts. They divided their patients into three groups: fistulas with low flows (25 patients); fistulas with moderate flows ( 35 patients) and fistulas with high flows (25 patients). In the last group ischemic steal syndrome and congestive heart failure in 6 patients necessitated fistula revision. ${ }^{38}$ Elfström et.al. found a positive correlation between the immediate flow in the fistula and the long-term survival of Brescia/ Cimino fistulas. ${ }^{22}$ Kaye et.al. used an isotope dilution method for flow measure- 
ment. Three needles were inserted into the fistula at the arterial end, directed against the direction of flow to measure recirculation; one in the direction of flow and used for infusion of the isotope and the third at the venous end of the fistula for venous sampling. Good correlation of this method compared to Doppler flow measurement was found. ${ }^{44}$

Flow volume measurement by means of Doppler investigation has been advocated by several authors. ${ }^{51,70}$ Continuous-wave as well as multigated Doppler devices can be used to measure fistula flow. However the reliability of these methods has not yet been proven compared to invasive methods of flow measurement. 


\section{1-5 REFERENCES}

$1 \quad$ Adar,R., Siegal,A., Bogokowsky „H., Mozes,M.:

The use of arteriovenous autograft and allograft fistulas for chronic hemodialysis. SGO 1973; 136: 941-944:

2 Anderson,C.B., Codd, J.R., Graff, R.A., Groce, M.A., Harter,H.R., Newton, W.T.: Cardiac failure and upper extremity arteriovenous dialysis fistulas.

Arch Int Med 1976; 136: 291.

3 Anderson,C.B., Etheredge,E.E., Harter, H.R., Codd,J.R., Graff,R.A., Newton, W.T.: Bloodflow measurements in arteriovenous dialysis fistulas. Surgery 1977; $81: 459-461$.

4 Anderson, C.B., Groce, M.A.:

Banding of arteriovenous dialysis fistulas to correct high-output cardiac failure. Surgery $1975 ; 78: 552-554$.

5 Anderson,C.B., Gilula,L.A., Sicard,G.A., Etheredge,E.E.: Venous angiography of subcutaneous hemodialysis fistulas. Arch Surg 1979; 114: 1320-1325.

6 Baalen,J.M.,van:

Noninvasive detection of lesions in the carotid artery bifurcation.

Thesis, Maastricht, the Netherlands, 1987.

7 Baalen,J.M.,van, Jakimowic., J.J., Flendrig,J.A.;

Spectral analysis of the Doppler signal in evaluation of arteriovenous shunts.

In: Kootstra G., Jörning P.J.G.: Access Surgery, Lancaster,MTP Press Ltd; 1983: 67.

8 Baker,L.D., Johnson,J.M., Goldfarb,D.:

Expanded polytetrafluoroethylene (PTFE) subcutaneous arteriovenous conduit: an improved vascular access for chronic hemodialysis.

Trans Amer Soc Artif Int Organs 1976; 22: 382-384.

9 Bast, T.J.:

De toegang tot de bloedbaan voor geregelde dialyse behandeling.

Thesis, Amsterdam, the Netherlands, 1974.

10 Berardinelli,L., Beretta,C., Pozzoli,E., Vegeto,A.:

A comparative study in angioaccesses for haemodialysis using homologous saphenous vein, bovine and PTFE graft:

In: Kootstra G., Jörning P.J.G.: Access Surgery, Lancaster, MTP Press Ltd; 1983: 99-101.

11 Berger,A., Rosenberg,N.:

Hypotension and closure of hemodialysis access shunts.

Am Surg 1983; 49: 551-553.

12 Bhat,D.J., Tellis, V.A., Kohlberg,W.I., Driscoll,B., Veith,F.J.:

Management of sepsis involving expanded polytetrafluorothylene grafts for hemodialysis access.

Surgery $1980 ; 87: 445-450$.

13 Bonnaud,Ph., Man, N.K.:

Ten years experience on 310 homologous vein grafts for arteriovenous fistula.

In: Kootstra G., Jörning P.J.G.:Access Surgery , Lancaster, MTP Pressi Ltd:1983;117. 
14 Bowmsma.J.H.B., Beukhof,J.R., Geerlings,W, Hem,G.K., wan der:

Intravenous digital subtraction angiography of arteriovenous fistulas and shunts for hemodialysis.

Diagn Imag Clin Med 1984; 53: 243-249.

15 Brescia,M.J., Cimino,J.E., Appel,K., Harwich,B.J.:

Chronic hemodialysis using venipuncture and a surgically created arteriovenous fistula.

N Engl J Med 1966; 275: 1089.

16 Breslau,P.J.:

Ultrasonic Duplex scanning in the evaluation of carotid artery disease.

Thesis, Maastricht, the Netherlands, 1981.

17 Burdick,J.F., Scott, W. Cosimi,A.B.:

Experience with Dacron graft arteriovenous fistulas for dialysis access.

Ann Surg 1978; 187: 262-266.

18 Cerilli,J., Limbert, JG.:

Technique and results of the construction of arteriovenous fistulas for hemodialysis.

SGO 1973; 137: 922-924.

19 Chinitz,J.L., Yokoyama, T., Bower,R., Schwartz, C.:

Self-sealing prosthesis for arteriovenous fistula in man..

Trans Am Soc Artif Intern Organs 1972; 18: 452.

20 Clarke,R.E., Apostolou,S., Kardos,J.L.:

Mismatch of mechanical properties as a cause of arterial prosthesis thrombosis.

Surg Forum 1976; $27: 208$.

21 Dardik,H., Ibrahim,I.M., Dardik,I.:

Evaluation of glutaraldehyde-tanned human umbilical cord vein graft as a vascular prosthesis for bypass to the popliteal, tibial and personeal arteries.

Surgery $1978 ; 83: 577-583$.

22 Elfström,J., Thomsen,M.:

The prognostic value of bloodflow measurements during construction of arteriovenous fistulae.

Scan J Urol Nephrol 1981; 15: 323-326.

23 Etheredge, E.E., Haid,S.D., Maeser,M.N., Sicard,G.A., Anderson,C.B.:

Salvage operations for malfunctioning polytetrafluoroethylene hemodialysis access grafts.

Surgery 1983; 94: 464-470.

24 Flores,L., Dunn,I., Frumkin,E, Forte,R., Requena,R., Ryan,J., Knopf,M., Kirschner,J., Levowitz; B.S.:

Dacron arterio-venous shunts for vascular access in hemodialysis.

Trans Amer Soc Artif Intern Organs 1973; 19: 33-35.

25 Fronek,A., Coel,M., Bemstein,E.F.:

Quantitative ultrasonographic studies of lower extremity flow velocities in health and in disease.

Circulation 1976; 53: 957-960.

26 Geis, W.P., Giacchino,J.L., Twatsuki,S., Vaz,A.J., Hano,J.E., Ing,T.S.:

The reverse fistula for vascular access.

SGO 1977; 145: 901-904. 
27 Giemert,M.J.C.,van, Bruyninckx, C.M.A.:

Haemodynamics of arteriovenous fistulas in the human arm.

In: Kootstra G., Jörning P.J.G.: Access surgery, Lancaster; MTP Press Lid; 1983: 155.

28 Gemert,M.J.C.,van, Bruyninckx, C.M.A.:

Simulated hemodynamic comparison of arteriovenous fistulas.

J Vasc Surg 1987; 6: 39-44.

29 Giacchino,J.L., Geis, W.P., Buckingham,J.M., Vertuno,L.L., Bansal, V.K.:

Vascular access: Long-term results, new techniques.

Arch Surg 1979; 114: 403-409.

30 Glanz,S., Bashist,B., Gordon,D.H., Butt,K.M.H., Adamsons,R.;

Angiography of upper extremity access fistulas for dialysis.

Radiology 1982; 143: 45-52.

31 Glickman,M.H., Clark,S., Goodrich, V.:

Determination of outflow stenosis of arteriovenous fistulas for hemodialysis.

Bruit 1985; 9: 16-19.

32 Gosling,R.C., Dunbar,G., King,D.H.:

The quantitative analysis of occlusive peripheral arterial disease by a non-intrusive ultrasonic technique.

Angiology 1971; 22: 52-55.

33 Gracz,K.C., Ing,T.S., Soung,L.S., Armbruster,K.F., Seim,S.K., Merkel,F.K.:

Proximal forearm fistula for maintenance hemodialysis.

Kidney Int 1977; 11: 71.

34 Haimov,M., Baez,A., Neff,M., Slifkin,R.:

Complications of arteriovenous fistulas for hemodialysis.

Arch Surg 1975; 110: 708-712.

35 Haimov,M., Burrows,L., Baez,A., Neff,M., Slifkin,R.:

Alternatives for vascular access for hemodialysis: experience with autogenous- saphenous vein autografts and bovine heterografts.

Surgery $1974 ; 75: 447-452$.

36 Haimov,M., Burrows,L., Schanzer,H., Neff,M., Baez,A., Kwun,K., Slifkin,R.

Experience with arterial substitutes in the construction of vascular access for hemodialysis. J Cardiovasc Surg 1980; 211: 149-154.

37 Hanel,K.C., McCabe,C., Abbott,W.M., Fallon,J., Megerman,J.:

Current PTFE grafts.

A biomechanical, scanning electron, and light microscopic evaluation.

Ann Surg 1982; 195: 456-463.

38 Hart,A., Oh,H.K.

Clinical significance of intraoperative flow measurement during bovine heterograft AV fistulae formation.

Trans Am Soc Artif Intern Organs 1981; 27: 623-624.

39 Hurwich,B.J.:

Brachial arteriography of the surgically created radial arteriovenous fistula in patients undergoing chronic intermittent hemodialysis by venipuncture technique.

Am J Roentgen 1968; 104: 394-402. 
40 Hurwich, B.J.:

Plethysmographic forearm blood flow studies in maintenance hemodiallysis patients with radial arteriovenous fistullae.

Nephron $1969 ; 6: 673-678$.

41 Imperato,A.M., Bracco,A., Kim,G.E., Zeff,R.:

Intimal and neointimal fibrous proliferation causing failure of arterial reconstructions. Surgery $1972 ; 72: 1007-1017$.

42 Janevski, B.K.

Arterio-venous shunts in hemodialysis.

In: Greep J.M. et.al.: Pain in shoulder and arm, Mart. Nijhoff Publ; 1979:42-48.

43 Karnahl,H.M., Konner, K., Hoeffken, W.:

Transwenous serial xeroradiography. Unproblematical examination of arteriovenous fistulae for long-term dialysis.

Diagnostic Imaging 1982; 51: 57-61.

44 Kaye,M., Lemaitre,P., O'Regan,S.:

A new technique for measuring blood flow in polytetrafluoroethylene grafts for hemodialysis.

Clinical Nephrology $1977 ; 8: 533-534$.

45 Kemkes,B.M., Borchard,F.:

Complications and surgical treatment after angioaccess.

In: Kootstra G., Jörning P.J.G.: Access Surgery, Lancaster, MTP Press Ltd; 1983: 203-210.

46 Kester,R.C.:

Early results with human umbilical cord vein allografts for haemodialysis.

Br J Surg 1978; 65: 609-610.

47 Kherlakian,G.M., Roedersheimer,L.R., Arbaugh,J.J., Newmark,K.J., King,L.R.:

Comparison of autogenous fistula versus expanded polytetrafluoroethylene graft fistula for angioaccess in hemodiallysis.

Am J Surg 1986; 152: 238-243.

48 Kinnaert,P., Vereerstraeten,P., Toussaint,C., Geertruyden,J.,van:

Nine years experience with internal arteriovenous fistulas for hemodialysis: a study of some factors influencing the results.

Br J Surg 1977; 64: 242-246.

49 Kitslaar,P.J.E.H.M.

Doppler viltrasound tests in the diagnosis of chronic aortoiliac obstruction.

Thesis, Masstricht, the Netherlands, 1982.

50 Kolff,W.J., Berk,H.T.J., Welle,M.,ter, Ley,J.W.,van der, Dijk,E.C.,van, Noordwijk $_{\mathrm{b}} \mathrm{J}_{\text {, }}$, van:

De kunstmatige nier: een dialysator met groot oppervlak.

Geneesk Gids $1943 ; 21: 27$.

51 Levy,B.I., Ponsin,J.C., Bourquelot,P., Amar,E., Martineaud,J.P.:

Non-invasive Doppler blood flow measurement in the vascular access of haemodialysis patients.

In: Kootstra G., Jörning P.J.G.:Access Surgery, Lancaster, MTP Press Ltd; 1983: 135-140. 
52 Lijftogt, H.J.A., Lobach, H.J.C., Vroonhoven, Th.J.M.V., van:

Saphenous vein arteriovenous fistulas for haemodialysis patients.

Neth J Surg 1982; 34: 63-67.

53 Matolo,N., Kastagir,B., Stevens,L.E., Chrysanthakopoulos,S., Weaver,D.H., Klinkman, $\mathbf{H}_{\text {: }}$

Neurovascular complications of brachial arteriovenous fistula.

Am J Surg 1971; 121: 716-719.

54 Mattson, W.J.:

Recognition and treatment of vascular steal secondary to hemodialysis prostheses.

Am J Surg 1987; 154: 198-201.

55 May,J., Harris,J., Patrick, W.:

Polytetrafluoroethylene (PTFE) grafts for haemodialysis:

patency and complications compared with those of saphenous wein grafts.

Aust N Z J Surg 1979; 49: 639-642.

56 May,J., Tiller,D., Johnson,J., Stewart,J,, Rossheill,A.G.:

Saphenous-vein arteriovenous fistula in regular dialysis treatment.

N Eng J Med 1969; 280: 770.

57 Mindich,B.P.:

Experimental and clinical experience with human umbilical cord for vascular replacement: continued follow-up.

Helv Chir Acta 1980; 47: 191-194.

58 Mindich,B.P., Silverman,M.J., Elguezabal,A., Levowitz,B.S.:

Umbilical cord vein fistula for vascular access in hemodialysis.

Trans Amer Soc Artif Int Organs 1975; 21: 273-279.

59 Müller-Wiefel,H., Haug,M.:

Zur Frage des geeigneten Gefässersatzes in der DialyseShunt-Chirurgie.

Angio 1983; 5: 199-209.

60 Munda,R., First,R., Wesley Alexander,J., Linnemann,C.C., Fidler,J.P., Kittur,D.:

Polytetrafluoroethylene graft survival in hemodialysis.

JAMA 1983; 249: 219-222.

61 Nghiem,D.D., Schulak,J.A., Corry,R.J.:

Management of the infected hemodialysis access grafts.

Trans Am Soc Artif Intern Organs 1983; 29: 360-362.

62 Palder,S.B., Kirkman,R.L., Whittemore,A.D., Hakim,R.M.,

Lazarus,J.M., Tilney,N.L.:

Vascular access for hemodialysis. Patency rates and results of revision.

Ann Surg 1985; 202: 235-239.

63 Personal communication Dutch Kidney Foundation.

December 1987.

64 Picus,D.D., Breda ,A. van., Katzen,B.T., Steinberg,D.L.:

Use of digital subtraction angiography for evaluation of

vascular access for hemodialysis.

Cardiovasc Int Rad 1987; 10: 210-214.

65 Planiol,T., Pourcellot, L., Pottier, J.M., Degiovanni, E.:

Etude de la circulation carotidienne par les methodes ultrasioniques et de la thermographie.

Rev Neurol 1972; 128: 127-141. 
66 Rosner H.M. Rosner, M.L.:

Non-invasive evaluation of arteriovenous hemodialysis fistula.

J Vasc Technol 1987; 11: 93-97.

67 Quinton, W., Dillard,D., Scribner, B.H.;

Cannitation of blood vessels for prolonged hemodialysis.

Trans Am Soc Artif Intern Organs 1960; 6: 104.

68 Raju, S:

PTFE grafts for hemodialysis access.

Ann Surg 1988; 206: 666-673.

69 Reis,F.J., Hirsch,A.T., Come,P.C.:

Detection and treatment of high-output cardiac failure resulting from a large hemodialysis fistula.

Cath Cardiovasc Diagnosis 1988; 14: 263-265.

70 Rittgers,S.E., Garcia-Valdez,C., McCormick,J.T., Posner,M.P.,

Noninvasive blood flow measurement in expanded polytetrafluoroethylene grafts for hemodialysis access.

J Vasc Surg 1986; 3: 635-642.

71 Rohr,M.S., Browder,W., Frentz, G.D., McDonald,J.C.:

Arteriovenous fistulas for long-term dialysis. Factors that influence fistula survival.

Arch Surg 1978; 113: 153-155.

72 Rosenthal,J.J., Bell,D.D., Gaspar,M.R., Movius,H.J., Lemire,G.G.:

Prevention of high flow problems of arteriovenous grafts.

Am J Surg 1980; 140: 231-233.

73 Rubio,P.A., Farrell,E.M.:

Modified human umbilical vein arteriovenous fistula for maintainance hemodialysis.

Arch Surg 1982; 117: 943-945.

74 Ruegsegger,C.H., Wauters,J.P., Mosimann,R.:

Long-term follow up of 170 Brescia-Cimino fistulas.

In: Kootstra G., Jörning P.J.G.: Access Surgery, Lancaster, MTP Press Ltd; 1983: 193-194.

75 Rutherford,R.B.:

Noninvasive testing in the diagnosis and assessment of arteriowenous fistulas.

In Bernstein,E.F.: Noninvasive diagnostic techniques in vascular disease, Mosby Company $1985 ; 666-679$.

76 SEOPF Newsletter; edited by Mary Sloan.

1984; $4: 31$.

77 Slooff,M.J.H.

Secondary access surgery for hemodialysis and chemotherapy.

Thesis, Groningen, the Netherlands, 1981.

78 Staple, T.W.:

Retrograde venography of subcutaneous arteriovenous fistulas created surgically for hemodialysis.

Radiology 1973; 106: 223-224.

79 Strandness,D.E., Sumner,D.S.:

Arteriovenous fistula.

In: Hemodynamics For Surgeons, Grune and Stratton 1975; 621-663. 
80 Tellis, V.A., Kohlberg,W.I., Bhat,D.J., Driscoll,B., Veith,F.J.:

Expanded Polytetrafluoroethylene graft fistula for chronic hemodialysis.

Ann Surg 1979; 189: 101-105.

81 Tellis, V.A., Veith,F.J., Soberman,R.J., Freed,S.Z., Gliedman,M.L.:

Internal arteriovenous fistula for hemodialysis.

SGO 1971; 139: 866-870.

82 Tice,D.A., Zerbino, V.:

Clinical experience with preserved human allografts for vascular reconstruction.

Surgery 1972; 72: 260.

83 Tordoir,J.H.M., Kwan, T.S., Herman,J.M.M.P.H., Carol, E.J., Jakimowicz,J.J.:

Primary and secondary access surgery for haemodialysis with the Brescia-Cimino fistula and the polytetrafluoroethylene (PTFE) graft.

Neth J Surgery $1.983 ; 35: 8-12$.

84 Tordoir,J.H.M., Herman,J.M.M.P.H., Kwan,T.S., Diderich,P.M.:

Long-term follow-up of the polytetrafluoroethyllene (PTFE)

prosthesis as an arteriovenous fistula for haemodialysis.

Eur J Vasc Surg 1988; 2: 3-7.

85 Zerbino,V.R., Tice,D.A., Katz,L.A., Nides,B.D.;

A 6 year clinical experience with arteriovenous fistulas and bypasses for hemodialysis.

Surgery $1974 ; 76: 1012-1023$. 



\title{
Chapter 2
}

\section{Noninvasive evaluation of prosthetic arteriovenous fistulas in asymptomatic dialysis patients}

\begin{abstract}
The value of Doppler spectral analysis for the diagnosis of fistula stenosis was evaluated in 23 Polytetrafluoroethylene (PTFE) graft fistulas in 22 patients on maintenance hemodialysis. Fourteen of these patients were also evaluated by means of real-time sonography. Maximal systolic frequencies, the degree of spectral broadening in the Doppler spectrum, and inner graftdiameters as measured by sonography were compared with the results of fistula angiography. A total of 16 stenotic lesions of $50 \%$ or more were found in the graft itself (3), at the graft-venous anastomosis (9) and in the efferent vein (4). The sensitivity of Doppler spectral analysis for the diagnosis of stenoses was $88 \%$ with a specificity of $89 \%$ using maximal systolic peak frequencies and $85 \%$ and $84 \%$ respectively using spectral broadening as parameter. For sonography a sensitivity of $69 \%$ was found with a specificity of $100 \%$. The combined use of Doppler analysis and sonography resulted in a sensitivity of $92 \%$ and a specificity of $100 \%$. Our study suggests that Doppler spectral analysis and sonography are useful methods for the detection of stenoses in PTFE graft AV fistulas and in the efferent veins.
\end{abstract}




\section{INTRODUCTION}

In patients with end-stage renal failure the maintenance of an access to the bloodstream for hemodialysis is of primary importance. The initial approach for the creation of a vascular access is the Brescia/Cimino radiocephalic arteriovenous fistula at the wrist. ${ }^{1}$ Some 30 to 40 percent of these fistulas will be lost with time because of irreversible complications. ${ }^{2}$ Patients with these complications need secondary access procedures, of which the implantation of prosthetic PTFE grafts is one of the most popular methods. ${ }^{3}$ The lifetime of these grafts is short with a cumulative patency rate of $84 \%$ at one year and $64 \%$ at three years. ${ }^{4}$ The most important cause of graft failure is thrombosis and progressive stenosis due to intimal proliferation at the graft-vein anastomosis and in the efferent vein. Prevention of thrombosis by elective correction of stenotic lesions either through surgical repair or transluminal angioplasty is more logical, than to wait untill the graft fails and to perform a thrombectomy at that moment. ${ }^{5,6,7}$ Most commonly angiography is recommended for the evaluation of fistula stenoses. This can be performed through cannulation of the brachial artery or by direct injection into the fistula with a proximal occluding pressure cuff. ${ }^{8}$ These methods have a proven applicability and accuracy, but entail the risk of occlusion of the access site and are unpleasant to the patient. Noninvasive vascular investigation with the use of Doppler ultrasound has been used on a large scale for detection of carotid and peripheral arterial disease with good results. ${ }^{9,10}$ In 1978 Kottle et.al. suggested the use of sonography for the diagnosis of AV fistula complications. ${ }^{11}$

The aim of this study is to evaluate the use of Doppler spectral analysis and real-time sonography for the detection of stenoses in asymptomatic patients with prosthetic (PTFE) graft fistulas. The results of the investigations are compared to angiographic findings.

\section{PATIENTS AND METHODS}

Doppler spectra were recorded in 22 patients with 23 prosthetic graft fistulas. There were 6 men and 16 women with a mean age of 61 years, ranging from 29 to 76 years. All patients had reinforced PTFE ( ${ }^{\circledR}$ Gore-tex) grafts with an inner diameter of $6 \mathrm{~mm}$, placed in the lower arm (21) or upper leg (2). Most grafts were placed in a loop configuration between the brachial artery and a vein at the elbow. There were 3 straight grafts between the radial artery and the cephalic vein at the elbow. The upper leg grafts were situated between the superficial 
femoral artery above the knee and the common femoral vein in the groin. The grafts were in position for a mean time of 30 months (3-98 months). All grafts were functioning satisfactorily with adequate flow for dialysis. The patients were examined prior to a dialysis treatment in the supine position. Doppler spectra were recorded with the use of a bidirectional continuous-wave Doppler flowmeter with an emitting frequency of $8 \mathrm{Mhz}$ (Medasonics Versatone D9) in combination with real-time display of the frequency spectrum of the Doppler signal (Unigon Angioscan). The Doppler spectra were represented by a gray scale display with time on the horizontal axis and frequency shift on the vertical axis. The frequency range display could be set to a maximum of $20 \mathrm{Khz}$. Five segments of the graft AV fistula were screened: the arterial anastomosis; the arterial site of the prosthesis; the venous site of the prosthesis; the venous anastomosis and the efferent vein. Representative spectra from the different locations were freezed and self-developing photographs were taken. In the analysis of the Doppler spectra the maximum systolic peak frequencies were recorded and the degree of spectral broadening was determined by visual interpretation (fig. 2.1). Spectral broadening was classified as grade I when in the display the window beneath the spectrum had disappeared or as grade II when negative frequencies occurred as result of severe turbulent flow.

Fourteen patients underwent B-mode sonography. The graft and efferent vein were examined by ultrasound with a $7.5 \mathrm{Mhz}$ real-time small-parts transducer in longitudinal and transverse direction. The course and diameter of the prosthesis, location of arterial and venous anastomoses as well as intra- and extraluminal lesions were identified and internal vessel- and graftdiameters were measured in millimeters.

Finally all patients had conventional angiography by direct injection through a needle inserted into the graft with the tip directed toward the arterial anastomosis. A pressure cuff on the upper arm was inflated to $250 \mathrm{~mm} \mathrm{Hg}$ to occlude the bloodflow in the arm. Twenty cc of contrast material was injected manually. During deflation of the upper arm cuff rapid filming was performed. This technique visuallized both the afferent artery and efferent vein with contrast flowing retrogradely in the artery and proximally in the veins thus allowing differentiation between these vessels. ${ }^{8}$

Fourteen patients had additional Digital Subtraction Angiography (DSA) either by serial intravenous bolus injection of $40 \mathrm{cc}$ contrast in the contralateral arm or direct injection of $20 \mathrm{cc}$ contrast into the graft with a proximal occluding cuff. 


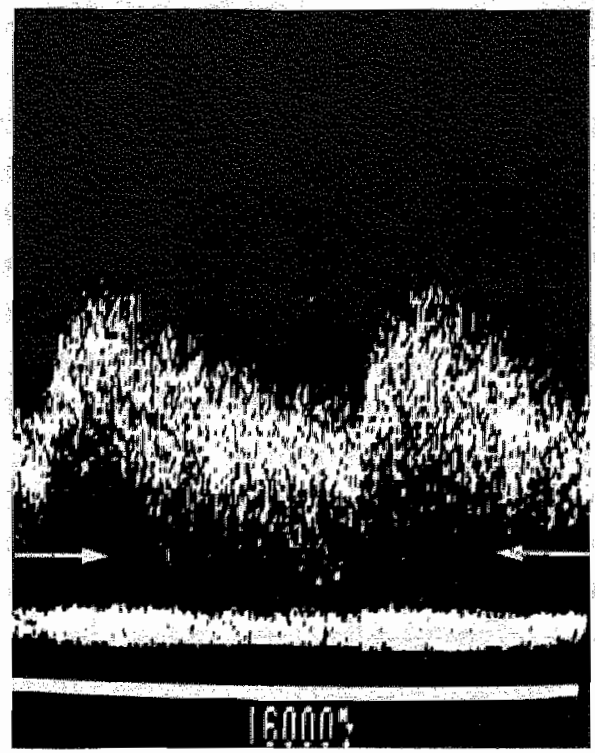

A

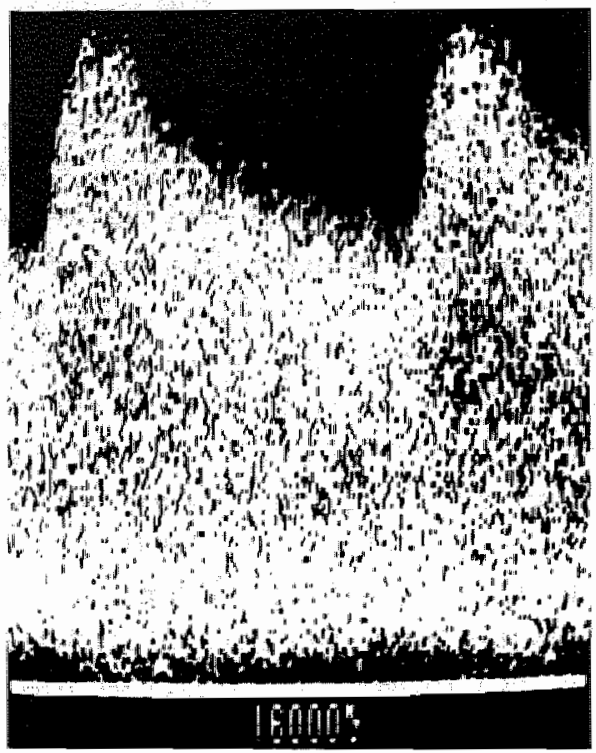

B

figure 2.1.: Spectral analysis of the Doppler signal of a PTFE graft fistula.

a. normal graft segment; low systolic frequencies and a clear window (arrows) are present.

b. stenotic graft segment; marked increase in peak systolic frequencies and spectral broadening with disappearence of the window are visible.

\section{RESULTS}

In all patients angiograms of sufficient quality were obtained with adequate visualisation of arterial and venous anastomoses and efferent veins. The fistula angiograms were interpreted by a radiologist, who had no knowledge of the results of the noninvasive tests. A total of 16 stenotic segments with a diameter reduction of $50 \%$ or more were found in 15 patients. These stenoses were located at the venous anastomosis in 9 patients, in the efferent vein in 4 patients and in the graft in 3 patients.

Also mild stenoses ranging from 20 to $40 \%$ were found in 4 patients at the level of the arterial and venous anastomosis. 


\section{Doppler spectral analysis}

In most patients adequate Doppler signals could be obtained from the graft, the anastomotic regions and the efferent vein. However in 2 patients we were unable to obtain good Doppler spectra. In these two patients the arterial anastomosis with the brachial artery was situated under the venous outflow tract. In the Doppler frequency spectra we compared the degree of spectral broadening and the peak systolic frequencies during systole and diastole as they were sampled over the anastomoses and the graft itself. In fig. 2.2 the maximal systolic frequencies as measured over different graft segments are plotted against degree of stenosis. All but two patients with stenoses of 50 percent or more had systolic frequencies well above $14 \mathrm{Khz}$. The two patients with stenoses of respectively 70 and $80 \%$, had low systolic frequencies of respectively 9 and $5 \mathrm{Khz}$.

The normal grafts without stenoses mostly had low systolic frequencies. There were however 9 normal graft segments with frequencies ranging over $14 \mathrm{Khz}$. The mean peak systolic frequencies and standard deviation in nonstenotic and stenotic graft segments are outlined in Table 2.1.

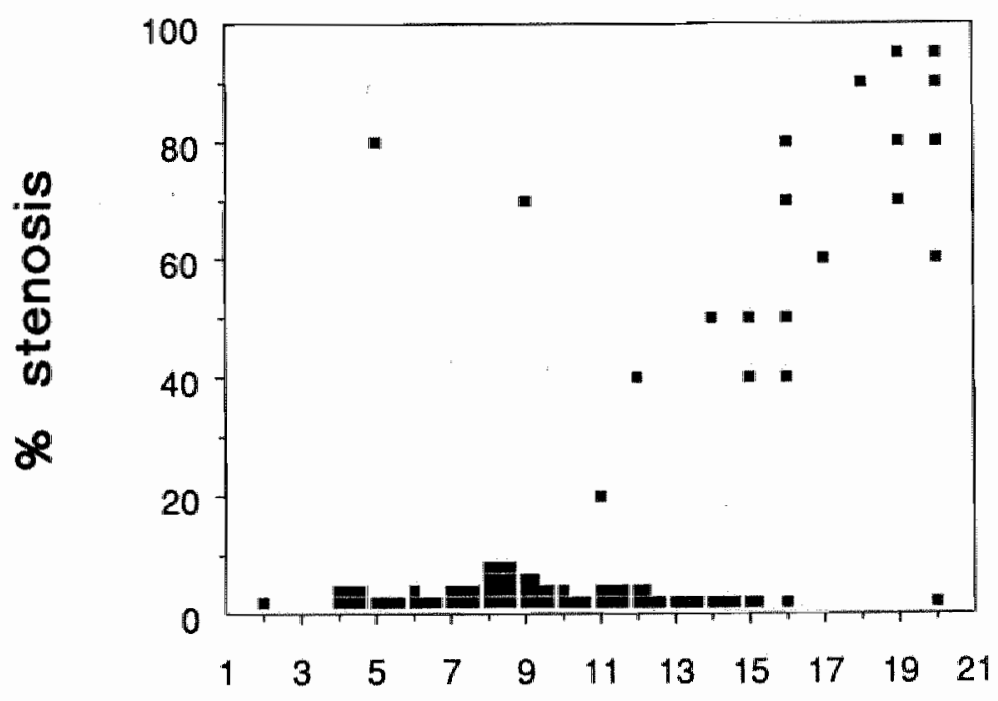

maximal systolic frequency

figure 2.2.: Scattergram of maximal systolic frequencies (Khz) in the graft segments and efferent vein plotted versus percentage of stenosis (angiogram). 
Table 2.1. Systolic peak frequencies (Khz) and inner diameters in nonstenotic and stenotic graft fistula segments (Mean and SD).

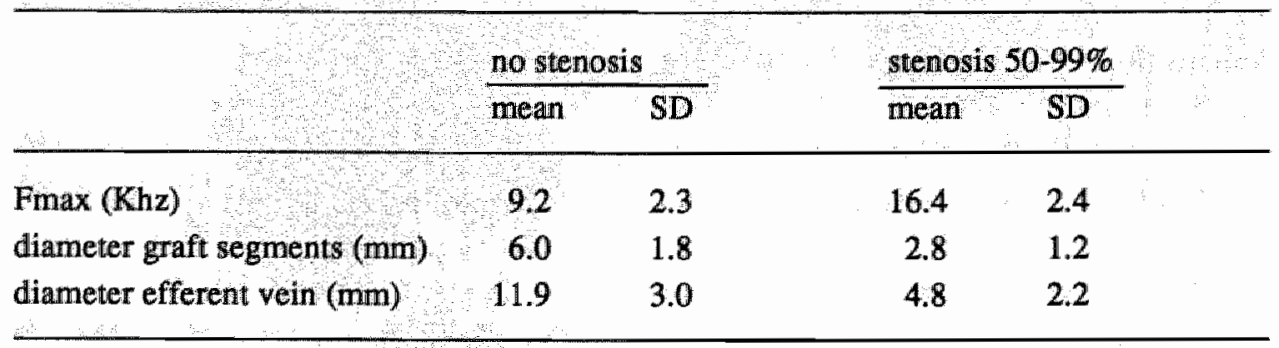

The sensitivity and specificity of the Doppler examination for stenoses of $50 \%$ and more are presented as ROC-curves in figure 2.3. The threshold for spectral broadening is set at grade I: disappearance of the spectral window and grade II: occurrence of negative frequencies. For grade I spectral broadening the sensitivity is $23 \%$ and the specificity $93 \%$; for grade II respectively 85 and $84 \%$. The threshold values for maximal systolic peak frequencies are made in steps of one Khz. At a threshold value of $14 \mathrm{Khz}$, the sensitivity is $88 \%$ and the specificity $89 \%$. The diagnostic accuracy is $89 \%$; the PPV $61 \%$ and the NPV $97 \%$ (Table 2.2).

Table 2.2. Discriminating value, diagnostic accuracy, sensitivity, specificity, positive predictive value (PPV) and negative predictive value (NPV) of maximal systolic frequencies (Fmax) and inner graft diameters (sonography).

\begin{tabular}{lllllll}
\hline & cut off value & accuracy & sensitivity & specificity & PPV & NPV \\
\hline $\begin{array}{l}\text { Fmax (Khz) } \\
\text { sonography } \\
\text { diameter (mm) }\end{array}$ & 14 & $89 \%$ & $88 \%$ & $89 \%$ & $61 \%$ & $97 \%$ \\
\hline
\end{tabular}




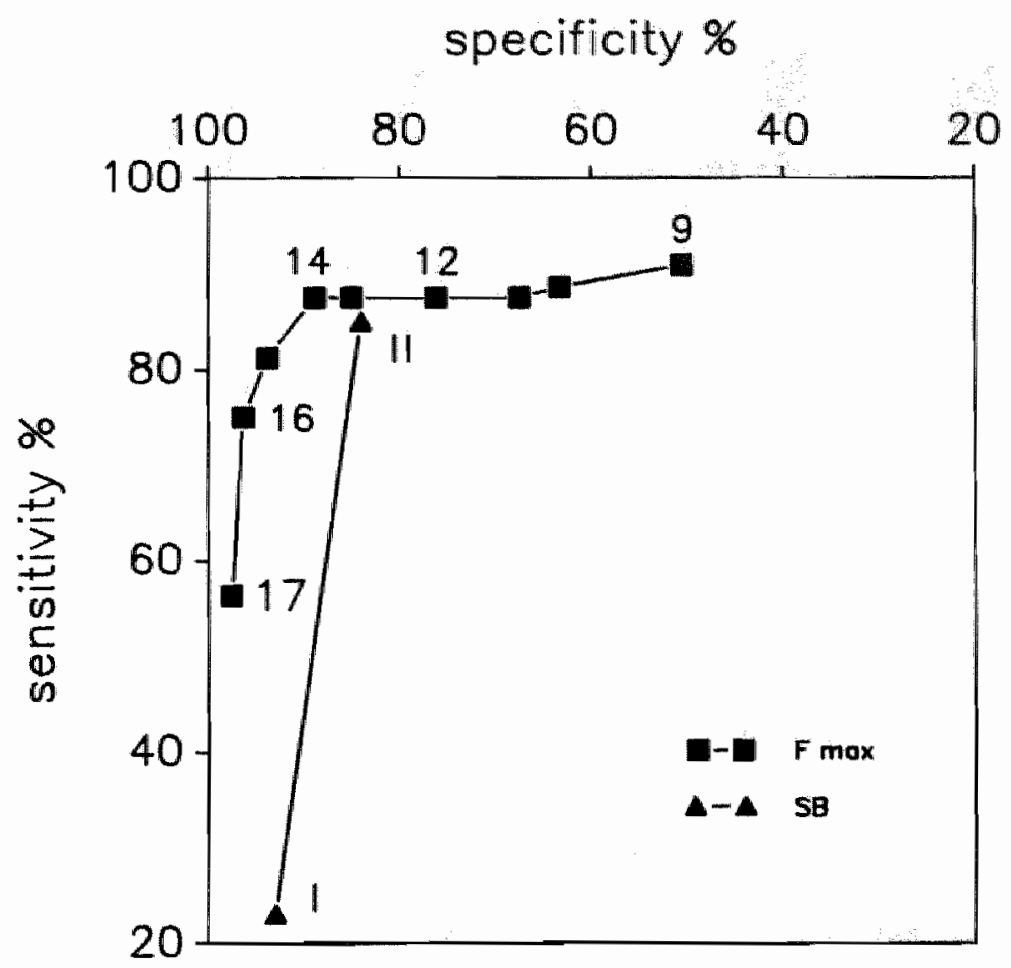

figure 2.3.: ROC-curves of maximal systolic frequency (squares) in kilohertz and degree of spectral broadening (triangles) for the diagnosis of stenoses of $50 \%$ and more.

I =grade I spectral broadening; II= grade II spectral broadening.

\section{Real-time sonography}

Fourteen patients were submitted to B-mode sonography. In all patients it was possible to obtain good quality sonograms. However the arterial anastomosis was sometimes difficult to examine (fig.2.4). The normal graft had an inner diameter of $6 \mathrm{~mm}$ with a hyperechogenic line along the wall, most likely representing the neo-intimal layer (fig.2.5). An acoustic shadow was seen behind the graft. The venous anastomosis was relatively easy to identify because of the acoustic shadow of the graft, in contrast to the lack of shadow behind the vein (fig.2.6). In most cases there was an abrupt dilatation of the efferent vein, proximal to the anastomosis. Two patients had false aneurysms located at the arterial and venous anastomosis, visible as an anechogenic space connected with the lumen of the graft (fig.2.7). 


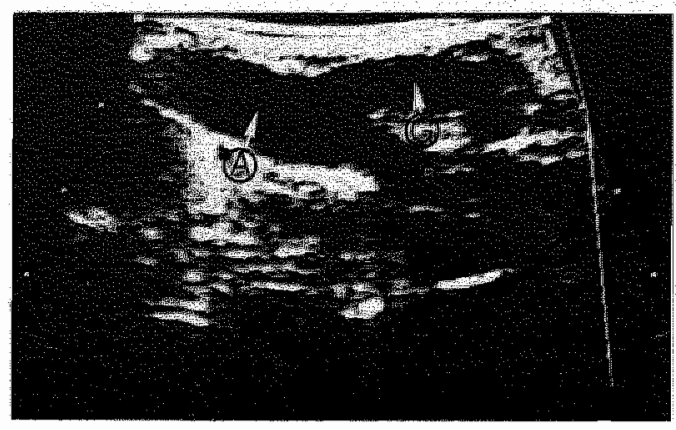

figure 2.4.: Sonographic image of the arterial anastomosis of a PTFE graft (G) to the brachial artery (A).

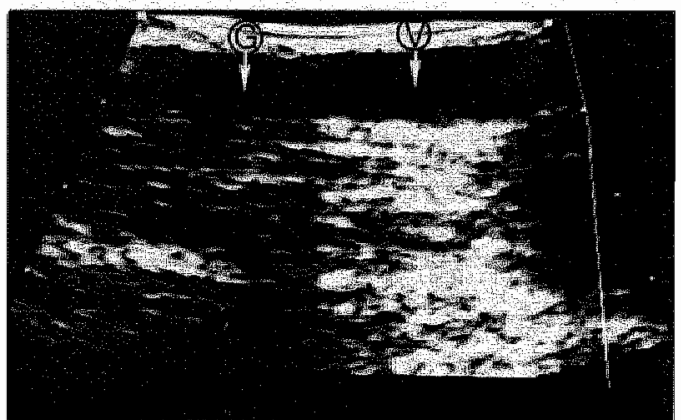

figure 2.6.: Real-time sonography of the graft(G)-venous (V) anastomosis of a PTFE AV fistula. An acoustic shadow can be noticed beneath the prosthesis.

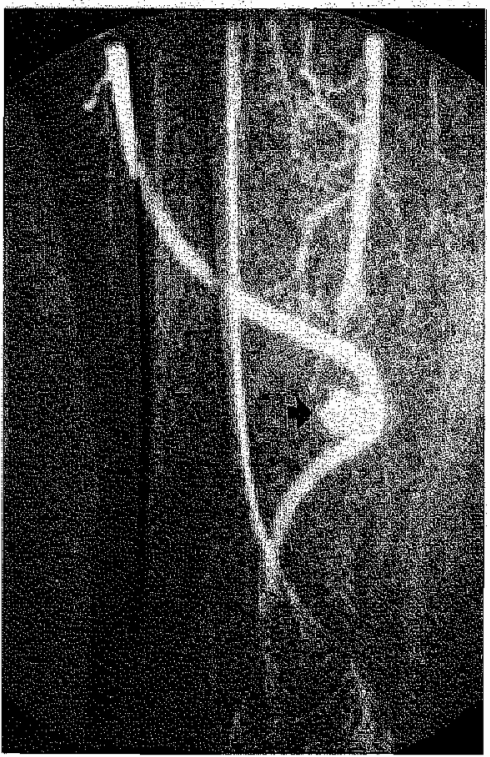

A

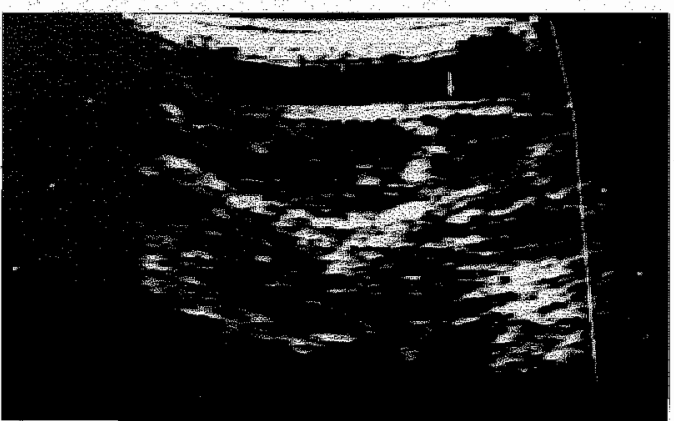

figure 2.5.: Sonography of the PTFE graft. Notice the pseudo-intimal layer (white arrow).

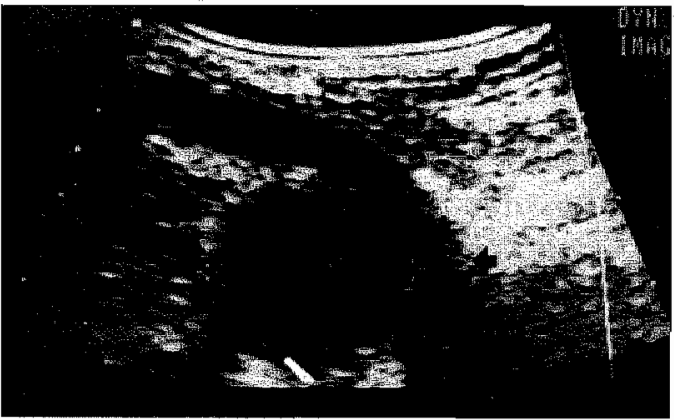

figure 2.7.: a. Intravenous DSA of a PTFE graft in the upper leg. An aneurysm at the arterial anastomosis is visualized (arrow). b. Sonographic image of this aneurysm. 

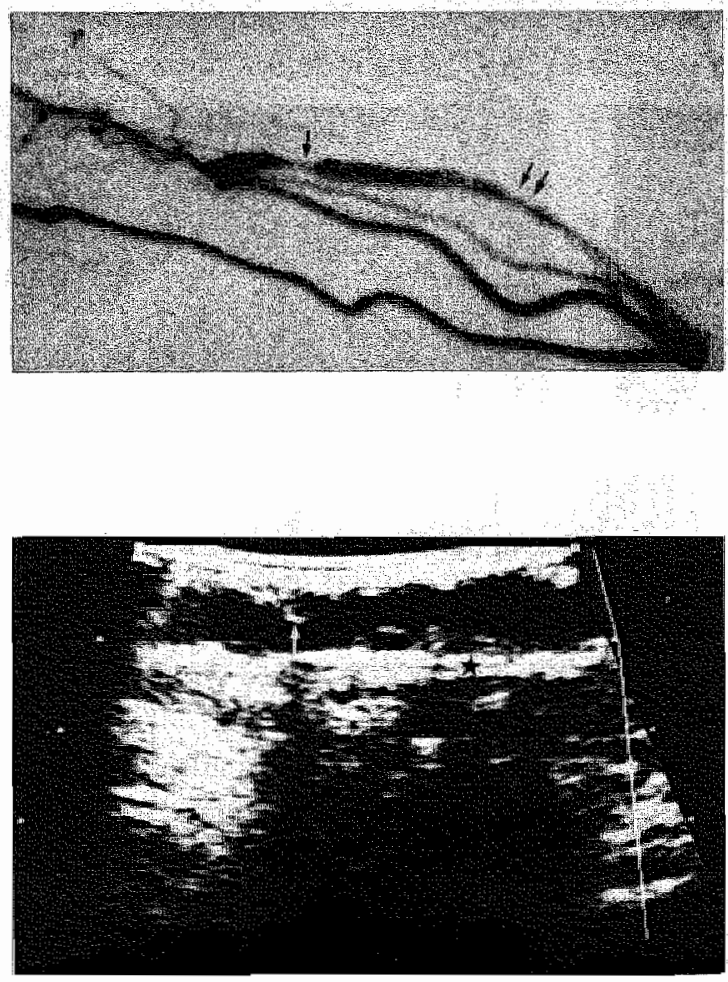

figure 2.8.: a. Intravenous DSA of a straight PTFE graft in the forearm. Stenotic lesions (arrows) are visible in the graft.b. Sonography reveals smooth thickening $\left(^{*}\right)$ and irregular structures (arrow) along the graft wall.

Hematomas were also anechogenic, but they lacked connection to the vascular lumen. The diameter of the efferent vein was variable but always more than 5 $\mathrm{mm}$. Stenoses were either visible as irregular structures along the wall with a mixed echogenicity, or as a smooth thickening of the neo-intima (fig.2.8). At the points where the dialysis needles had been inserted, irregularities were often seen and sometimes aneurysmatic dilatations (fig.2.9).

In 14 patients a total of 9 stenoses were detected, 7 times in a graft segment and 2 times in the efferent vein; all stenoses found with sonography were also detected by angiography. Four stenoses were missed with sonography. The mean diameters and standard deviation, measured by sonography, in stenotic and nonstenotic graft segments are summarized in Table 2.1. The inner diameters versus percentage of stenosis (angiography) are outlined in fig.2.10. For a threshold value of $3 \mathrm{~mm}$ in the graft segments and $5 \mathrm{~mm}$ in the efferent vein, the best results are obtained with a diagnostic accuracy of $92 \%$, a sensitivity of $69 \%$ and a specificity of $100 \%$. The PPV is $100 \%$ and the NPV is $92 \%$ (Table 2.2 ). 


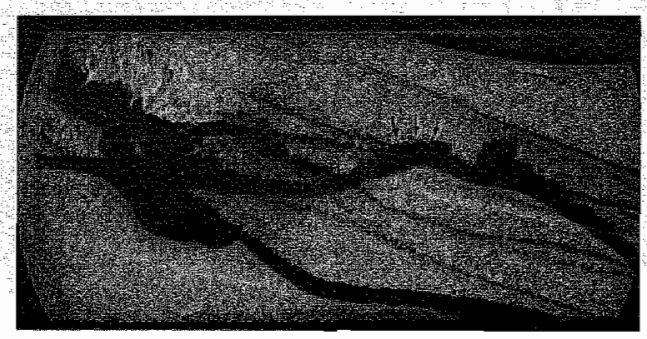

A

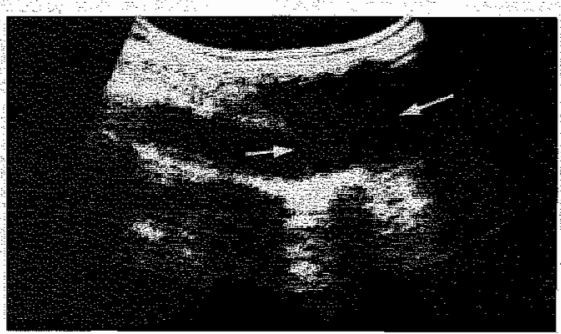

B

figure 2.9.: a. Intravenous DSA of a loop PTFE graft in the forearm. Local aneurysms (arrows) can be noticed along the graft. b. Sonographic picture of these aneurysms (arrows).

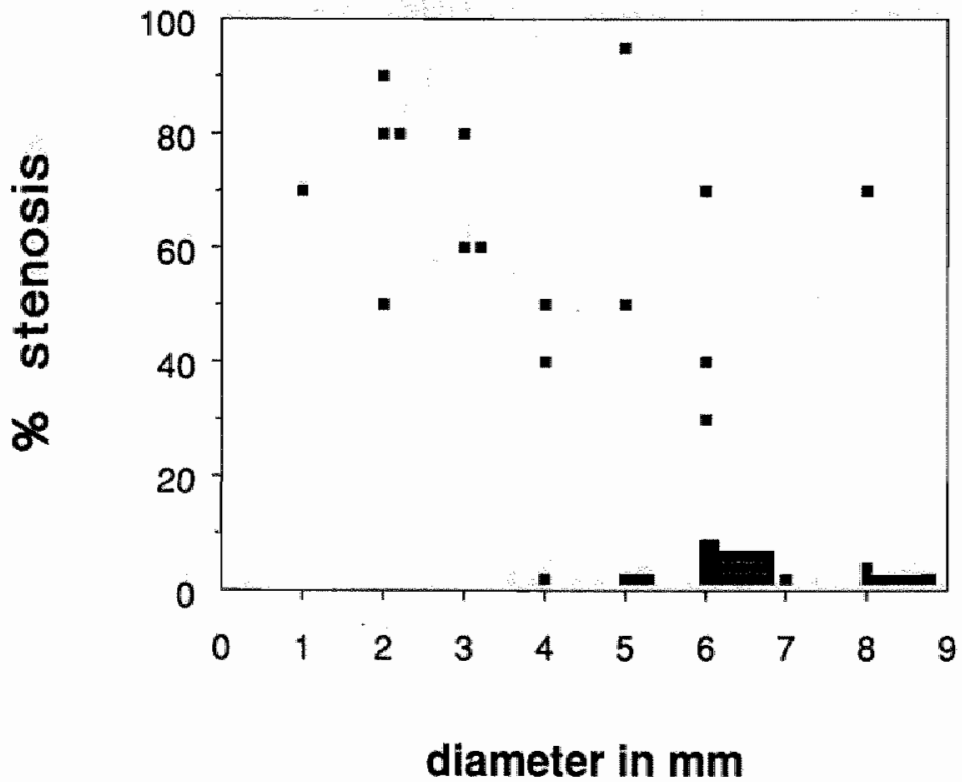

figure 2.10: Scattergram of graft and efferent vein diameters (mm), measured by sonography versus percentage of stenosis (angiogram). 
When the results of Doppler spectral analysis are combined with the outcome of real-time sonography, only one significant stenosis was missed and no false positive results are obtained. This means a sensitivity of $92 \%$ and a specificity of $100 \%$.

\section{DISCUSSION}

Graft AV fistulas may be complicated by infection or false aneurysm formation of the graft, and peripheral ischemia or venous hypertension of the hand. All can lead to loss of the access. The most important complication is thrombosis due to progressive stenosis at the venous anastomosis or at the efferent vein based on intimal hyperplasia. Palder et.al. reported that $91 \%$ of the fistula complications in PTFE graft fistulas were due to thrombotic events. In $56 \%$ of these thrombosed fistulas anatomical causes could be elucidated. They found the stenotic lesions at the venous anastomosis and just proximal to it in the efferent vein. $^{12}$

Flow problems during dialysis will occur relatively late in the course of development of a stenosis and only when a severe stenosis (more than $90 \%$ ) has been reached. This is in contrast to stenoses in peripheral arteries, in which a low-grade stenosis can cause significant symptoms especially during exercise. The difference between the arterial and venous pressure in an AV fistula as well as in a graft fistula is high, because there is no capillary bed. Consequently the flow velocity in the system is high. Only a very severe stenosis will result in a decrease in flow. This decrease in flow together with low bloodpressure during dialysis and puncture lesions of the graftwall, may result in a thrombotic occlusion. Early diagnosis and follow-up of asymptomatic stenoses of grafts could be of importance for the prevention of fistula thrombosis. The use of sonography for the diagnosis of AV fistula complications was first reported by Kottle et.al. in 1978. They could accurately differentiate hematoma from aneurysm formation in Brescia/Cimino AV fistulas and graft fistulas. ${ }^{11}$

Scheible et.al. reviewed the outcome of sonography in 30 patients with Brescia/ Cimino fistulas, bovine and synthetic grafts. They showed examples of sonographic images of normal and complicated fistulas. In only 5 cases was additional angiography necessary to confirm the clinical diagnosis. They prefer the use of a $10 \mathrm{Mhz}$ transducer, because of superior resolution. ${ }^{13}$ Weber et.al. investigated the vascular access of 88 chronic hemodialysis patients with clinically presumed fistula or graft complications by ultrasonography. In 77 patients (88\%) abnormal sonographic patterns were found and the cause for malfunc- 
tioning of the fistula could be elucidated. The information was insufficient in cases with intraluminal vessel diameters of less than $3 \mathrm{~mm}$. In these fistulas it was impossible to differentiate normal fistulas from occluded fistulas. ${ }^{14}$ Very good results of sonographic investigation were published by Corbetti et.at. ${ }^{15}$ The fistula anatomy was correctly diagnosed in twenty-one out of 23 Brescia/Cimino fistulas and graft fistulas. The findings were all confirmed by angiography.

In our study four significant stenoses were missed with sonography. Two of these stenotic lesions were caused by severe kinking of the efferent vein. This was probably the reason for the false negative results of sonography. A stenosis of $50 \%$ at the graft-venous anastomosis was not detected by sonography. The measured inner diameter of this anastomosis was $5 \mathrm{~mm}$ compared to $10 \mathrm{~mm}$ in the efferent vein. No false positive results of sonography were obtained.

The best results for the detection of stenoses of $50 \%$ and more are obtained with a threshold value for the inner graft diameter of $3 \mathrm{~mm}$ and efferent vein of 5 $\mathrm{mm}$. The sensitivity is $69 \%$ and the specificity $100 \%$. Sonography also revealed additional abnormalities like aneurysms and hematoma. This might be an important benefit of this method above other methods of investigation.

Doppler analysis has been extensively used for the diagnosis of peripheral arterial disease. It has also been used for quantitative flow measurement in graft fistulas. Rittgers et.al. used a continuous-wave Doppler device for volume flow measurement in 31 PTFE grafts. No succesful Doppler recordings could be made in PTFE grafts implanted less than 24 hours prior to investigation. In the grafts with dialysis problems due to low flow they found elevated velocities and turbulence at the venous anastomosis. Exact data on systolic frequencies and spectral broadening were not provided in their report. ${ }^{16}$ Glickman et.al. reported on the use of Duplex imaging and pulsed Doppler analysis for the investigation of asymptomatic PTFE graft fistulas. ${ }^{17}$ Twenty-five grafts in 18 patients were studied. The results of noninvasive study were compared to angiograms and operative findings. Ten normal fistulas had systolic peak frequencies ranging from 1.5 to $2.2 \mathrm{Khz}$ over the graft and 1.2 to $8.0 \mathrm{Khz}$ over the venous anastomosis. In grafts with stenoses at the venous anastomosis, frequencies were recorded from 8.0 to $9.6 \mathrm{Khz}$. Fistulas with stenoses in the efferent vein had low frequencies and minor spectral broadening. The results in our study correspond well with these data. With the use of Doppler analysis we found a marked elevation of peak systolic frequencies to over $14 \mathrm{Khz}$ in 14 of the 16 fistulas with stenoses of $50 \%$ or more. These values are higher than in the study of Glickman et.al. due to the use of a $8 \mathrm{Mhz}$ instead of a $5 \mathrm{Mhz}$ transducer. We also found a slight elevation of peak frequencies in 4 patients with minor stenotic 
lesions (20 and 40\%). With Doppler anallysis two significant stenotic lesions were missed, while in two patients the arterial anastomosis could not be screened because of an overlying venous anastomosis.

A false positive result was obtained over the venous anastomosis in one patient: This patient had a marked stenosis in the graft just before the venous anastomosis and this might explain the result of the false positive Doppler examination. From our study it can be concluded that the threshold value of $14 \mathrm{Khz}$ for peak systolic frequencies gives the best diagnostic results with a sensitivity of $88 \%$ and a specificity of $89 \%$.

The degree of spectral broadening of the Doppler signal is an important determinant for the diagnosis of carotid artery disease. ${ }^{18}$ However for the diagnosis of stenoses in AV fistulas, spectral broadening has a limited value. In high-flow systems like AV fistulas, turbulent flow will often be present. In this study only severe turbulence with retrograde flow components in the Doppler spectrum was found to be an accurate method for the diagnosis of stenoses. The occurrence of grade II spectral broadening (with negative reflections in the Doppler signal) led to a sensitivity of $85 \%$ and a specificity of $84 \%$.

In this study conventional and Digital Subtraction Angiography were used as a reference method. Conventional angiography was performed with direct injection of $20 \mathrm{cc}$ of contrast medium into the fistula. With the use of a proximal occluding pressure cuff the arterial anastomosis and afferent artery could be visualized in most cases. This technique could not be applied to the patients with upper leg fistulas. In these fistulas only the graft and outflow tract could be screened by contrast injection in the graft.

The introduction of Digital Subtraction Angiography has several advantages in the investigation of AV fistulas. Intravenous contrast injection in the contralateral extremity provides a good image of afferent arteries and efferent veins. A fysiologic study of flowpatterns in the fistula extremity can be made without the danger of complications caused by direct fistula cannulation. However additional angiographic series are often needed due to overprojection of vessels at the level of the anastomosis. Direct injection of a small amount of diluted contrast into the graft, through the dialysis needle, has also advantages. Patients on chronic hemodialysis often have fragile vessels. In these patients it is difficult or even impossible to find a vein capable of withstanding the high pressure and flow, necessary for adequate visualization with intravenous subtraction angiography. Patient tolerance and image quality are much better and there is no overprojection of vessels. However with direct injection the arterial anastomosis and afferent arteries are not always very well visualized. 


\section{Conclusions}

Contrast angiography provides an objective assessment of the presence of stenoses in AV fistulas. However this technique is not only time-consuming, but also presents a risk to the patient and the fistula. Noninvasive methods of examination can circumvent the drawbacks of angiography. Therefore, two noninvasive diagnostic tests were appplied to the investigation of graft fistulas. From the results of this study we can conclude that Doppler spectral analysis and real-time sonography are useful methods for the detection of significant stenoses in graft AV fistulas. The combined use of these methods results in a high accuracy. 


\section{REFERENCES}

1 Brescia,M.J., Cimino,J.E., Appel,K., Hurwich,B.J.:

Chronic hemodialysis using venipuncture and a surgically created arteriovenous fistula.

N Engl J Med 1966; 20: 1089-1092.

2 Seccia,M., Buccianti,P., Chiarugi,M., Moriconi,L., Rindi,P.:

The PTFE graft as alternative blood access in the surgical management of long-tem haemodialysis.

Life Support Systems 1984; 2: 63-70.

3 Baker,L.D., Johnson,J.M., Goldfarb, D.:

Expanded polytetrafluoroethylene (PTFE) subcutaneous arteriovenous conduit: an improved vascular access for chronic hemodialysis.

Trans Am Soc Artif Intern Organs 1976; 22:382.

4 Tordoir,J.H.M., Herman,J.M.M.P.H., Kwan,T.S., Diderich,P.M.:

Long-term follow-up of the polytetrafluoroethylene (PTFE) prosthesis as an arteriovenous fistula for haemodialysis.

Eur J Vasc Surg 1988; 2: 3-7.

5 Etheredge,E.E., Haid,S.D., Maeser,M.N., Sicard,G.A., Anderson,C.B.:

Salwage operations for malfunctioning polytetrafluoroethylene hemodialysis access grafts.

Surgery $1983 ; 94: 464-470$.

6 Glanz,S., Gordon,D., Butt,K.M.H., Hong,J., Adamson, R., Sclafani,S.J.A.:

Dialysis access fistulas: treatment of stenoses by transluminal angioplasty.

Radiology 1984; 152: 637-642.

7 Schwab,S.J., Saeed,M., Sussman,S.K., McCann,R.L., Stickel,D.L.:

Transluminal angioplasty of venous stenoses in polytetrafluoroethylene vascular access grafts.

Kidney Intern 1987; 32: 395-398.

8 Anderson,C.B., Gilula,L.A., Sicard,G.A., Etheredge, E.E.:

Venous angiography of subcutaneous hemodialysis fistulas.

Arch Surg 1979; 114: 1320-1325.

9 Baalen,J.M.,van:

Noninvasive detection of lesions in the carotid artery bifurcation.

Thesis, Maastricht, the Netherlands, 1987.

10 Kitslaar,P.J.E.H.M.:

Doppler ultrasound tests in the diagnosis of chronic aortoiliac obstruction.

Thesis, Maastricht, the Netherlands, 1982.

11 Kottle,S.P., Gonzalez,A.C., Macon,E.J., Felliner,S.K.:

Ultrasonographic evaluation of vascular access complications.

Radiology 1978; 129: 751-754.

12 Palder,S.B., Kirkman,R.L., Whittemore,A.D., Hakim,R.M., Lazarus,J.M., Tillney, N.L.:

Vascular access for hemodialysis, patency rates and results of revision.

Ann Surg 1985; 202: 235-239.

13 Scheible,W., Skram,C., Leopold,G.R.:

High resolution real-time sonography of hemodialysis vascular access complications.

AJR 1980; 134: 1173-1176. 
14 Weber,M., Kuhn,F.P., Quintes, W., Keidi,E., Köhler,H.:

Sonography of arteriovenous fistulae in hemodialysis patients.

Clin Nephrol 1984; $22: 258-261$.

15 Corbetti, F, Vigo,M, Biondetti,P.R., Angelini,F, Benedetti,L:

High resolution echography and angiography in the study of dialysis fistulas.

Radiol Med 1987; 73:298-303.

16 Rittgers,S.E., Garcia-Valdez,C., McCormick,J.T., Posner,M.P.:

Noninvasive blood flow measurement in expanded polytetrafluoroethylene grafts for hemodialysis access.

J Vasc Surg 1986; 3: 635-42.

17 Glickman,M.H., Clark,S., Goodrich,V.:

Determination of outflow stenosis of arteriovenous fistulas for hemodialysis.

Bruit 1985; 9: 16-19.

18 Johnston,K.W., Baker,W.H., Burnham,S.J., Hayes,A.C., Kuper,C.A., Poole,M.A.:

Quantitative analysis of continuous wave Doppler spectral broadening for the diagnosis of carotid disease: results of a multicenter study.

J Vase Surg 1986; 4: 493-504.

Parts of this chapter have been previously published:

Tordoir,J.H.M., Baalen,J.M., van, Haeck,L.B.A.:

Doppler ultrasound diagnosis of complications of polytetrafluoroethylene (PTFE) graft shunts.

Neth J Surgery 1984; 36: 42-44.

Pieterman,H., Tordoir,J.H.M.:

Noninvasive evaluation of prosthetic dialysis shunts in asymptomatic patients.

Fortschr Röntgenstr 1986; 145: 541-546. 


\section{Chapter 3}

\section{Duplex ultrasound scanning in the assessment of arteriovenous fistulas created for}

\section{hemodialysis access: comparison with digital subtraction angiography}

Jan H.M. Tordoir, ${ }^{1}$ Hein G. de Bruin, ${ }^{2}$ Hans Hoeneveld, ${ }^{3}$ Bert C. Eikelboom, ${ }^{1}$ Peter J.E.H.M. Kitslaar. ${ }^{4}$

J Vasc Surg, 1989; 10:122-128.

${ }^{1}$ Department of Vascular Surgery, ${ }^{2}$ Department of Radiology, ${ }^{3}$ Vascular Laboratory, St. Antonius Hospital, Nieuwegein, the Netherlands, ${ }^{4}$ Department of Surgery, University Hospital Maastricht, the Netherlands.

\section{ABSTRACT}

The results of Duplex scanning for the diagnosis of stenoses in Brescia/Cimino AV fistulas and graft AV fistulas for hemodialysis are reported. Quantitative Doppler spectral analysis in 64 AV fistulas was correlated with the outcome of Digital Subtraction Angiography. The best Doppler parameter for the detection of a stenosis was the peak systolic frequency (Fmax). In graft AV fistulas the use of this parameter resulted in a diagnostic accuracy of $86 \%$, a sensitivity of $92 \%$ and a specificity of $84 \%$ in the detection of stenoses. In Brescia/Cimino AV fistulas the diagnosis of anastomotic stenoses was possible with a diagnostic accuracy of $81 \%$, a sensitivity of $79 \%$ and a specificity of $84 \%$. Measurement of peak systolic frequency ratios (Fratio) or enddiastolic frequencies (Fdias) had no additional diagnos tic value for the detection of stenoses. The diagnosis of efferent vein stenoses was very accurate with Duplex investigation (accuracy $96 \%$, sensitivity $95 \%$ and a specificity of $97 \%$ ).

It is concluded that Duplex scanning is a promising noninvasive method for the diagnosis of stenoses in AV fistulas for hemodialysis. 


\section{INTRODUCTION}

A well-functioning vascular access is the lifeline for patients on maintenance hemodialysis. The Brescia/Cimino AV fistula has been the primary method of access for the past two decades. ${ }^{1}$ The continuous growth of the number" of dialysis patients with relatively more elderly patients and diabetics has increased the need for secondary access procedures. This means that both primary and secondary access procedures will be performed more often and therefore more complications might be encountered.

For the diagnosis of AV fistula complications usually conventional angiography or Digital Subtraction Angiography is performed by either brachial artery cannulation, direct contrast injection into the AV fistula or intravenous injection in the contralateral extremity. ${ }^{2,3,4}$ Recently noninvasive Doppler analysis has been advocated for the evaluation of dialysis fistulas. ${ }^{5,6}$ These studies have not convincingly demonstrated the accuracy and value of the Doppler tests.

In the present study Duplex scanning was performed in Brescia/Cimino AV fistulas and in graft AV fistulas for hemodialysis. The purpose of the study is to determine the diagnostic value of quantitative analysis of the Doppler spectrum in the detection of AV fistula stenoses. This article presents the results of a prospective investigation of $64 \mathrm{AV}$ fistulas in 58 patients. The outcome of Duplex scanning was correlated with the results of Digital Subtraction Angiography.

\section{PATIENTS AND METHODS}

Duplex scanning was performed in 58 patients on maintenance hemodialysis (females 27 ; males 31 ; mean age 55 yrs; range $21-78$ yrs). Fourty-seven patients had asymptomatic AV fistulas ( $73 \%$ ), 8 patients suffered low flows through the AV fistula with dialysis problems, 4 patients had a venous hypertension, one patient had distal ischemia, 2 patients had aneurysms and in 2 patients difficulties with puncture were observed. A total of $64 \mathrm{AV}$ fistulas for dialysis were examined: 36 Brescia/Cimino AV fistulas and 28 graft AV fistulas (14 PTFE; 10 saphenous vein; 4 homologous vein grafts). The AV fistulas were in position from 1 to 160 months (mean $34 \mathrm{mts}$ ). 


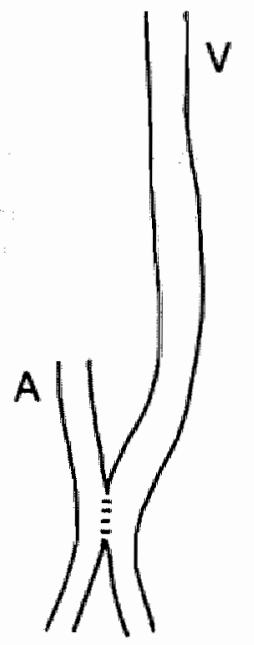

a

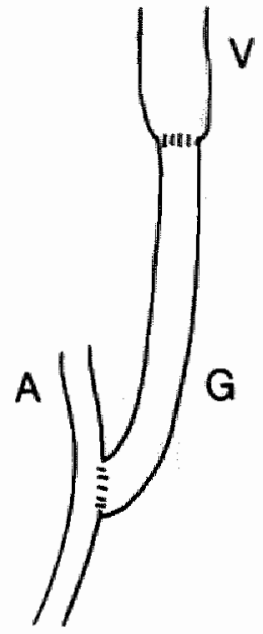

b

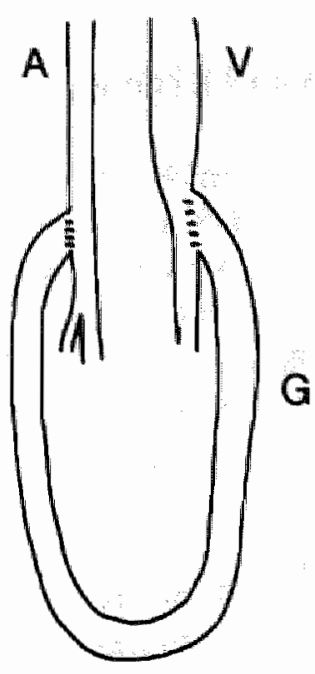

C

figure 3.1. Diagram of the different types of AV fistulas for hemodialysis.

a. Brescia/Cimino AV fistula; b. straight graft interposition; c. loop graft interposition.

$A=$ afferent artery $; G=$ graft interposition; $V=$ efferent vein.

\section{Vascular segments}

For comparison of the results of Duplex scanning and angiographic data, in any of the types of AV fistulas for hemodialysis a number of fixed segments were defined (fig.3.1).

For Brescia/Cimino AV fistulas a total of 7 segments per fistula were screened: the proximal and distal radial artery and cephalic vein, within $2 \mathrm{~cm}$ of the anastomosis (anastomotic segments) and the efferent vein in the forearm, the elbow and upper arm. For the graft AV fistulas a total of 5 segments were investigated: the arterial and venous anastomoses, the arterial and venous part of the graft interposition (graft segments), and the efferent vein in the upper arm. 


\section{Duplex technique}

The Duplex scanning was performed in the supine position prior to a dialysis treatment. Doppler signals were obtained with a hand-held probe incorporating a $5 \mathrm{Mhz}$ pulsed Doppler system and a $10 \mathrm{Mhz}$ B-mode imager (ATL Ultramark IV Duplex system). The recordings were made by a technologist with a longstanding experience in Duplex scanning.

In the case of a Brescia/Cimino AV fistula, the analysis started with B-mode vessel imaging of the radial artery $5 \mathrm{~cm}$ proximal to the wrist. Subsequently the radial artery was followed distally to the anastomosis. The radial artery and cephalic vein proximally and distally of the anastomosis were selectively insonated. The efferent vein was screened from the anastomosis at the wrist upwards to the upper arm. The graft AV fistulas were examined starting from the arterial anastomosis, along the graft itself to the venous anastomosis and downstream along the efferent vein. The insonation of the vessels was carried out with a constant angle of sixty degrees. Representative spectrum analysed Doppler recordings were made at the different locations and freezed on the screen. Hard copy registrations of the spectra were kept for quantitative analysis.

\section{Quantification of Doppler spectra}

For each recording site, the following measurements were made: peak systolic frequency in Khz (Fmax), enddiastolic frequency in Khz (Fdias), peak frequency ratios (Fratio) and Resistance Index (RI). This last parameter reflects the grade of peripheral resistance and is represented by the formula: RI=(FmaxFdias)/ Fmax. The peak frequency ratios were calculated as the quotients of peak systolic frequencies (Fmax) of the different anastomotic segments in Brescia/Cimino AV fistulas over the peak systolic frequency in the radial artery (reference site) $5 \mathrm{~cm}$ proximal to the anastomosis. For graft $\mathrm{AV}$ fistulas in a loop configuration the brachial artery just proximal to the arterial anastomosis was taken as reference site. All frequencies in the Doppler spectrum were recalculated according to the angle of insonation to the reference of 60 degree of insonation. 


\section{Angiography}

The Philips Release-V angiography unit was used for Digital Subtraction Angiography of the AV fistulas. The examination was performed by serial intravenous bolus injection of $40 \mathrm{ml}$ ioxaglate $\left({ }^{3}\right.$ Hexabrix 320$)$ in the contralateral extremity. Images with a rate of 1 to 2 per second were obtained with different projections of the fistula. To avoid the risk of volume overloading the DSA examinations were performed immediately preceding dialysis treatment. If the quality of intravenous DSA was insufficient or intravenous contrast injection was impossible, direct contrast injection into the fistula was carried out according to the method described by Staple ${ }^{7}$. The Digital Subtraction Angiograms were interpreted by a radiologist who was blinded to the results of the Duplex scanning.

The maximum stenoses in the anastomotic segments, graft segments and efferent veins were recorded. The degree of stenosis was measured as the ratio of the minimal residual lumen diameter at the stenosis over the diameter of the normal adjacent artery or vein. Angiograms in two directions were used to select the maximal degree of stenosis.

\section{Data analysis}

The Digital Subtraction Angiogram was used as "Gold Standard" to determine the accuracy of the noninvasive measurements. Angiographic evidence of a stenosis of $50 \%$ or more was considered as pathological.

The results of the noninvasive tests in comparison to the results of the Digital Subtraction Angiography can be described as the ability of the noninvasive tests to detect stenotic lesions or their ability to exclude such lesions. True positive and true negative results of the noninvasive measurements compared to angiography were obtained. With the aid of a decision matrix the diagnostic accuracy, sensitivity and specificity of the noninvasive measurements were determined. For the final interpretation of the various parameters of the Doppler analysis, receiver-operating-characteristic curve (ROC) analysis was performed ${ }^{8}$. The cut off value of the various parameters resulting in the highest sensitivity and specificity was selected. Mean values and standard errors of the mean for the different Doppler parameters were calculated and statistical analysis performed with the Student's t-test. 


\section{RESULTS}

\section{A) Angiography}

Fifty-seven DSA examinations were carried out with the use of intravenous contrast injection. Five direct angiograms ( $8 \%$ ) were necessary because of poor quality of the intravenous DSA or failing of venipuncture. Two patients had a combination of intravenous and direct contrast injection. Angiograms of sufficient quality for evaluation were obtained in all patients. However, inadequate views were obtained of the proximal radial artery in one patient $(2 \%)$, of the distal radial artery in 5 patients $(8 \%)$, of the distal fistula vein in one patient (2\%) and of the efferent vein in 2 patients (3\%). In two graft AV fistulas the arterial anastomosis could not be visualized adequately. Complications of the angiography were not encountered. A total of 381 angiographic well-defined segments were available for correlation with the results of the Duplex examination.

There were a total number of 83 stenoses ( $50-99 \%$ diameter reduction) in $50 \mathrm{AV}$ fistulas. Fifty-seven percent of the stenoses were located in the anastomotic region of the Brescia/Cimino AV fistulas; 5\% were situated at the arterial anastomosis of the graft AV fistulas; $10 \%$ in the graft interposition; $15 \%$ at the graft-venous anastomosis and $13 \%$ in the efferent veins. Thirty-six occlusions of various fistula segments were encountered in $33 \mathrm{AV}$ fistulas. Proximal radial artery occlusion was found in 2 patients, distal radial artery occlusion in 4 patients, occlusion of the proximal fistula vein in $4 \mathrm{AV}$ fistulas and in 23 Brescia/Cimino AV fistulas the distal vein was occluded or absent. In 3 graft AV fistulas the efferent vein proximal to the graft-venous anastomosis was occiuded.

\section{B) Duplex examination}

\section{Brescia/Cimino AV fistulas}

In Table 3.1 the mean values of the different Doppler parameters with the standard error of the mean have been calculated for stenotic and non stenotic anastomotic segments. Statistical significance $(P<0.001)$ was reached with the use of Fmax, Fdias and Fratio as parameters. 
Table 3.1. Mean values of Fmax, Fdias, Fratio and RI (Brescia/Cimino AV fistulas) for nonstenotic and stenotic anastomotic segments

\begin{tabular}{|c|c|c|c|c|c|}
\hline & \multicolumn{2}{|c|}{$\begin{array}{l}\text { no stenosis }(<50 \%) \\
\mathrm{N}=62\end{array}$} & \multicolumn{2}{|c|}{$\begin{array}{l}\text { stenosis }(50-99 \%) \\
\mathrm{N}=47\end{array}$} & \multirow[b]{2}{*}{ P-value } \\
\hline & mean & SEM & mean & SEM & \\
\hline$F_{\max }(\mathrm{Khz})$ & 8.50 & 0.54 & 13.42 & 0.55 & $<0.001$ \\
\hline$F_{\text {dias }}(\mathrm{Khz})$ & 5.54 & 0.44 & 9.81 & 0.56 & $<0.001$ \\
\hline Fratio & 2.61 & 0.19 & 4.10 & 0.19 & $<0.001$ \\
\hline RI & 0.3633 & 0.0192 & 0.3240 & 0.0183 & N.S. \\
\hline
\end{tabular}

Table 3.2. Discriminating value, maximum accuracy, sensitivity, specificity, positive predictive value (PPV) and negative predictive value (NPV) of the different Doppler parameters in Brescia/Cimino AV fistulas

\begin{tabular}{lllllll}
\hline & cut off value & accuracy & sensitivity & specificity & PPV & NPV \\
\hline Fmax $(\mathrm{Khz})$ & 12 & $81 \%$ & $79 \%$ & $84 \%$ & $86 \%$ & $76 \%$ \\
Fdias $(\mathrm{Khz})$ & 7 & $76 \%$ & $75 \%$ & $77 \%$ & $72 \%$ & $80 \%$ \\
Fratio $_{\text {RI }}$ & 3 & $73 \%$ & $76 \%$ & $71 \%$ & $68 \%$ & $79 \%$ \\
& 0.3 & $50 \%$ & $58 \%$ & $37 \%$ & $41 \%$ & $53 \%$ \\
\hline
\end{tabular}

As illustrated in the ROC curve in fig. 3.2, as the peak systolic frequency (Fmax) threshold is increased, the sensitivity decreases but the specificity increases. The Fmax appeared to be the best diagnostic parameter for the detection of stenoses. With a threshold value of $12 \mathrm{Khz}$ the accuracy was $81 \%$, the sensitivity $79 \%$ and the specificity $84 \%$. The use of Fdias and Fratio has no additional diagnostic value. The maximal accuracies of these parameters were respectively $76 \%$ and $73 \%$. Calculation of the Resistance Index (RI) has a very limited diagnostic value with a low accuracy of $50 \%$, a sensitivity of $58 \%$ and a specificity of $37 \%$ (Table 3.2 ). 


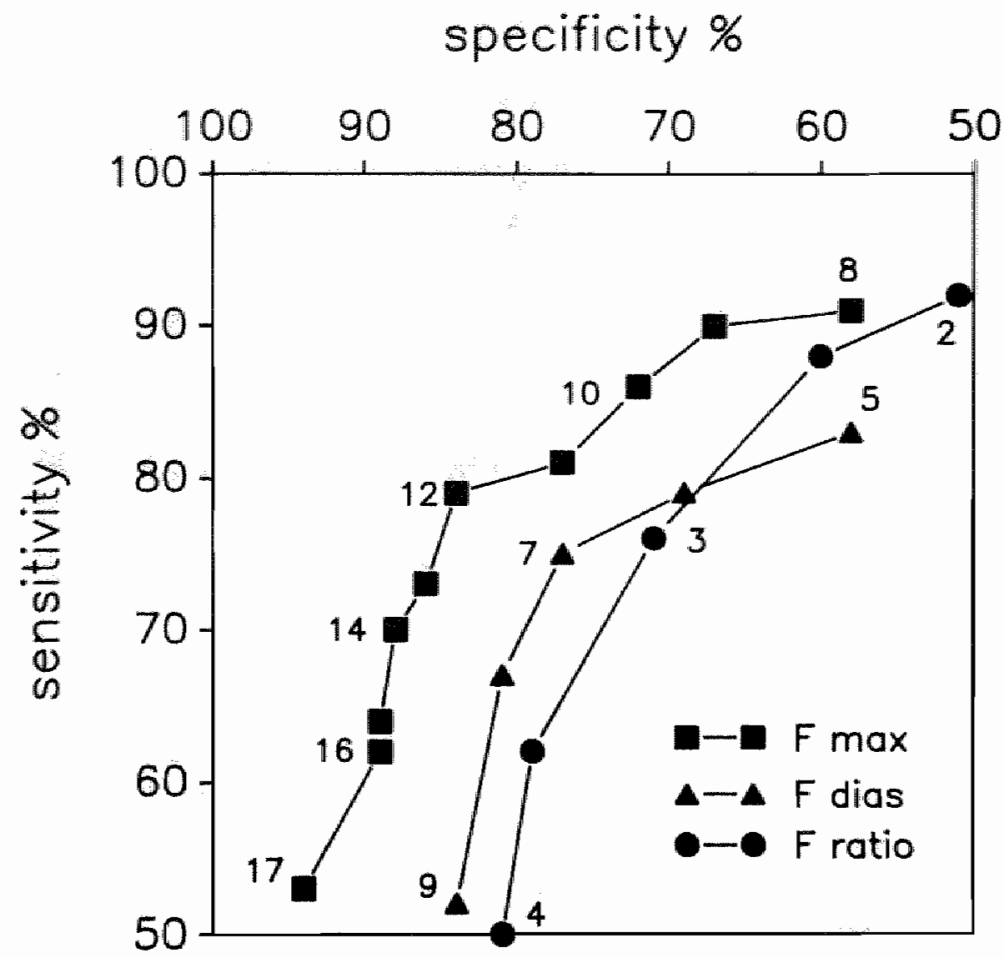

figure 3.2. ROC-curves of Fmax in Khz (squares), Fdias in Khz (triangles) and Fratio (circles) for stenoses of $50-99 \%$ in the anastomotic segments of Brescia/Cimino AV fistulas.

Table 3.3. Mean values of Fmax, Fdias, Fratio and RI (Graft AV fistulas) for nonstenotic and stenotic graft segments

\begin{tabular}{|c|c|c|c|c|c|}
\hline & \multicolumn{2}{|c|}{$\begin{array}{l}\text { no stenosis }(<50 \%) \\
N=73\end{array}$} & \multicolumn{2}{|c|}{$\begin{array}{l}\text { stenosis }(50-99 \%) \\
\mathrm{N}=25\end{array}$} & \multirow[b]{2}{*}{ P-value } \\
\hline & mean & SEM & mean & SEM & \\
\hline$F_{\max }(\mathrm{Khz})$ & 6.01 & 0.36 & 13.42 & 0.50 & $<0.001$ \\
\hline$F_{\text {dias }}(\mathrm{Khz})$ & 3.70 & 0.25 & 9.39 & 0.67 & $<0.001$ \\
\hline Fratio & 1.48 & 0.09 & 4.72 & 0.38 & $<0.001$ \\
\hline RI & 0.3883 & 0.0148 & 0.3047 & 0.0322 & N.S. \\
\hline
\end{tabular}


Table 3.4. Discriminating value, maximum accuracy, sensitivity, specificity, positive predictive value (PPV) and negative predictive value (NPV) for the different Doppler parameters in graft $\mathrm{AV}$ fistulas

\begin{tabular}{lclllll}
\hline & cut off value & accuracy & sensitivity & specificity & PPV & NPV \\
\hline Fmax $(\mathrm{Khz})$ & 10 & $86 \%$ & $92 \%$ & $84 \%$ & $66 \%$ & $97 \%$ \\
Fdias $(\mathrm{Khz})$ & 7 & $88 \%$ & $84 \%$ & $89 \%$ & $72 \%$ & $94 \%$ \\
Fratio & 3.5 & $91 \%$ & $75 \%$ & $96 \%$ & $86 \%$ & $92 \%$ \\
RI & 0.3 & $40 \%$ & $48 \%$ & $23 \%$ & $18 \%$ & $57 \%$ \\
\hline
\end{tabular}

\section{Graft AV fistulas}

Mean Fmax, Fdias, Fratios and mean RI for normal and stenotic graft segments are listed in Table 3.3. The maximal accuracy in the detection of stenoses of $50-99 \%$ is obtained with the use of the calculated Fratio at a threshold value of 3.5. The accuracy is $91 \%$ with a sensitivity of $75 \%$ and a specificity of $96 \%$. Also the best positive predictive value is obtained with the use of the Fratio. In Table 3.4 the results are summarized for different Doppler parameters. In fig. 3.3 the ROC-curves are outlined according to different threshold values of the Doppler spectrum parameters.

\section{Efferent veins}

In fig. 3.4 the results of the Duplex scanning of a stenosis in the efferent vein is shown. At the level of the stenotic lesion a sharp increase in peak systolic frequency can be noticed.

The mean values and standard error of the mean of the different Doppler parameters measured in the stenotic and nonstenotic efferent veins are summarized in Table 3.5. The detection of stenoses in the efferent vein, using the parameter Fmax at a cut off value of $8 \mathrm{Khz}$, is very accurate with a sensitivity of $95 \%$ and a specificity of $97 \%$. The diagnostic accuracy of $96 \%$ can not be surpassed by use of Fdias or the RI (Table 3.6). The results of Duplex scanning for the detection of efferent vein stenoses, with different threshold values for Fmax and Fdias are outlined as ROC-curves in fig. 3.5. 


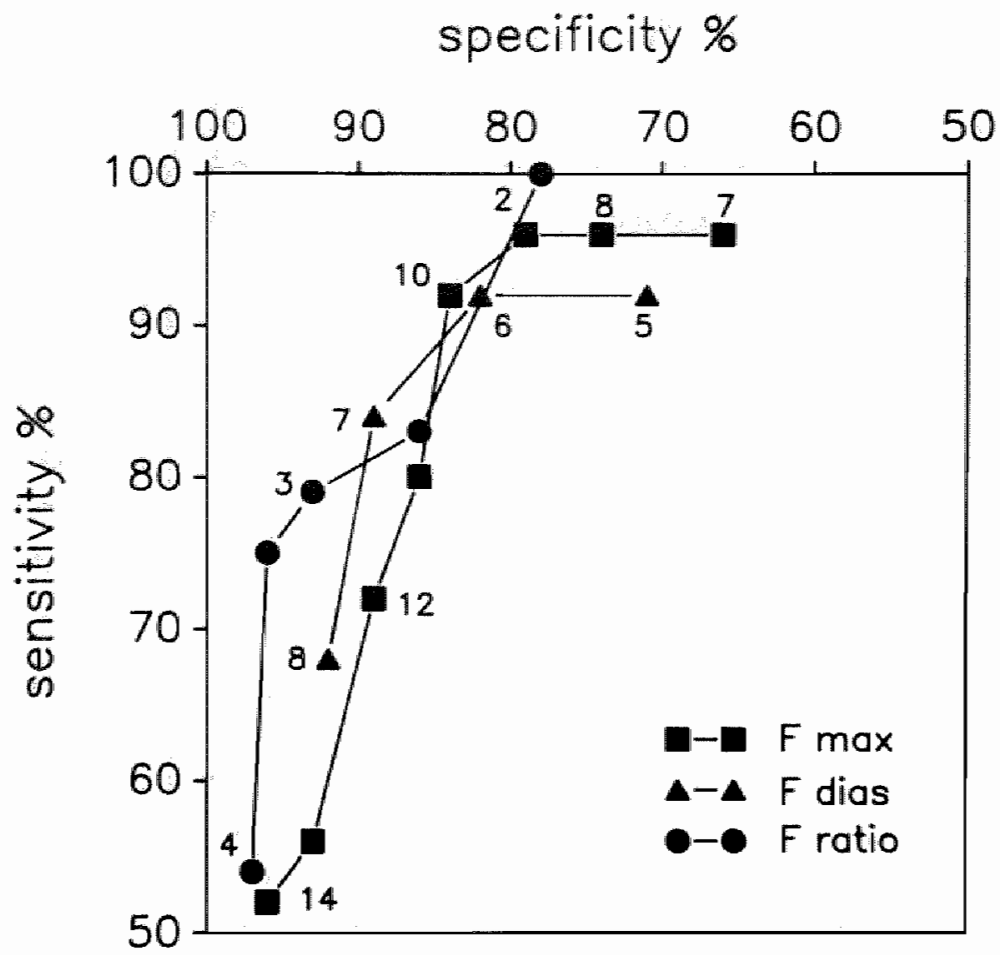

figure 3.3. ROC-curves of Fmax in Khz (squares), Fdias in Khz (triangles) and Fratio (circles) for stenoses of 50-99\% in the graft segments of graft AV fistulas.

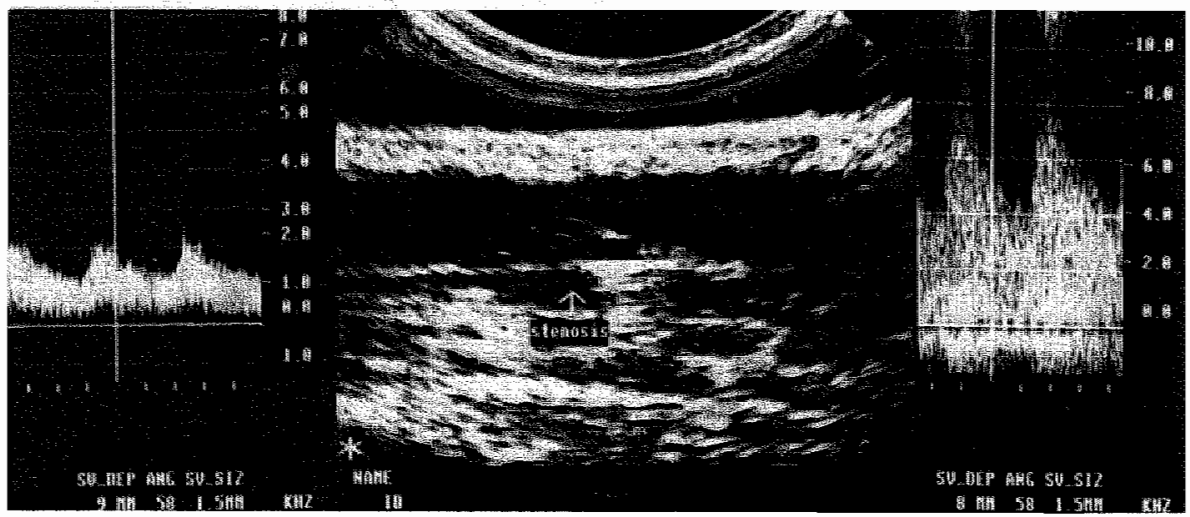

figure 3.4. Duplex scan of the efferent vein. B-mode imaging shows a significant stenosis ( arrow). At the site of this stenosis increased systolic (Fmax) and enddiastolic (Fdias) frequencies (right-hand side: Doppler registration). 
Table 3.5. Mean vallues of Fmax, Fdias and RI (efferent veín) for nonstenotic and stenotic segments

\begin{tabular}{llllll}
\hline & $\begin{array}{l}\text { no stenosis }(<0 \%) \\
\mathrm{N}=119\end{array}$ & & \multicolumn{2}{l}{$\begin{array}{l}\text { stenosis }(50-99 \%) \\
\mathrm{N}=11\end{array}$} & \\
\cline { 2 - 5 } & mean & SEM & mean & SEM & P-value \\
\hline Fmax (Khz) & 3.37 & 0.17 & 12.00 & 1.02 & $<0.001$ \\
Fdias (Khz) & 2.11 & 0.13 & 7.84 & 1.09 & $<0.001$ \\
RI & 0.3880 & 0.0123 & 0.3737 & 0.0466 & N.S. \\
\hline
\end{tabular}

Table 3.6. Discriminating value, maximum accuracy, sensitivity, specificity, positive predictive value (PPV) and negative predictive value (NPV) for the different Doppler parameters in the efferent veins

\begin{tabular}{lllllll}
\hline & cut off value & accuracy & sensitivity & specificity & PPV & NPV \\
\hline F & & $96 \%$ & $95 \%$ & $97 \%$ & $82 \%$ & $99 \%$ \\
Fax $(\mathrm{Khz})$ & 8 & $91 \%$ & $82 \%$ & $91 \%$ & $50 \%$ & $98 \%$ \\
$\mathrm{RI}$ & 0.4 & $55 \%$ & $33 \%$ & $58 \%$ & $8 \%$ & $89 \%$ \\
\hline
\end{tabular}

Occlusion of fistula segments

The Duplex scan was able to detect occlusion in 34 of the 36 occluded fistula segments. In these segments no flow could be determined with Doppler spectral analysis. In two AV fistulas with proximal radial artery occlusion detected by angiography, low values of respectively 2 and $3 \mathrm{Khz}$ for Fmax and 0.7 and 0.8 $\mathrm{Khz}$ for Fdias, were found in the proximal radial artery. The diagnostic accuracy is $99 \%$, the sensitivity $94 \%$ and the specificity $100 \%$ for the detection of fistula segment occlusions. 
specificity $\%$

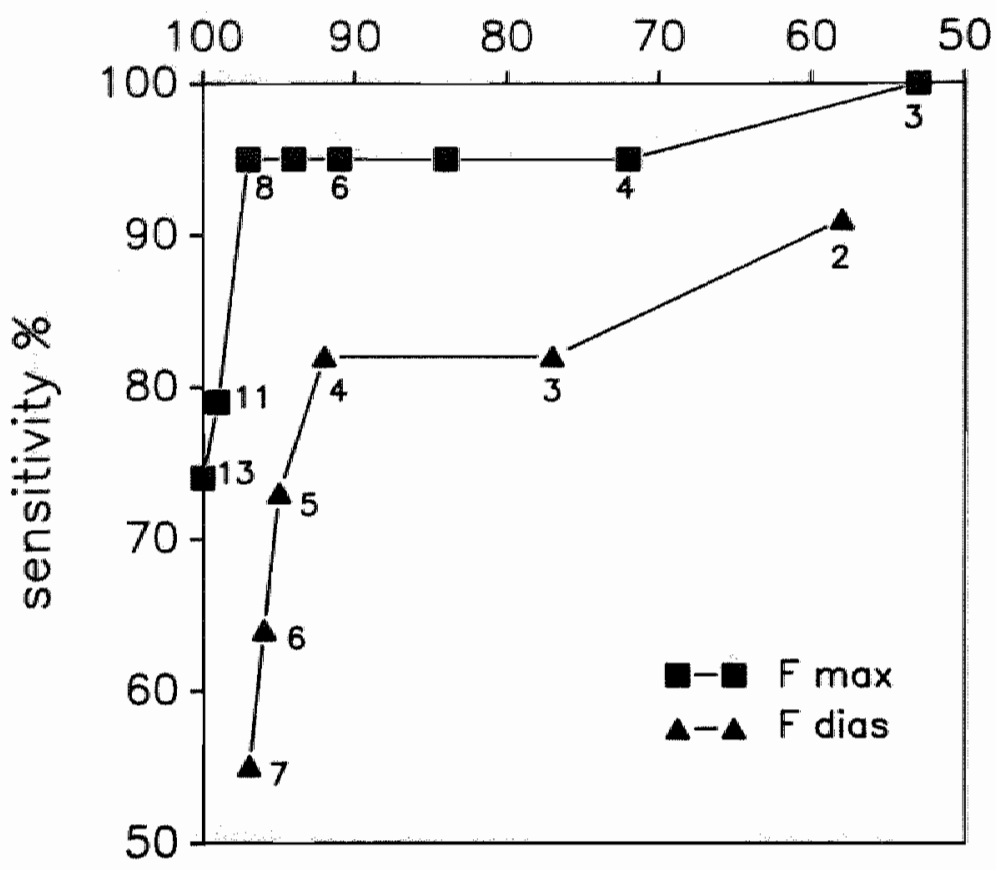

figure 3.5. ROC-curves of Fmax in Khz (squares) and Fdias in Khz (triangles) for stenoses of $50-99 \%$ in the efferent vein of Brescia/Cimino and graft AV fistulas.

\section{DISCUSSION}

Thrombotic occlusion is an important complication of AV fistulas for hemodialysis and the major reason for failure of the access site. Progressive stenosis in the anastomotic vessels or efferent vein has been recognized as the major cause for fistula thrombosis. Etheredge et.al. reported on the results of salvage surgery in malfunctioning PTFE graft fistulas for hemodialysis. ${ }^{9}$ The most common failure was thrombosis and the most commonly appreciated mechanical cause was venous outflow stenosis. In more than $60 \%$ of the occluded grafts additional patchplasty and bypass graft interposition was necessary to restore normal function. Raju published on the outcome of 312 PTFE grafts implanted as a dialysis AV fistula. ${ }^{10}$ In one third of the observed graft occlusions no technical problem such as stenosis or poor inflow could account for the thrombosis. In the remaining two-thirds of the cases, an anatomical cause requiring surgical revision was found to be responsible for the graft failure. 
Sixty-six percent of these revisions were needed at the venous anastomosis. Arterial revision was required in $15 \%$ and correction of graft stenosis in another $15 \%$.

In our study also a great number of stenotic segments of $50 \%$ and more diameter reduction were found in both malfunctioning and in normal AV fistulas. Sixty percent of all stenoses were located in one or more of the vessels of the arteriovenous anastomosis of Brescia/Cimino AV fistulas. In graft AV fistulas the stenoses were mainly located at the site of the graft-venous anastomosis and efferent vein. In saphenous vein grafts also multiple stenotic areas were determined in the graft itself.

In the last years noninvasive methods have become available for the investigation of AV fistulas for hemodialysis. Duplex ultrasound scanning combines two noninvasive techniques: B-mode sonography and pulsed Doppler insonation. Vessels are detected by sonography after which Doppler spectral analysis is performed with a known sample volume and angle of insonation. Stenotic lesions in bloodvessels will cause an increase in bloodflow velocity resulting in an increase in frequency shift of the backscattered Doppler signal. Beyond the stenosis, turbulence of the bloodflow occurs with broadening of the Doppler spectrum as result. Measurements of peak frequencies and spectral broadening in carotid artery disease have proven to be an accurate method for the detection of stenosis and even allow the calculation of the degree of stenosis. ${ }^{11}$

In the present study Duplex scanning was performed in Brescia/Cimino AV fistulas and in graft AV fistulas for hemodialysis. In 5 Brescia/Cimino AV fistulas $(11 \%)$ one or more of the anastomotic vessels could not be visualised and examined adequately. In one graft AV fistula (4\%) the arterial anastomosis could not be determined. The efferent veins were in all cases well visualised. The Digital Subtraction Angiography was unable to visualize the anastomotic region in 6 Brescia/Cimino AV fistulas (16\%) and 2 graft AV fistulas (7\%). In another 2 fistulas the efferent veins were not adequately imaged.

The best results of Duplex scanning for the detection of stenoses of $50 \%$ or more were obtained in graft AV fistulas and at the site of the efferent vein. When we use Fmax above $10 \mathrm{Khz}$ for grafts and above $8 \mathrm{Khz}$ for efferent veins respectively as criteria for stenosis, very acceptable accuracies of $86 \%$ and $96 \%$ respectively are obtained. The use of Fratio did improve the accuracy only in graft AV fistulas. Measurement of the Fdias and calculation of the RI provided no additional diagnostic value. The detection of stenoses at the arteriovenous anastomosis of Brescia/Cimino AV fistulas is less accurate. The maximal accuracy obtained in this area was $81 \%$, using a threshold value for Fmax of 12 $\mathrm{Khz}$. No further improvement could be reached with the use of the Fratio or the 
Fdias as parameter. Difficulties in recognition of the AV fistula anatomy and the high velocities over the anastomosis may account for these relatively poor results of the Duplex scanning. Better results may be obtained by combined use of spectral analysis and diameter measurement with the B-mode imager. Segmental vessel occlusion in the AV fistula can be diagnosed by Duplex scanning with a high accuracy of $99 \%$. In 2 AV fistulas with proximal radial artery occlusion, detected by angiography, low Doppler frequencies were measured, indicating flow. In these cases the Duplex scan is perhaps more sensitive than the angiography.

There are only few reports from the literature concerning the use of noninvasive methods for the detection of stenoses in AV fistulas for hemodialysis. Van Baalen et.al. used a continuous-wave Doppler device for the diagnosis of venous anastomosis stenoses in PTFE graft AV fistulas with good results. ${ }^{12}$ Glickman et. al. have published on the use of Duplex scanning for the diagnosis of stenoses in 25 PTFE graft AV fistulas. ${ }^{5}$ The outcome of the Duplex scan was compared to angiograms and intraoperative findings. With the use of peak systolic frequencies and spectral broadening, diagnosis of stenoses at the venous anastomosis was obtained in all stenosed grafts. Stenotic lesions in the efferent veins up to the subclavian vein could be diagnosed accurately. Zwicker et. al. reported on the results of Duplex investigation of $27 \mathrm{Brescia} / \mathrm{Cimino} \mathrm{AV}$ fistulas and 3 PTFE graft AV fistulas for hemodialysis. ${ }^{13}$ In 8 Brescia/Cimino AV fistulas the outcome of the Duplex scan and Digital Subtraction Angiography were identical. The criteria for the diagnosis of stenoses are not obvious in their study.

\section{CONCLUSIONS}

This study was carried out to determine the value of Duplex ultrasound scanning for the investigation of Brescia/Cimino AV fistulas and graft AV fistulas for hemodialysis. The results document that quantitative analysis of Doppler spectral recordings can be of diagnostic value in detecting fistula stenoses. The best results are obtained at the site of the efferent vein and in graft AV fistulas. Further experience with Duplex scanning and the combined use of Doppler spectral analysis with B-mode diameter measurement may improve the diagnostic accuracy. 


\section{REFERENCES}

1 Brescia, M.J., Cimino, J.E., Appel, K., Hurwich, B.J..

Chronic hemodialysis using venipuncture and a surgically created arteriovenous fistula.

N Engl J Med 1966; 275: 1089-1092.

2 Anderson, C.B., Gillula, L.A., Sicard, G.A., Etheredge, E.E.:

Venous angiography of subcutaneous hemodialysis fistulas.

Arch Surg 1979; 114: 1320-1325.

3 Glanz, S., Bashist, B., Gordon, D.H., Butt, K.M.H., Adamsons, R.:

Angiography of upper extremity access fistulas for dialysis.

Radiology 1982; 143: 45-52.

4 Picus, D.D., Breda, A. van, Katzen, B.T., Steinberg, D.L.:

Use of Digital Subtraction Angiography for evaluation of vascular access for hemodialysis.

Cardiovasc Int Rad 1987; 10: 210-214.

5 Glickman, M.H., Clark, S., Goodrich, V.:

Determimation of outflow stenosis of arteriovenous fistulas for hemodialysis.

Bruit 1985; 9: 16-19.

6 Rittgers, S.E., Garcia-Valdez, C., McCormick, J.T., Posner, M.P.*

Noninvasive blood flow measurement in expanded polytetrafluoroethylene grafts for hemodialysis access.

J Vasc Surg 1986; 3: 635-642.

7 Staple, T.W:

Retrograde venography of subcutaneous arteriovenous fistulas created surgically for hemodialysis.

Radiology 1973; 106: 223-224.

8 Sackett, D.L., Haynes, R.B., Tugwell, P.:

Clinical Epidemiology. A basic science for clinical medicine.

Editors Little, Brown and Compagny 1985.

9 Etheredge, E.E., Haid, S.D., Maeser, M.N., Sicard, G.A., Anderson, C.B.:

Salvage operations for malfunctioning polytetrafluoroethylene hemodialysis access grafts.

Surgery $1983 ; 94: 464-470$.

10 Raju, S.:

PTFE grafts for haemodialysis access.

Ann Surg 1988; 206: 666-673.

11 Johnston, K.W., Baker, W.H., Bumham, S.J., Hayes, A.C., Kuper, C.A., Poole, M.A."

Quantitative analysis of continuous wave Doppler spectral broadening for the diagnosis of carotid disease: results of a multicenter study.

J Vasc Surg 1986; 4: 493-504.

12 Baalen, J.M., van, Jakimowicz, J.J., Flendrig, J.A.:

Spectral analysis of the Doppler signal in evaluation of arteriovenous shunts.

In: Kootstra G., Jörning P.J.: Access Surgery ,Lancaster;MTP Press Ltd.; 1983: 67.

13 Zwicker, C., Langer, M., Huben, H., Pustelnik, A., Fiegler, W., Felix, R.:

Duplexsonographie von Hämodialyseshunts.

Angio $1987 ; 9: 47-52$. 


\section{Chapter 4}

\section{The correlation between clinical and duplex ultrasound parameters and the development of complications in arteriovenous fistulas for hemodialysis}

Jan H.M. Tordoir, ${ }^{1}$ Hans Hoeneveld, ${ }^{2}$ Bert C. Eikelboom, ${ }^{1}$ Peter J.E.H.M. Kitslaar $^{3}$

Eur J Vasc Surg, in press.

${ }^{1}$ Department of Vascular Surgery, ${ }^{2}$ Vascular Laboratory, St.Antonius Hospital, Nieuwegein, ${ }^{3}$ Department of Surgery, University Hospital Maastricht, the Netherlands.

\section{ABSTRACT}

In a 2-years prospective study of the fate of arteriovenous hemodialysis fistulas, the influence of several clinical and noninvasive measured variables in 90 patients on maintenance hemodialysis was evaluated. A total of $58 \mathrm{Brescia} / \mathrm{Cimino}$ fistulas, $30 \mathrm{graft}$ fistulas and 2 elbow fistulas were investigated by means of Duplex ultrasound scanning.

Sixty-two out of these 90 patients had no problems with their AV fistulas. Twenty-eight patients developed 29 complications, including poor flow (6), thrombosis (7), venous hypertension (8), false aneurysm formation (4), distal ischemia (2) and puncture problems (2).

Univariate statistical analysis performed on the clinical variables diabetes, previous access surgery, type of fistula, duration of fistula implantation, congestive heart failure, peripheral arterial disease, age and sex showed that the type of fistula, previous access surgery, congestive heart failure and sex were significantly correlated $(\mathrm{P}<0.05)$ to the development of poor flow and thrombosis (flow-related complications). Determination of the maximal systolic frequency 
(Fmax), endiliastolic frequency (Fdias) and the frequency ratio (Fratio) in the brachial artery Doppler spectrum, was of prognostic value to discriminate between noncomplicated fistulas and fistulas which developed flow-related complications.

The total number of fistula stenoses ( $250 \%$ diameter reduction), detected by the Duplex scan, correlated also with the rate of thrombosis and poor flow $(\mathrm{P}=0.007)$.

The presence of peripheral arterial disease and the number of stenoses in the efferent veins were of predictive value for the development of venous hypertension.

A multivariate analysis of the most important clinical and Duplex variables, showed the number of stenoses in the efferent veins, the maximal systolic frequency of the brachial artery, sex and congestive heart failure to be significant independent riskfactors for the devellopment of fistula complications.

It is suggested that follow-up of AV fistulas by means of Duplex ultrasound scanning may be useful to select fistulas at risk for complications.

\section{INTRODUCTION}

Complications of AV fistulas for hemodialysis frequently occur. Low flow with inadequate perfusion of the artificial kidney and thrombotic occlusion are the most important fistula complications and the major cause for failure of the vascular access. Nonthrombotic complications like aneurysm formation, infection, venous hypertension and distal ischemia, may impair the function of the fistula and cause discomfort to the patient. Different etiological factors for the development of complications have been pointed out: stenoses in the fistula vessels; hypotension during dialysis and operation or due to congestive heart failure, ${ }^{1}$ and lesions of the veins caused by the punctures. ${ }^{2}$ Sex, Diabetes Mellitus and the type of access have been mentioned to exert influence on fistula function and complications. $3,4,5$

Usually clinical symptoms and difficulties with dialysis will point to the existence of fistula complications. Fistula stenoses are often elucidated by angiography or during surgical exploration, in malfunctioning or thrombosed fistula. ${ }^{6,7}$ In a previous study we have proved the value of noninvasive examination for the detection of stenoses in the afferent arteries, the arteriovenous anastomosis and efferent veins. ${ }^{8}$ It can be assumed that significant stenoses cause an increase in resistance of the vascular bed. These changes are reflected in the Doppler spectrum waveform proximal to the pathology.

Thus, noninvasive investigation of the fistula and the brachial artery may play an important role in the selection of patients at risk.

The aim of this study was to determine the influences of some clinical variables, the number of fistula stenoses and brachial artery Doppler-derived parameters on the subsequent development of complications in patients with AV fistulas. 
Therefore, we have used Duplex ultrasound scanning and performed a statistical correlative analysis of several Doppler and patients-linked variables and the occurrence of fistula complications during the follow-up period.

\section{PATIENTS AND METHODS}

Between March 1986 and February 1988 a prospective study was performed in 90 patients on maintenance hemodialysis: 53 men and 37 women with a mean age of 57 years (range 21 to 84 years). Fifty-eight Brescia/Cimino fistulas, 13 saphenous vein grafts, 12 PTFE ( ${ }^{8}$ Gore-tex) grafts, 5 homologous vein (\$) Vascogref) grafts and 2 brachial artery-to-cephalic vein fistulas were investigated by means of Duplex ultrasound scanning and clinical examination. The fistullas were in function for a mean period of 29 months ( 1 to 168 months). The Duplex scanning was performed with regular intervals of 3 to 6 months.

\section{Clinical investigation}

All patients were evaluated for the presence of Diabetes Mellitus, congestive heart failure necessitating hospital admission and peripheral arterial disease (history of claudication or previous arterial reconstruction). Also age, sex, type of fistula, duration of fistula implantation and previous access surgery were considered for analysis. These clinical parameters were correlated with the occurrence of fistula complications.

Three groups of complications were defined:

a. Flow-related complications: low flow through the artificial kidney $(<200 \mathrm{cc}$ $/ \mathrm{min}$ ) or thrombotic occlusion of the fistula.

b. Puncture-related complications: aneurysms $>3 \mathrm{~cm}$ in diameter and venipuncture difficulties.

c. Hemodynamic complications: ischemia (pain and discoloration of the hand) and venous hypertension (oedema or major venous drainage through the hand veins; fig. 4.1). 

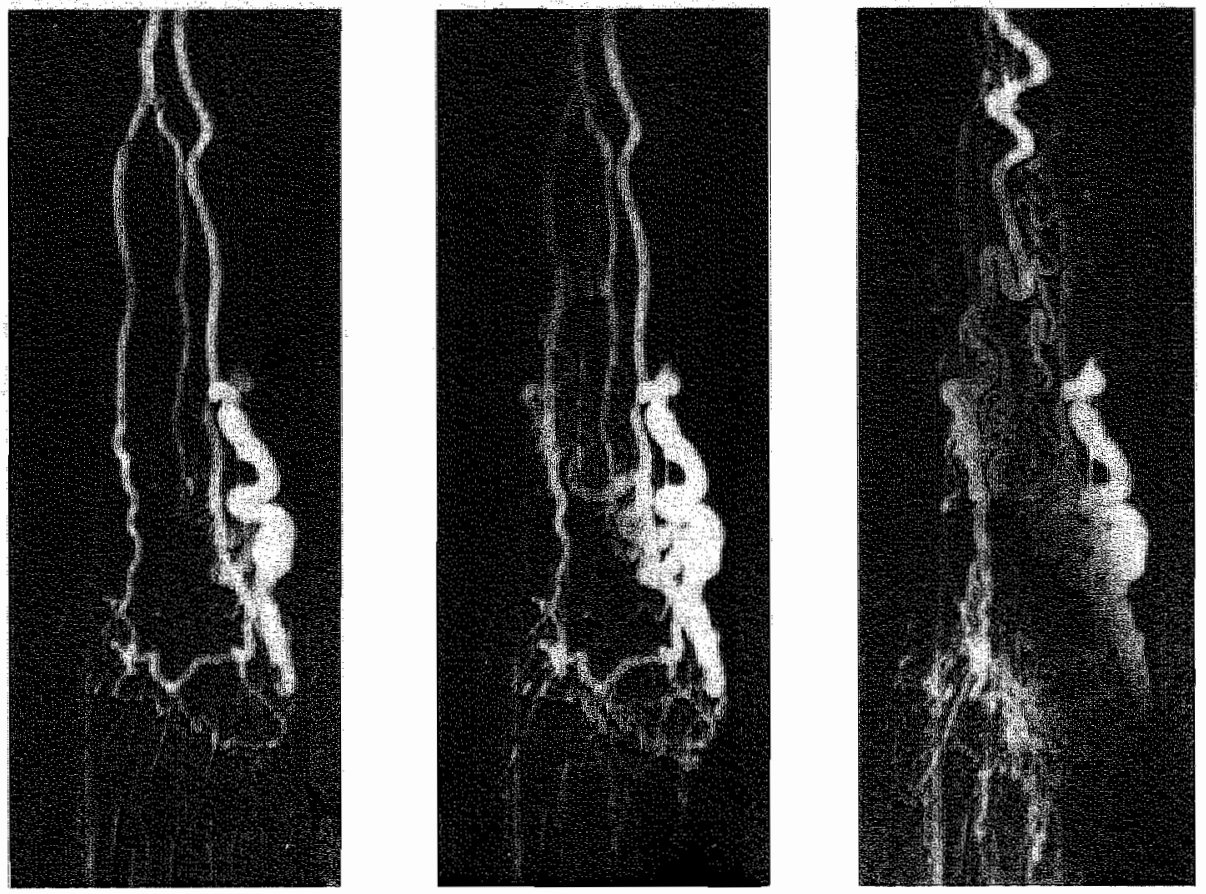

fig. 4.1. Intravenous DSA of a Brescia/Cimino fistula in a patient with venous hypertension. The proximal cephalic vein (big arrow) is occluded and the major venous drainage is through collaterals in the hand (small arrows).

\section{Duplex examination}

All patients were submitted to noninvasive examination in the supine position and prior to a dialysis treatment. Duplex scanning was performed with a hand-hold probe incorporating a $5 \mathrm{Mhz}$ pulsed Doppler system and a $10 \mathrm{Mhz}$ B-mode imager (ATL Ultramark IV Duplex system). The B-mode imager was used for localisation and detection of the fistula vessels. The Brescia/Cimino fistulas were screened from the distal brachial artery to the arteriovenous anastomosis at the wrist and the efferent veins from the forearm upwards to the upper arm. The graft AV fistulas were investigated from the distal brachial artery along the arterial anastomosis, the graft itself and the venous anastomosis to the efferent vein in the upper arm. The insonation of the vessels was carried 


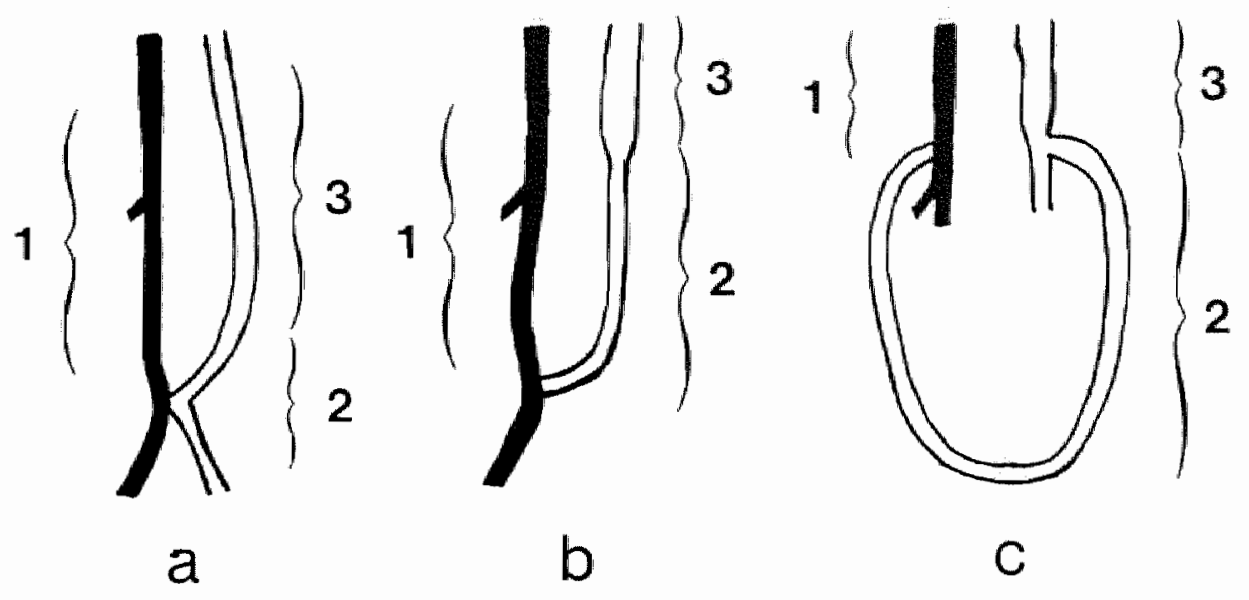

fig. 4.2. Type of fistula and vessel segments in the Duplex examination.

a. Brescia/Cimino fistula; b. straight graft interposition; c. loop graft interposition.

1. the arterial vessels; 2 the fistula complex; 3 the venous vessels.

out with a constant angle of 60 degrees. Representative Doppler recordings were made at different locations and freezed on the screen. Hard copy registrations of the spectra were kept for quantitative analysis.

Specific segments in the fistula circuit were distinguished (fig.4.2):

1. the arterial (afferent) vessels (from the distal brachial artery to the arteriovenous or arterial-graft anastomosis)

2. the fistula complex $(<2 \mathrm{~cm}$ from the arteriovenous anastomosis in Brescia/Cimino and elbow fistulas; the arterial and venous anastomosis and the graft itself in the case of graft AV fistulas)

3. the venous (efferent) vessels $(\geq 2 \mathrm{~cm}$ from the arteriovenous or graft-venous anastomosis upwards to the upper arm).

For all fistula segments maximal systolic frequencies (Fmax); enddiastolic frequencies (Fdias) and the Resistance Index (RI) were measured in the Doppler spectral. This last parameter reflects the degree of peripheral resistance and is calculated by the formula: RI=(Fmax-Fdias)/Fmax.

The number of stenoses of $50 \%$ to $99 \%$ diameter reduction in the different segments (arterial/fistula complex/venous) were determined by Doppler spectral analysis. The criteria for the diagnosis of significant stenosis (50-99\% diameter reduction) have been discussed previously. ${ }^{8}$ 
Also the brachial artery Fmax, Fdias and RI were determined. The Fratio of the brachial artery Doppler waveform was calculated as the ratio of Fmax without fistula compression over the Fmax with compression. The number of fistula stenoses in the different fistula segments, the total number of stenoses, brachial artery Fmax, Fdias, RI and Fratio were correlated with the development of fistula complications.

\section{Statistical analysis}

Statistical analysis was performed on the differences between all variables in the groups with and without complications. Univariate analysis was performed with the Student's t-test and the chi-square test. A P-value of 0.05 or less was considered as statistically significant. Multivariate analysis was performed using multiple regression analysis (stepwise method) of the SPSS statistical software package for PC's. ${ }^{9}$

Table 4.1. Type and number of complications in $28 \mathrm{AV}$ fistulas

flow-related complications

low flow

thrombosis

hemodynamic complications

venous hypertension

ischemia

puncture-related complications

aneurysm formation

puncture difficulties

total number of complications
13

7

6

10

8

2

6

4

2

\begin{tabular}{ll}
4 & 6 \\
2 & \\
\hline 29
\end{tabular}


Table 4.2. Clinical data, riskfactors and type of fistula by complication group

\begin{tabular}{|c|c|c|c|}
\hline & $\begin{array}{l}\text { no } \\
\text { complications }\end{array}$ & $\begin{array}{l}\text { flow-related } \\
\text { complications }\end{array}$ & $\begin{array}{l}\text { hemodynamic } \\
\text { complications }\end{array}$ \\
\hline & $N=67$ & $N=13$ & $N=10$ \\
\hline sex (male/female) & $44 / 23$ & $3 / 10$ & $6 / 4$ \\
\hline mean age patients (yrs) & 57 & 57 & 59 \\
\hline diabetes mellitus & 7 & 1 & 2 \\
\hline congestive heart failure & 2 & 5 & 1 \\
\hline peripheral arterial disease & 4 & 1 & 3 \\
\hline previous AV fistulas & 12 & 6 & 1 \\
\hline duration fistula in situ (mts) & 31 & 19 & 31 \\
\hline \multicolumn{4}{|l|}{ type of fistula: } \\
\hline Brescia/Cimino-Elbow fistula & 47 & 3 & 8 \\
\hline venous interposition & 6 & 7 & 0 \\
\hline graft interposition & 14 & 3 & 2 \\
\hline
\end{tabular}

\section{RESULTS}

In the period from March 1986 till February 1988, 29 complications developed in $28(31 \%)$ fistulas. The mean interval between the Duplex examination and the occurrence of any of the complications was $3.1 \mathrm{mts}$ (range 1 to 8 months). In Table 4.1 the type and number of the fistula complications are outlined. Adequate Duplex data could be obtained in all patients. However in 9 patients $(10 \%)$, it was impossible to scan the brachial artery, because of a proximally situated brachial artery bifurcation. None of these patients developed fistula complications.

The clinical and Duplex data in patients with noncomplicated fistulas were compared to the patients which developed flow-related and hemodynamic complications (Table 4.2 and 4.3).

Univariate analysis showed that sex, type of fistula, previous access surgery and the presence of congestive heart failure were significantly associated with the development of flow-related complications $(\mathrm{P}<0.05)$. In addition 4 Duplex parameters, brachial artery Fmax, Fdias, Fratio and the total number of ste- 
Table 4.3. Duplex data of the warious fistulas by complications (Mean and SEM)

\begin{tabular}{|c|c|c|c|c|c|c|}
\hline & \multicolumn{2}{|c|}{$\begin{array}{l}\text { no } \\
\text { complications } \\
N=67\end{array}$} & \multicolumn{2}{|c|}{$\begin{array}{l}\text { flow-related } \\
\text { complications } \\
N=13\end{array}$} & \multicolumn{2}{|c|}{$\begin{array}{l}\text { hemodynamic } \\
\text { complications } \\
\mathrm{N}=10\end{array}$} \\
\hline & mean & $\pm S E M$ & mean & $\pm S E M$ & mean & $\pm \mathrm{SEM}$ \\
\hline brachial artery Fmax (Khz) & 4.6 & 0.2 & 2.5 & 0.3 & 5.1 & 0.7 \\
\hline brachial artery Fdias (Khz) & 2.3 & 0.2 & 1.1 & 0.3 & 2.6 & 0.5 \\
\hline brachial artery Fratio & 2.32 & 0.12 & 1.57 & 0.17 & 2.29 & 0.18 \\
\hline brachial artery RI & 0.508 & 0.023 & 0.595 & 0.055 & 0.516 & 0.032 \\
\hline total number of stenoses & 1.38 & 0.71 & 2.38 & 1.12 & 1.90 & 0.30 \\
\hline arteriall stenoses & 0.07 & 0.02 & 0.15 & 0.06 & 0.10 & 0.04 \\
\hline fistula stenoses & 1.00 & 0.19 & 1.69 & 0.38 & 0.80 & 0.20 \\
\hline venous stenoses & 0.31 & 0.06 & 0.54 & 0.18 & 1.00 & 0.21 \\
\hline
\end{tabular}

Table 4.4. R-square values (multivariate analysis) of significant clinical and Duplex variables for various fistula complications

$\begin{array}{lll}\text { flow-related } & \text { hemodynamic } & \text { all } \\ \text { complications } & \text { complications } & \text { complications }\end{array}$

\begin{tabular}{llll}
\hline sex & 0.45796 & - & - \\
congestive heart failure & 0.41737 & - & 0.27143 \\
brachial artery Fmax & 0.30005 & - & 0.32913 \\
venous stenoses & - & 0.16140 & 0.19766 \\
\hline
\end{tabular}

noses, detected in the fistula vessels, were found to be significant predictors of complications $(\mathrm{P}<0.005)$.

As regards hemodynamic complications, only the presence of peripheral arterial disease was of prognostic value. The number of venous stenoses in the efferent veins was significantly greater $(\mathrm{P}<0.01)$ in fistulas which developed hemodynamic complications compared to noncomplicated fistulas. 
specificity \%

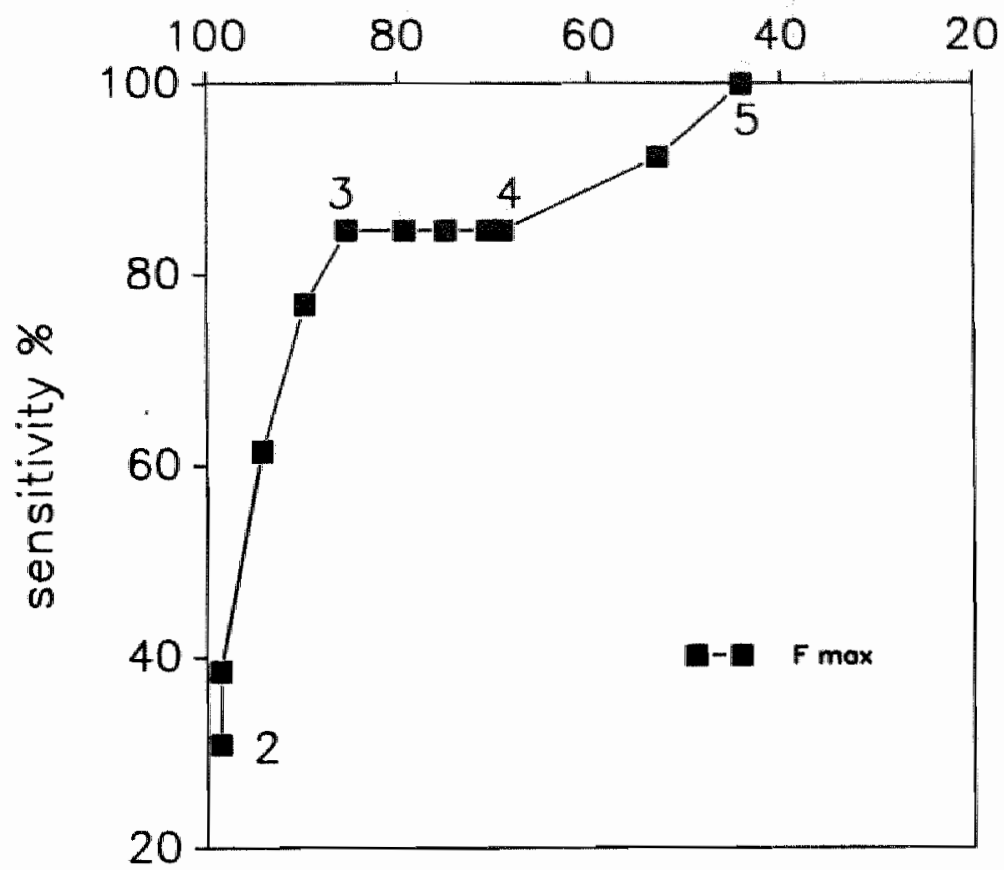

fig. 4.3. ROC-curve of brachial artery Fmax in Khz in fistulas with flow-related complications.

Taking all complications together, congestive heart failure, peripheral arterial disease, total number of stenoses, number of venous stenoses and Fratio appeared to be of prognostic value $(\mathrm{P}<0.05)$.

For each complication group stepwise multiple regression was performed to determine which clinical variables, brachial artery Doppler-derived variables and fistula variables (stenoses) could be considered predictors of later fistula complications (Table 4.4).

Sex, congestive heart failure, Fmax and number of venous stenoses were the most important independent variables to predict complications. In competition with each other, only the number of venous stenoses, Fmax and congestive heart failure remained in the analysis.

In fig. 4.3 the ROC-curve for different threshold values of brachial artery Fmax as a predictor of flow-related complications, is outlined. With a cut off value of $3 \mathrm{Khz}$, the sensitivity is $84.6 \%$, the specificity $85.3 \%$ and accuracy $85 \%$. 


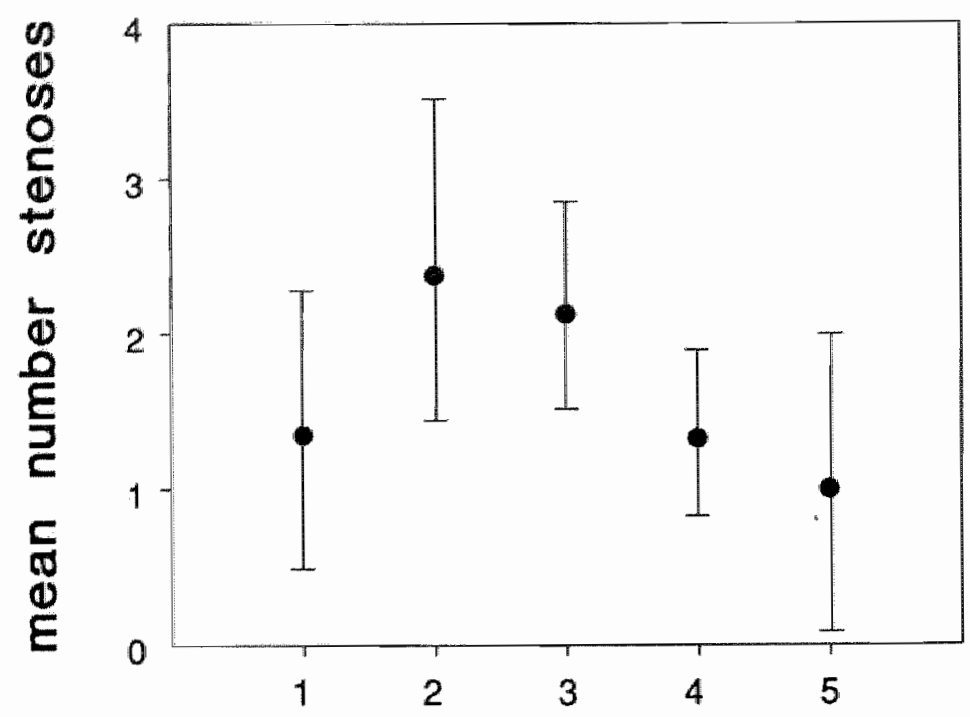

fig.4.4. Mean number of stenoses (and SD) in the fistula circuit in relationship to the type of complication.

1. no complications; 2. flow-related complications; 3. venous hypertension; 4. aneurysm; 5. ischemia.

The relationship between the total number of stenoses in the fistula circuit and the type of complication can be noticed in fig. 4.4. Noncomplicated fistulas had a mean of 1.4 stenoses in contrast to a mean of 2.4 stenoses in patients with flow-related complications, and 2.1 stenoses in patients with venous hypertension. Patients with aneurysms and ischemia had a mean of respectively 1.3 and one stenosis.

\section{DISCUSSION}

In this study, univariate analysis showed a significant correlation between the clinical variables sex, congestive heart failure, previous access surgery and type of fistula and the development of flow-related complications, like low perfusion flow and thrombotic occlusion. Smaller size of vessels and a greater tendency for vasoconstriction can explain the higher incidence of failure in women. The lowered forward flow induced by congestive heart failure may be responsible for fistula thrombosis. Venous interposition grafts had a high rate of flow-related complications $(54 \%)$. In most of these grafts multiple stenoses could be 
detected in the vein itself, in contrast to only graft-venous anastomosis stenoses in prosthetic grafts. This feature is probably responsible for a greater risk for complications in the venous grafts.

The multivariate analysis showed sex and congestive heart failure to be the most important clinical risk factors for flow-related complications. None of these parameters were however significantly correlated with the occurrence of venous hypertension. In our study patients with Diabetes Mellitus had no greater risk for the development of complications than patients without diabetes.

In previous studies on clinical parameters influencing the complication and survival rate of $\mathrm{AV}$ fistulas, different influences of sex, age and Diabetes Mellitus have been mentioned. ${ }^{10,11}$ Kinnaert et. al. found lower survival rates of AV fistulas in women compared to men. ${ }^{3}$ This was however only the case in patients treated by a combined program of dialysis and transplantation. Other investigators could not detect any influence of sex or age on fistula complications. ${ }^{12,13}$ Aman et. al. showed that diabetics had a greater risk for both complications and low survival. ${ }^{4}$ Such differences were found in Brescia/Cimino fistulas and were not present in bovine and PTFE grafts. Prosthetic grafts are reported to have a significantly higher incidence of thrombosis, infection and. aneurysm formation and a shorted duration of patency compared to Brescia/ Cimino fistulas. ${ }^{5,14}$

It is generally accepted that the development of stenoses in the fistula circuit is a major cause for fistula complications and failure. The presence of critical stenoses together with hypotension during dialysis can induce thrombosis. The influences of the severity, location and number of stenotic lesions has not yet been studied. Noninvasive Duplex ultrasound scanning allows the accurate diagnosis of stenoses of $50 \%$ and more. We found a significantly higher total number of stenoses in the fistula vessels in patients which developed flow-related and hemodynamic complications. The number of stenoses found in the efferent veins also correlated with the chance on venous hypertension.

Spectral analysis of the brachial artery Doppler waveform is able to select fistulas at risk for the development of flow-related complications. The values of Fmax, Fdias and the Fratio were significantly decreased in patients which later developed complications. The critical threshold value of Fmax, for the prediction of thrombosis and poor flow was $3 \mathrm{Khz}$. None of the brachial artery Doppler parameters was however of value for the prediction of hemodynamic complications.

Redmond et.al. showed that mean velocity and volume flows, measured with a range-gated pulsed Doppler system, were important prognostic factors for early failure in newly created Brescia/Cimino fistulas. ${ }^{15}$ The arterial and venous 
vessel sizes were not significantly different in succesful and failed fistulas. Reilly et.al. investigated the influence of rheological factors on fistula function. ${ }^{16}$ The best discriminants for separation between thrombotic and nonthrombotic fistulas, were blood platelet count, beta-thromboglobulin and plasma viscosity. They advised prophylaxis with platelet inhibitory agents in high-risk patients.

From the results of our study, we can conclude that clinical variables, like sex and the presence of congestive heart failure, are significantly related to the occurrence of flow-related complications. Moreover, Duplex ultrasound scanning has the potential to select patients at risk and is valuable for the follow-up of AV fistulas for hemodialysis. Determination of the brachial artery Fmax and early detection of stenoses in the efferent veins can be of importance in the prediction of complications.

Clinical validation studies should be undertaken to see whether in this way fistula survival can be improved. 


\section{REFERENCES}

1 Berger, A., Rosenberg, N.:

Hypotension and closure of hemodialysis access shunts.

Am Surg 1983; 49: 551-553.

2 Rohr, M.S, Browder, W., Frentz, G.D., McDonald, J.C.:

Arteriovenous fistulas for long-term dialysis.

Factors that influence Fistula survival.

Arch Surg 1978; 113: 153-155.

3. Kinnaert, P., Vereerstraeten, $\mathrm{P}_{\text {, }}$ Toussaint, $\mathrm{C}_{\text {, }}$, Geertruyden, J.J. van:

Nine years experience with internal arteriovenous fistulas for hemodialysis: a study of some factors influencing the results.

Br J Surg 1977; 64: 242-246.

4 Aman, L.C., Smith, D.W., Oh, H.K., Levin, N.W.*

Vascular access survival in diabetic and non-diabetic haemodialysis patients.

In: Kootstra G., Jörning P.J.G. Access Surgery, Lancaster: MTP Press Ltdl., 1983; 179-190.

$5 \quad$ Keller, F., Loewe, H.J., Bauknecht, K.J., Schwarz, A., Offerman, G."

Kumulative Funktionsraten von orthotopen Dialysefisteln und Interponaten.

Dtsch Med Wochenschr 1988; 113: 332-336.

6 Slifkin, R.F., Haimov, M., Neff, M.S., Eiser, A., Baez, A., Amarga, E., Gupta, S.:

The role of angiography in vascular access surgery.

In: Kootstra G., Jörning P.J.G. Access Surgery, Lancaster: MTP Press Ltd., 1983; 59-65.

7 Etheredge, E.E., Haid, S.D., Maeser, M.N., Sicard, G.A., Anderson, C.B.:

Salvage operations for malfunctioning polytetrafluoroethylene hemodialysis access grafts.

Surgery $1983 ; 94: 464-470$.

8 Tordoir, J.H.M., Bruin, H.G. de, Hoeneveld, H., Eikelboom, B.C., Kitslaar, P.J.E.H.M.: Duplex ultrasound scanning in the assessment of arteriovenous fistulas created for hemodialysis access: comparison with Digital Subtraction Angiography.

J Vasc Surg 1989; 10:122-128.

9 Norusis, M.J.: SPSS/ PC+.

SPSS Inc, Chicago 1988; Library of Congres Catalog Card Number: 87-062353. ISBN 0-918469-55-4.

10 Hammill, F.S., Johnston, G.G., Collins, G.M., Halasz, N.A., Dilley, R.B., Bernstein, E.F.: A critical appraisal of the changing approaches to vascular access for chronic hemodialysis.

Dial Transpl 1980; 9: 325-328.

11 Hinsdale, J.G., Lipkowitz, G.S., Hoover, E.L.:

Vascular access for hemodialysis in the elderly: results and perspectives in a geriatric population.

Dial Transpl 1985; 14: 560-565.

12 Reilly, D.T., Wood, R.F.M., Bell, P.R.F.:

Prospective study of dialysis fistulas: problem patients and their treatment.

Br J Surg 1982; 69: 549-553. 
13 Wetrig, G.A., Gough, L.R., Furnival, C.M.:

One hunderd cases of arteriovenous fistulas for hemodialysis access: the effect of cigarette smoking on patency.

Aust N Z J Surg 1985; 55: 551-554.

14 Zibari, G.B., Rohr, M.S., Landreneau, M.D., Bridges, R.M., DeVault, G.A., Petty, F.H., Costley, KJ., Brown, S.T., McDonald, J,C.:

Complications from permanent hemodialysis vascular access.

Surgery 1988; 104: 681-686.

15 Redmond, H.P., Fitzgerald, D.E., Walker, J.F., Donohoe, J.:

A non-invasive method in the assessment of surgically created arteriovenous fistulae for uraemia.

Eur J Vasc Surg 1987; 1: 311-314.

16 Reilly, D.T., Wood, R.F.M., Bell, P.R.F.:

A prospective study of the correlation between rheological factors and fistula failure.

In: Kootstra G., Jörning P.J.G. Access Surgery, Lancaster: MTP Press Ltd., 1983; 51 -57. 


\section{Chapter 5}

\section{Hemodynamic sequelae of dialysis fistulas: a noninvasive study with duplex ultrasound scanning and digital bloodpressure}

measurement

Jan H.M. Tordoir, ${ }^{1}$ Hans Hoeneveld, ${ }^{2}$ Bert C. Eikelboom, ${ }^{1}$ Peter J.E.H.M. Kitslaar $^{3}$

J Vasc Surg, submitted.

${ }^{1}$ Department of Vascular Surgery, ${ }^{2}$ Vascular Laboratory, St. Antonius Hospital, Nieuwegein,

${ }^{3}$ Department of Surgery, University Hospital Maastricht, the Netherlands

\section{ABSTRACT}

The influences of artificial arteriovenous fistulas on local circulatory hemodynamics in the forearm, were investigated in 59 patients on maintenance hemodialysis. A total of 60 fistulas (42 Brescia/Cimino fistulas, 16 graft interposition fistulas and 2 brachial fistulas) were evaluated by means of Duplex ultrasound scanning and digital bloodpressure measurement. Complications in this patient group, included thrombosis (3), venous hypertension (5) and peripheral ischemia (4).

Fistula function, direction of bloodflow and collateral flow in the peripheral vessels, were determined by Doppler spectral analysis of the brachial, radial and ulnar arteries. The number and location of significant stenoses or occlusions in the vessels of the fistula circuit were also determined by Doppler spectral analysis.

Patients with peripheral ischemia and patients with a permanent steal in the distal radial artery had significant lower thumb bloodpressures and thumb/brachial (T/B) pressure indices than patients without complications or patients with a transient steal phenomenon. 
Fistulas with large wolume flows, documented by high maximal systolic or enddiastolic frequencies in the brachial artery Doppler spectrum, had relatively low thumb pressures and T/B pressure indices. The presence of proximal or distal radial artery stenoses and occlusions had no influence on digital bloodpressures. Also significant efferent vein stenoses did not influence digital bloodpressures.

The lowest values of thumb bloodpressures were found in Brescia/Cimino fistulas and loop graft fistulas.

Duplex scanning is able to quantify the steal phenomenon in dialysis fistulas and to document excessive shunting by brachial artery Doppler spectral analysis.

\section{INTRODUCTION}

Adequate vascular access in patients on long-term hemodialysis is achieved with the use of a subcutanuous arteriovenous fistula. Direct anastomosis between radial artery and cephalic vein (Brescia/Cimino fistula) or interposition of various graft materials between suitable arteries and veins, can be performed for this purpose. The subsequent blood shunting from the arterial into the venous system may result in local or general hemodynamic changes. ${ }^{1}$ Arterial insufficiency and venous hypertension of the hand are recognized complications of dialysis fistulas. Several authors ascribe these complications to a steal of blood from the hand arteries (Steal syndrome) or to excessive shunting in the AV fistula. ${ }^{2,3}$ Patients with Diabetes Mellitus and peripheral arterial disease have been known to be at risk for peripheral ischemia. ${ }^{4,5}$ Also the type of fistula can be of importance in the development of ischemia. ${ }^{6}$

Various invasive and noninvasive methods have been used to detect this steal phenomenon and to quantify the function of the fistula. $7,8,9,10,11$ However none of these studies has clarified the steal with a direct noninvasive technique.

We performed Duplex ultrasound scanning of the arteries of forearm and hand to detect and quantify steal in the radial artery and collateral flow in the ulnar artery in Brescia/Cimino and graft fistulas. Also quantitative Doppler spectral analysis was performed to measure fistula function and to diagnose significant stenoses in the fistula circuit. Digital bloodpressure measurement was carried out to investigate the hemodynamic influence of the AV fistula on the distal circulation. The results of the Duplex scanning were correlated to the outcome of the bloodpressure measurements. 


\section{PATIENTS AND METHODS}

Between March 1986 and February 1988 a prospective hemodynamic study was carried out in 59 patients on maintenance hemodialysis: 35 men and 24 women with a mean age of 56 years (range 23-84 yrs). Forty-two Brescia/Cimino fistulas ( 36 side-to-side, 6 end-to-side vein to artery), 7 straight forearm interpositions (5 venous grafts; 2 PTFE grafts), 9 loop forearm interpositions (6 PTFE grafts; 2 venous grafts; one homologous vein graft) and 2 brachial artery-to-cephalic vein fistulas were studied by means of Duplex ultrasound scanning and digital bloodpressure measurement. The fistulas were functioning for a mean period of 25 months (range 1-143 mts). Five patients had Diabetes Mellitus. Four patients had evidence of arterial insufficiency with symptoms of pain, coldness and discoloration of the hand. None of these patients had ulcerations. Other complications included venous hypertension (oedema and major drainage through the handveins) in 5 patients and fistula failure in 3 patients.

\section{Duplex examination}

All patients were investigated in the supine position and prior to a dialysis treatment. Duplex scanning was performed with a hand-hold probe incorporating a $5 \mathrm{Mhz}$ pulsed Doppler system and a $10 \mathrm{Mhz}$ B-mode imager (ATL Ultramark IV Duplex scanner). The B-mode imager was used for localisation and detection of the fistula vessels. The Brescia/Cimino fistulas and straight forearm graft interpositions were examined from the distal brachial artery along the radial artery to the arteriovenous anastomosis at the wrist. Also the radial artery distal of the anastomosis and the distal ulnar artery at the wrist were examined. The type of bloodflow in the radial artery distal to the AV anastomosis was distinguished in antegrade flow, alternating forward and retrograde flow synchronous with the heartcycle (transient steal), permanent retrograde flow (fig. 5.1) and no flow due to occlusion. The efferent vein was screened from the anastomosis upwards to the upper arm. The loop graft interpositions were evaluated from the distal brachial artery along the arterial anastomosis, the graft itself and the venous anastomosis to the efferent vein in the upper arm. The insonation of the vessels was with a constant angle of 60 degrees. Representative Doppler recordings were made at various locations and after Doppler spectral analysis kept as hard copy registrations. 

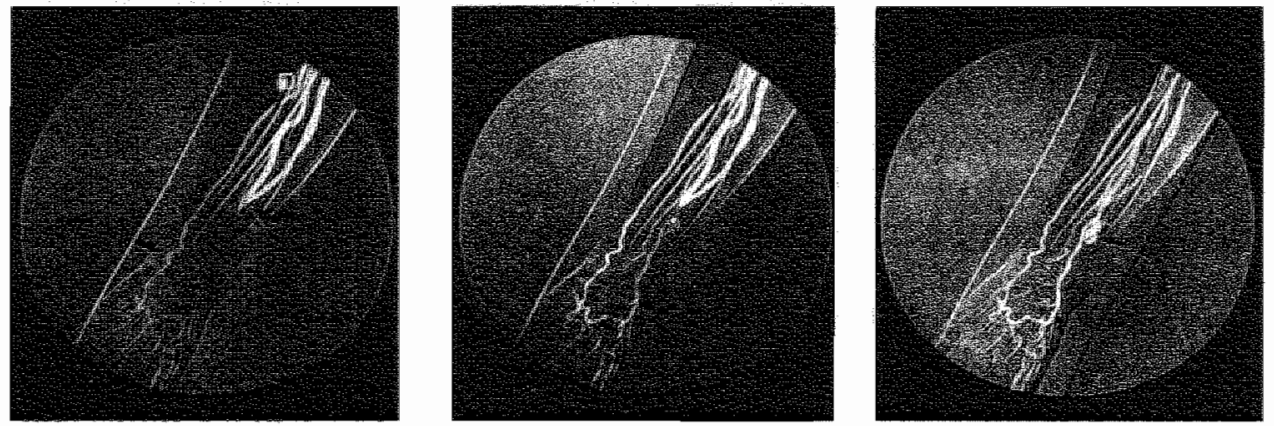

fig. 5.1. Permanent steal from the distal radial artery (small arrows), shown by serial images after intravenous contrast injection (Digital Subtraction Angiography), in a patient with a end-to-side Brescia/Cimino AV fistula (big arrow= AV anastomosis).

In the Doppler spectrum the maximal systolic frequency (Fmax) and enddiastolic frequency (Fdias) were determined. Also the ratio of the maximal systolic frequencies in the brachial artery without and with digital compression of the fistula was calculated (Fratio). Furthermore the Resistance Index (RI) was calculated: $\mathrm{RI}=$ (Fmax-Fdias)/Fmax.

Significant stenoses in the vessels were diagnosed by a local increase of Fmax according to criteria discussed previously. ${ }^{12}$

\section{Digital bloodpressure measurement}

The bloodpressures in both thumbs were measured in the supine patient after a period of 15 minutes rest. Systolic thumb bloodpressure was determined by slowly deflating a $20 \mathrm{~mm}$ wide cuff around the base of the thumb, inflated to a suprasystolic level and recording the first inflow with a photoplethysmography cell used as a pulse sensor (Medasonics Vasculab). The brachial systolic bloodpressure was measured by the standard auscultationmethod with the use of a 12 $\mathrm{cm}$ wide cuff on the upper arm. For comparison between patients the thumb-tobrachial artery bloodpressure index (T/B index) was calculated. Thumb bloodpressures were measured:1. with open fistula, 2 . during digital compression of the fistula and 3 . during compression of the distal ulnar artery. 


\section{Statistical analysis}

Statistical analysis of Duplex data and digital pressure measurements was performed on the differences between the patient groups by means of the Student's t-test. Correlation between Doppler parameters and digital pressure measurements was made with lineair regression analysis of the SPSS software package for $\mathrm{PC}$ "s.

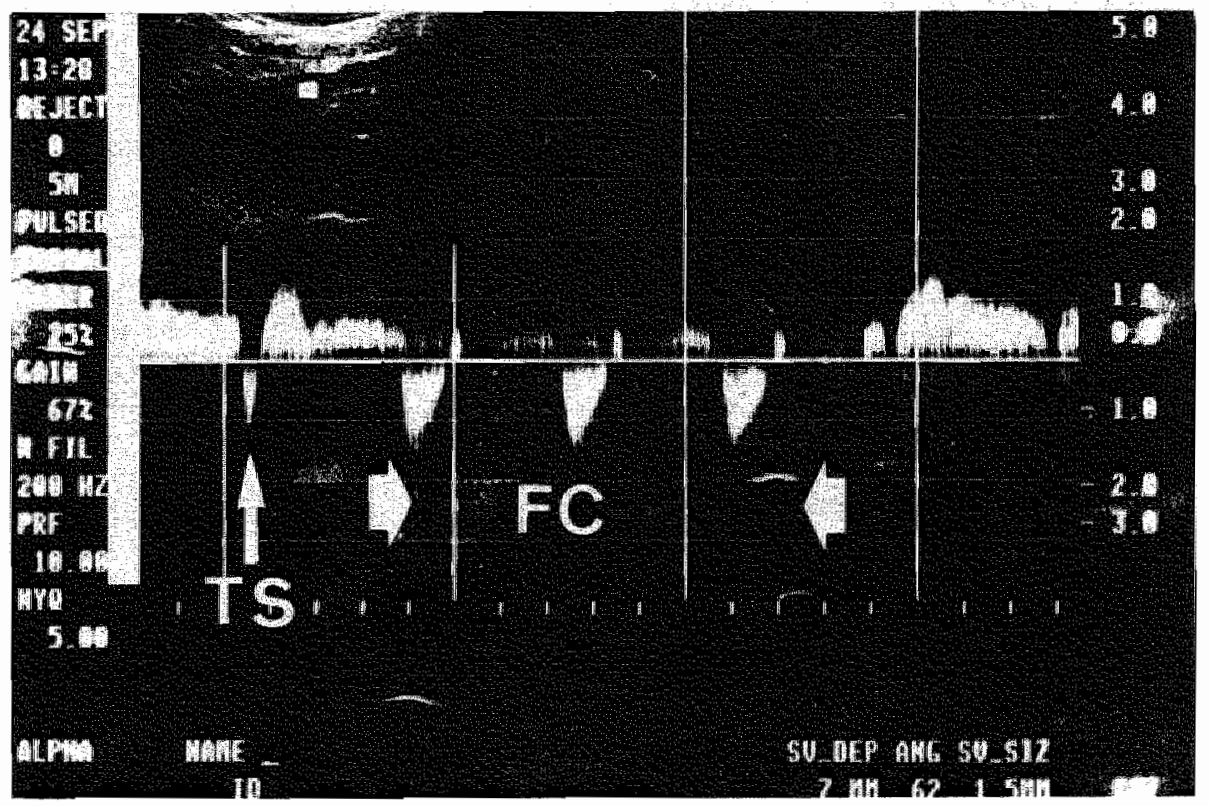

fig. 5.2 Duplex scan of the distal radial artery in a patient with a Brescia/Cimino fistula. A transient steal (TS) can be noticed with retrograde flow during the systole and antegrade flow at the end of diastole (small arrow). During fistula compression (FC), permanent antegrade flow occurs (big arrows). 


\section{RESULTS}

Adequate Duplex scans of the distal arteries could be obtained in all Brescia/ Cimino and straight graft fistulas. Thirty-six patients $(73 \%)$ had a permanent steal in the distal radial artery, while only 2 patients had antegrade bloodflow. In 4 patients a transient steal was observed, characterised by alternating retrograde and forward flow during systole and diastole (fig.5.2).

The correlation between the flow direction in the distal radial artery and the T/B index is shown in Table 5.1. Patients with a permanent steal had significant lower $\mathrm{T} / \mathrm{B}$ indices than patients with transient steal $(\mathrm{P}<0.01)$. The differences in $\mathrm{T} / \mathrm{B}$ indices between patients with permanent steal and patients with antegrade flow or distal radial artery occlusion were not statistical significant $(P>0.1)$. The effect of fistula compression or compression of the ulnar artery on the thumb pressure in Brescia/Cimino fistulas can be seen in fig. 5.3.

In this figure also the $\mathrm{T} / \mathrm{B}$ indices of the contralateral extremity are expressed.

Table 5.1. Grading of Steal phenomenon in the distal radial artery versus Thumb pressure and T/B pressure Index (Mean and SD)

\begin{tabular}{|c|c|c|c|c|c|}
\hline & \multirow[b]{2}{*}{$\mathbf{N}$} & \multicolumn{2}{|c|}{ Thumb pressure $(\mathrm{mm} \mathrm{Hg}$ ) } & \multicolumn{2}{|c|}{$\mathrm{T} / \mathrm{B}$ pressure Index } \\
\hline & & mean & SD & mean & $\mathrm{SD}$ \\
\hline antegrade flow & 2 & 169 & 41 & 0.77 & 0.10 \\
\hline transient steal & 4 & 162 & 20 & 0.80 & 0.06 \\
\hline permanent steal & 36 & 100 & 35 & 0.67 & 0.22 \\
\hline distal radial artery occlusion & 7 & 137 & 49 & 0.83 & 0.26 \\
\hline
\end{tabular}

The mean T/B index in the fistula arm was 0.73 (range 0.20-1.29). With fistula compression the mean T/B index rose to 1.04 (range 0.81-1.26), an increase of $42 \%$. With compression of the ulnar artery a further reduction in mean $\mathrm{T} / \mathrm{B}$ index of $28 \%$ was seen to a $\mathrm{T} / \mathrm{B}$ index of 0.52 . 


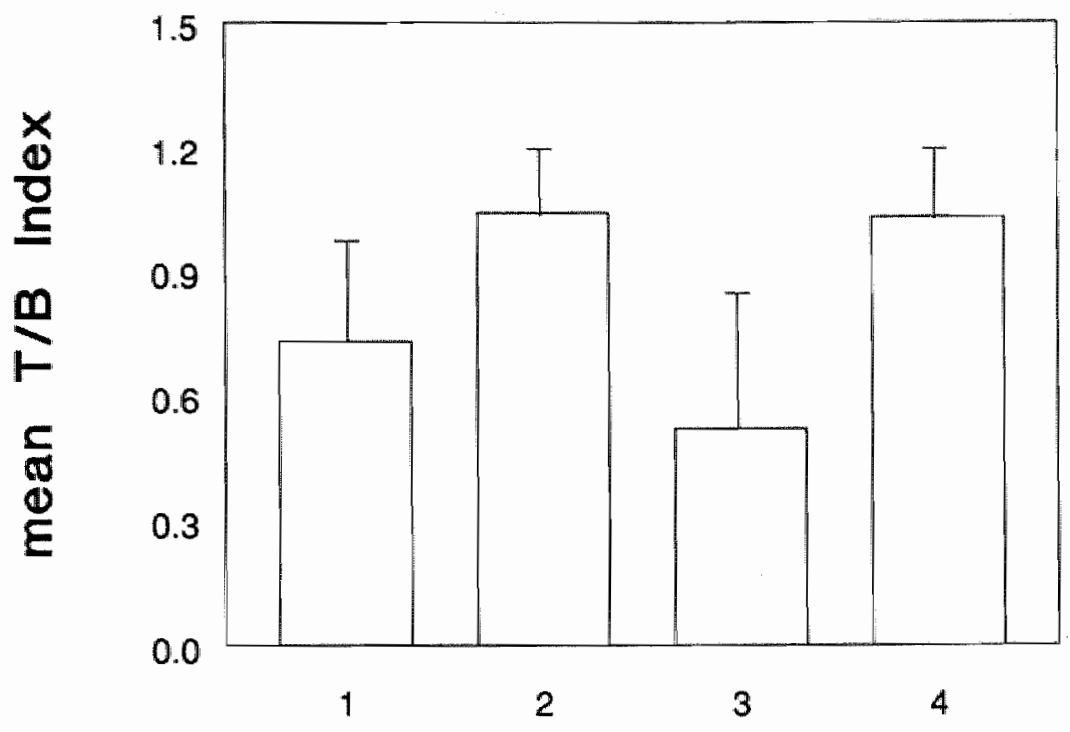

fig. 5.3. Mean T/B indices and SD in 1. noncompressed fistulas 2. fistulas with digital compression of the fistula circuit and 3. with compression of the distal ulnar artery. 4. mean $\mathrm{T} / \mathrm{B}$ index and SD in the contralateral arm.

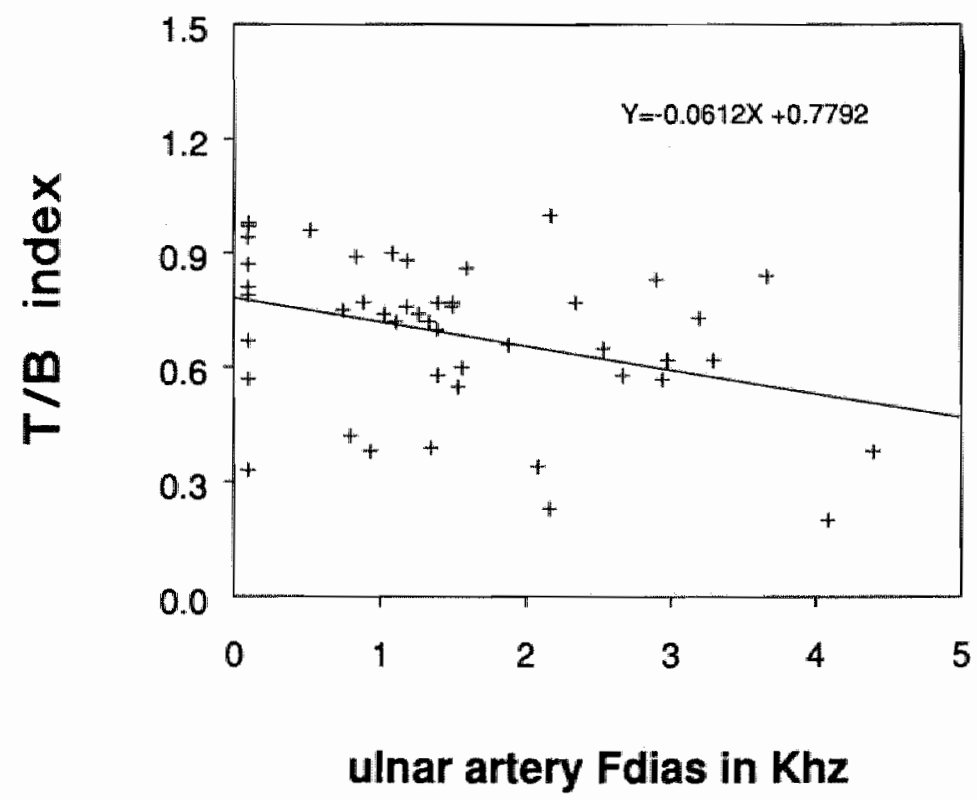

fig. 5.4. Scattergram of ulnar artery Fdias in Khz versus T/B index in Brescia/Cimino fistulas and straight graft interpositions $(\mathrm{R}=-0.3581 ; \mathrm{P}=0.01)$. 
Table 5.2. Type of fistula versus Thumb pressure and $\mathrm{T} / \mathrm{B}$ pressure index (Mean ard SD)

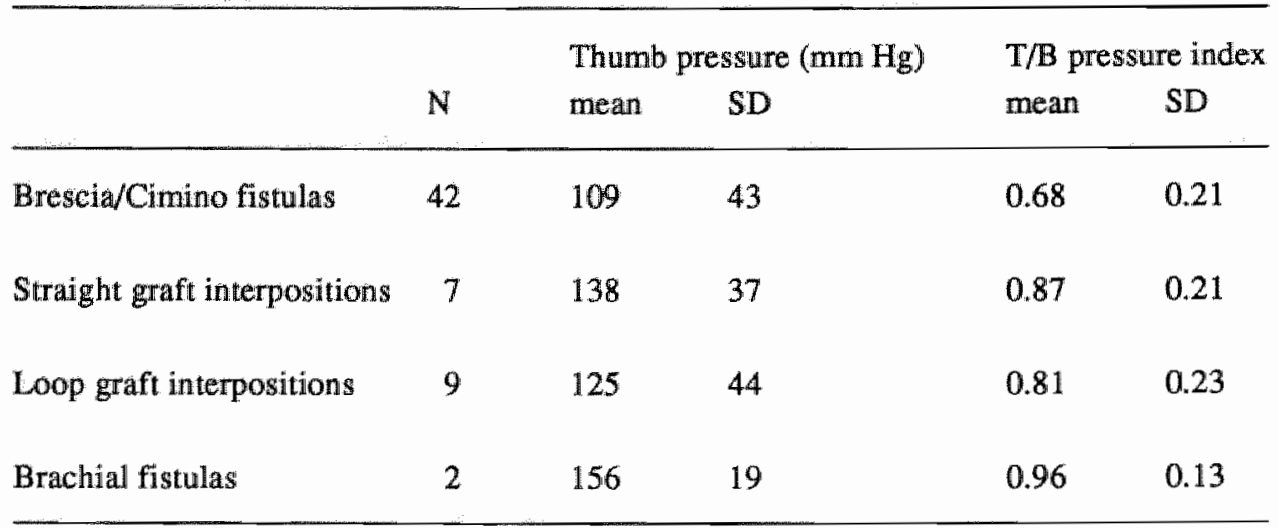

No significant correlation between ulnar artery Fmax, ulnar artery RI and thumb pressure or $\mathrm{T} / \mathrm{B}$ index could be detected. However ulnar artery Fdias correlated to $T / B$ indices ( $R$-value $=-0.3581$ ). In fig. 5.4 ulnar artery Fdias is plotted against corresponding $\mathrm{T} / \mathrm{B}$ indices.

The influence of the type of fistula on distal pressures can be noticed in Table 5.2. In Brescia/Cimino fistulas significant lower thumb pressures and $T / B$ indices were found compared to straight graft interpositions $(\mathrm{P}<0.05)$ and brachial fistulas $(\mathrm{P}<0.01)$. Mean $\mathrm{T} / \mathrm{B}$ indices in loop graft fistula and Brescia/ Cimino fistulas were not significantly different.

Fistula function was indirectly evaluated by means of Doppler spectral analysis of the brachial artery with and without digital compression of the fistula (Fratio). The mean values of thumb pressures and T/B indices with corresponding ranges of Fmax, Fdias and Fratios are given in Table 5.3, 5.4 and 5.5. An increase of brachial artery Doppler frequencies and Fratio results in a decrease of the thumb bloodpressure and T/B index. Only brachial artery Fratio correlated significantly $(R-v a l u e=-0.3926)$ with $\mathrm{T} / \mathrm{B}$ indices (fig. 5.5).

The type of fistula complication and corresponding distal bloodpressures are outlined in Table 5.6. Patients with ischemia had significantly lower bloodpressures and T/B indices than patients without complications $(\mathrm{P}<0.001)$. One out of 6 patients with Diabetes Mellitus developed hand ischemia, against 3 out of 53 nondiabetic patients ( $17 \%$ versus $6 \% ; \mathrm{P}>0.1$ ). No differences in digital pressures were found between patients with thrombosis or venous hypertension and patients without any complication. 
Table 5.3. Brachial artery Fmax versus Thumb pressure and T/B pressure Index (mean and SD)

\begin{tabular}{lrrrrr}
\hline \multirow{2}{*}{ Fmax $(\mathrm{Khz})$} & \multicolumn{3}{c}{ Thumb pressure (mm Hg) } & \multicolumn{2}{c}{ T/B pressure index } \\
& $\mathrm{N}$ & mean & $\mathrm{SD}$ & mean & SD \\
\hline$<4.0$ & 27 & 120 & 43 & 0.77 & 0.18 \\
$4.0-5.9$ & 23 & 123 & 46 & 0.76 & 0.26 \\
$6.0-7.9$ & 6 & 88 & 37 & 0.53 & 0.18 \\
$\geq 8.0$ & 2 & 80 & 0.5 & 0.50 & 0.08 \\
\hline
\end{tabular}

Table 5.4. Brachial artery Fdias versus Thumb pressure and $\mathrm{T} / \mathrm{B}$ pressure Index (Mean and SD)

\begin{tabular}{lrrrrr}
\hline \multirow{2}{*}{ Fdias (Khz) } & \multicolumn{3}{c}{ Thumb pressure (mm Hg) } & \multicolumn{2}{c}{ T/B pressure index } \\
& $\mathrm{N}$ & mean & $\mathrm{SD}$ & mean & SD \\
\hline 2.0 & 27 & 121 & 43 & 0.78 & 0.21 \\
$2.0-3.9$ & 26 & 119 & 47 & 0.72 & 0.25 \\
$\geq 4.0$ & 5 & 80 & 10 & 0.52 & 0.11 \\
\hline
\end{tabular}

Table 5.5. Brachial artery Fratio versus Thumb pressure and T/B pressure Index (mean and SD)

\begin{tabular}{|c|c|c|c|c|c|}
\hline \multirow[t]{2}{*}{ Fratio } & \multirow[b]{2}{*}{$\mathrm{N}$} & \multicolumn{2}{|c|}{ Thumb pressure (mm Hg) } & \multicolumn{2}{|c|}{$\mathrm{T} / \mathrm{B}$ pressure index } \\
\hline & & mean & $\mathrm{SD}$ & mean & $\mathrm{SD}$ \\
\hline$<2.0$ & 22 & 135 & 42 & 0.83 & 0.19 \\
\hline $2.0-2.9$ & 22 & 113 & 44 & 0.73 & 0.24 \\
\hline $3.0-3.9$ & 7 & 87 & 39 & 0.53 & 0.22 \\
\hline$\geq 4.0$ & 2 & 82 & 8 & 0.68 & 0.06 \\
\hline
\end{tabular}




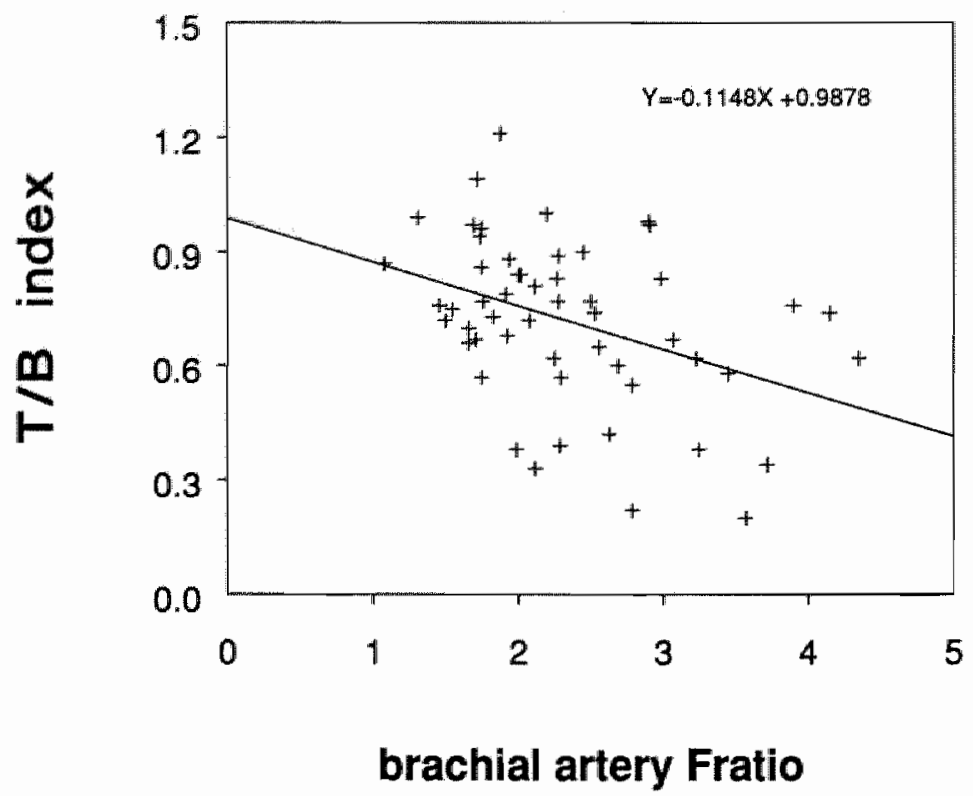

fig. 5.5. Scattergram of brachial artery Fratio versus $T / B$ index in Brescia/Cimino and graft AV fistulas $(R=-0.3926 ; P=0.01)$.

Table 5.6. Type of complication versus Thumb pressure and T/B pressure Index (Mean and SD)

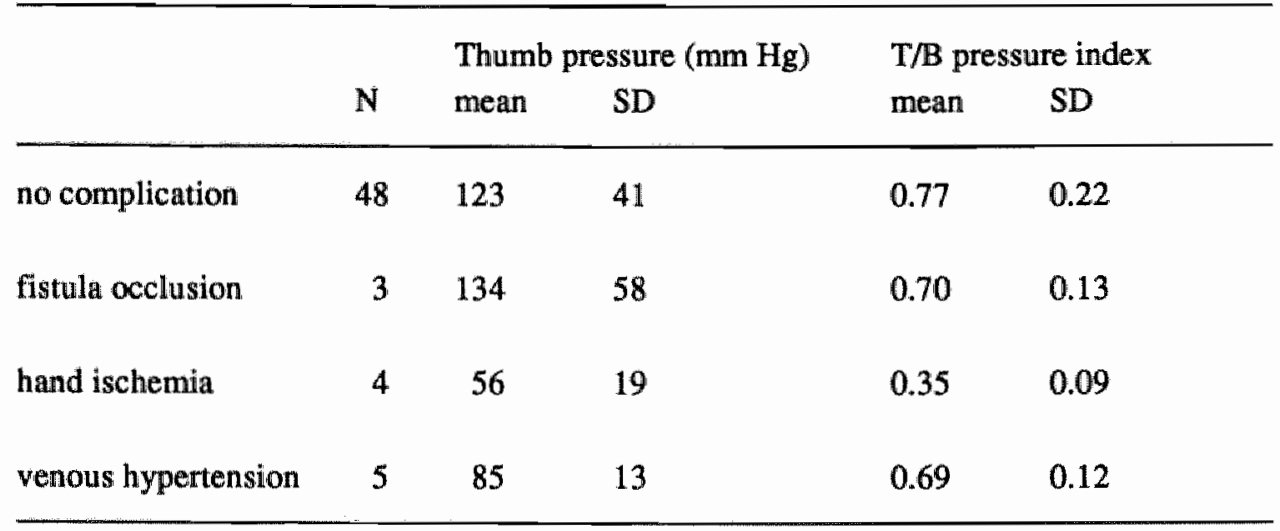


Table 5.7. Proximal radial artery stenosis, distal radial artery stenosis and efferent vein stenosis versus Thumb pressure and T/B pressure index (Mean and SD)

\begin{tabular}{|c|c|c|c|c|c|}
\hline & \multirow[b]{2}{*}{$\mathbf{N}$} & \multicolumn{2}{|c|}{ Thumb pressure ( $\mathrm{mm} \mathrm{Hg}$ ) } & \multicolumn{2}{|c|}{$\mathrm{T} / \mathrm{B}$ pressure index } \\
\hline & & mean & $\mathrm{SD}$ & mean & $\mathrm{SD}$ \\
\hline \multicolumn{6}{|c|}{ proximal radial artery } \\
\hline stenosis - & 26 & 116 & 49 & 0.68 & 0.20 \\
\hline stenosis + & 20 & 112 & 32 & 0.71 & 0.16 \\
\hline occlusion & 3 & 100 & 52 & 0.57 & 0.27 \\
\hline \multicolumn{6}{|c|}{ distal radial artery } \\
\hline stenosis - & 32 & 112 & 41 & 0.68 & 0.18 \\
\hline stenosis + & 10 & 99 & 38 & 0.64 & 0.20 \\
\hline occlusion & 7 & 137 & 49 & 0.77 & 0.22 \\
\hline \multicolumn{6}{|l|}{ efferent vein } \\
\hline stenosis - & 13 & 111 & 48 & 0.65 & 0.25 \\
\hline stenosis + & 30 & 115 & 40 & 0.70 & 0.17 \\
\hline occlusion & 6 & 109 & 49 & 0.71 & 0.13 \\
\hline
\end{tabular}

The influences of severe stenoses in the radial artery proximal and distal to the arteriovenous anastomosis and of efferent vein stenoses on digital bloodpressure are shown in Table 5.7. No significant differences in T/B indices could be detected between patients with and without proximal or distal stenoses. Also the presence of efferent vein stenoses had no significant effect on thumb bloodpressure. 


\section{DISCUSSION}

Reversal of bloodflow does occur in dialysis fistulas and is comparable to the flow reversal observed in the vertebral arteries in patients with subclavian steal syndrome. Whether the flow in the distal radial artery will be antegrade or retrograde depends on local vessel resistances, intravascular pressures and the magnitude of the bloodleakage from the arterial into the venous system. In our study $74 \%$ of the AV fistulas with the anastomosis to the distal radial artery, showed a steal phenomenon detectable by Duplex examination. In analogy of the grading of steal in the vertebral artery, a differentation between permanent and transient steal can be made in AV fistulas. The degree of the steal in the distal radial artery depends on the amount of shunted blood and the collateral. flow in the ulnar artery. A permanent steal results in a lowering of distal bloodpressures. We found the lowest thumb pressures and $T / B$ indices in patients with a Brescia/Cimino fistula and permanent steal. In fistulas with a high shunt volume, as documented by a high Fmax and Fratio of the Doppler signal of the brachial artery, relatively low digital pressures are measured. These findings correspond well with clinical reports from the literature. ${ }^{10}$ In contrast to previous reports, ${ }^{4,5}$ patients with Diabetes Mellitus in our study had no significantly greater risk for the development of distal ischemia compared to nondiabetic patients. However in ischemic hands, significantly lower thumb pressures and indices were found than in noncomplicated extremities. Three of the patients with hand ischemia had Brescia/Cimino fistulas with severe proximal arterial disease in two of them. The other patient was an 83-years old woman with a loop prosthetic graft anastomosed to the brachial. artery. Doppler spectral analysis of the brachial artery of this patient showed an excessive fistula flow and this feature together with possibly arteriosclerotic disease in the forearm vessels might explain the distal ischemia. Haimov et. al. found severe symptomatic steal in $1.6 \%$ of $516 \mathrm{AV}$ fistulas of different types. ${ }^{13}$ They could define a specific patient group prone to ischemic complications, i.e. the female diabetic with preexisting sclerotic vessels. In their study elbow fistulas had a high incidence of ischemia. Kinnaert et.al. ${ }^{14}$ have done a followup study of 85 patients with Brescia/Cimino fistulas. Twenty-four patients $(28 \%)$ with either side-to-side or end-to-end anastomoses, complained of hand claudication. None of the patients developed trophic lesions. The authors ascribed the claudication to insufficient arterial blood supply either caused by retrograde flow in the distal radial artery or insufficient collateral flow in the ulnar artery. Van Gemert et. al. ${ }^{15}$ simulated the local hemodynamics of arteriovenous fistulas in an in vitro model. They could prove, that patients with 
end-to-end artery-to-vein Brescia/Cimino fistulas have the lowest chance on ischemia. In this in vitro model, fistulas with highly resistant afferent arteries or with large flows in the fistulas (e.g. fistulas with an arterial anastomosis to the brachial artery), were especially prone to distal ischemia. In particular, snuffbox AV fistulas and Brescia/Cimino fistulas with proximal radial artery occlusion had the greatest chance on finger ischemia.

In our study 2 out of 4 patients with ischemia had proximal radial artery sclerosis or occlusion. However overall no statistical significant influence of severe proximal or distal radial artery stenoses on digital bloodpressure could be detected. Adequate collateral flow through the ulnar artery probably compensates distal perfusion. Neither venous outflow stenoses or obstructions resulted in low thumb pressures. Patients with occlusion of the radial artery distal to the anastomosis had the highest thumb bloodpressures.

The diastolic flow in the distal ulnar artery has a direct relationship with distal pressures. Enddiastolic flow in peripheral arteries increases in case of reduced peripheral resistance. Thus a high ulnar diastolic flow (Fdias) indicates a low resistance in the palmar arch, distal radial artery and arteriovenous anastomosis. Subsequently as a result of these low resistance, distal bloodpressure will be lowered. This observation corresponds well with the mathematical theories from the literature. ${ }^{1,15}$

In the case of radial artery steal always diastolic flow in the ulnar artery will be noticed. Thus screening of the ulnar artery Doppler spectrum can indicate a steal phenomenon.

To our opinion digital ischemia may develop in patients with excessive fistula flow and/or proximal radial artery obstruction with excessive collateral flow through the ulnar artery. A radial steal phenomenon can be detected in most patients and has no clinical significance. Before creating any type of arteriovenous fistula for access purpose, the extremity should be investigated by Duplex scanning with special focus on the brachial and radial arteries. Collateral flow through the ulnar artery can be tested by digital bloodpressure measurement with and without distal radial artery compression. Excessive fistula flow should be avoided by creation of an arteriovenous anastomosis with a critical diameter or the use of tapered grafts especially in fistulas with the anastomosis to the brachial artery. 


\section{REFERENCES}

1 Strandness, D.E., Sumner, D.S.:

Hemodynamics for surgeons, Grune and Stratton 1975; 621-663.

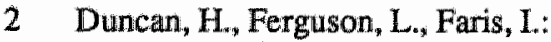

Incidence of the radial steal syndrome in patients with Brescia fistula for hemodialysis:

Its clinical significance.

J Vasc Surg 1986; 4: 144-147.

3 Mattson, W.J.:

Recognition and treatment of vascular steal secondary to hemodialysis prostheses.

Am J Surg 1987; 154: 198-201.

4 Buselmeier, T.J., Kjellstrand, C.M., Rattazzi, L.C.:

The A-V fistula in the diabetic: Ischemia and gangrene resulting in amputation.

Clin Dial Transplant Forum 1972; $2 ; 6$.

5 Storey, B.G., George, C.R.P., Stewart, J.H., Tiller, D.J., May, J., Sheil, A.G.R.:

Embolic and ischemic complications after anastomosis of the radial artery to cephalic vein. Surgery 1969; 66: 325-327.

6 Matolo, N., Kastagir, B., Stevens, L.E., Chrysanthakopoulos, S., Weaver, D.H., Klink$\operatorname{man}_{3} \mathrm{H}$ :

Neurovascular complications of brachial arteriovenous fistula.

Am J Surg 1971; 121: 716-719.

7 Bussell, J.A., Abbott, J.A., Lim, R.C.:

A radial steal syndrome with arteriovenous fistula for hemodialysis.

Ann Internal Med 1971; 75: 387-394.

$8 \quad$ Lindstedt, E., Westling, $\mathrm{H}$.:

Effects of an antebrachial Cimino-Brescia arteriovenous fistula on the local circulation in the hand.

Scan J Urol Nephrol 1975; 9": 119-124.

9 Gundersen, J.:

The systolic finger blood pressure before and after establishment of a Brescia fistula. Vasa 1980; 9: 21-23.

10 Gerwen, J.A. van, Bruyninckx, C.M.A., Gemert, M.J.C. van, Gerlag, P.G.G.:

Noninvasive tests assessing the capacity and hemodynamic sequelae of arteriovenous fistulas for hemodialysis.

Dialysis Transplantation 1986; 15: 97-100.

11 Dally, P., Brantigan, C.O.:

Plethysmography and the diagnosis of the steal syndrome following placement of arteriovenous fistulas and shunts for hemodialysis access.

J Cardiovasc Surg 1987; 28: 200-203.

12 Tordoir, J.H.M., Bruin, H.G., de, Hoeneveld, H., Eikelboom, B.C., Kitslaar, P.J.E.H.M.: Duplex ultrasound scanning in the assessment of arteriovenous fistulas created for hemodialysis access: comparison with Digital Subtraction Angiography.

J Vasc Surg 1989; 10:122-128

13 Haimov, M., Baez, A., Neff, M., Slifkǐn, R.:

Complications of arteriovenous fistulas for hemodialysis.

Arch Surg 1975; 110; 708-712. 
14 Kinnaert, $P_{\star s}$ Struyven, J., Mathieu, J., Vereerstraeten, P., Toussaint, C., Geertruyden, J. van:

Intermittent claudication of the hand after creation of an arteriovenous fistula in the forearm.

Am J Surg 1980; 139: 838-843.

15 Gemert, M.J.C., van, Bruyninckx, C.M.A.:

Simulated hemodynamic comparison of arteriovenous fistulas.

J Vasc Surg 1987; 6: 39-44. 


\section{Chapter 6}

\section{General discussion}

\section{INTRODUCTION}

In most countries, there has been a steady increase in patients with terminal renal failure, treated by dialysis (hemodialysis and CAPD). In 1988, 2958 patients ( 211 patients pro million) were on dialysis in 52 centers in the Netherlands. In the USA about 100.000 patients ( 435 patients pro million) are kept alive by means of dialysis. In particular the number of elderly patients and patients with diabetes seems to show a marked increase during the last years. ${ }^{2}$ Therefore, it can be assumed that rising problems in the creation and maintenance of vascular access may develop. Inability to obtain or maintain vascular access may threaten the life expectance and the quality of life of these patients. Generally, primary access by means of a radiocephalic Brescia/Cimino fistula at the wrist, will be sufficient for adequate vascular access. Some $20 \%$ of the patients are not suitable for the construction of this fistula because of lacking veins. Another $30 \%$ of the patients will loose their AV fistula because of irreversible thrombotic occlusion. Two to five percent of the patients will develop clinical symptoms of ischemia, high-output failure or venous hypertension, due to hemodynamic changes in the forearm. ${ }^{16}$ In secondary access methods the complication rate is even higher. Thrombosis and infection are responsible for fistula failure in respectively 60 and 10 percent of the patients. ${ }^{14}$ The formation of false aneurysms or peripheral ischemia are less frequently occurring problems.

Development of stenotic lesions at the site of the arteriovenous anastomosis in Brescia/Cimino fistulas or at the site of the graft-to-vein anastomosis in graft fistulas, are likely to be responsible for fistula occlusion. Local hemodynamic disturbances in the forearm and hand, are usually the result from proximal venous outflow obstruction or an excessive bloodflow steal from the distal radial artery. 
An accurate diagnosis of complications in AV fistulas is of paramount importance for the treatment and thus maintenance of the vascular access site.

Furthermore it could be of interest to identify patients at risk for the development of complications and to determine clinical and noninvasively measured parameters with predictive value.

Therefore, the goal of this thesis is to determine the value and accuracy of new noninvasive methods for the investigation of Brescia/Cimino and graft AV fistulas. In addition, the prognostic value of clinical and noninvasively measured parameters, for the prediction of complications has been studied. Finally, the changes in local hemodynamics in the forearm, caused by the AV fistula, have been investigated noninvasively.

The specific topics studied in patients with terminal renal failure and arteriovenous fistulas in the forearm were:

- the diagnostic accuracy of continuous-wave Doppler spectrall analysis and sonography for the evaluation of PTFE graft AV fistulas (Chapter 2).

- the value of Duplex ultrasound scanning in the assessment of Brescia/Cimino and graft AV fistulas (Chapter 3).

- the prognostic value of clinical and noninvasively measured parameters for the development of fistula complications (Chapter 4).

- the influences of the AV fistula on local hemodynamics in the hand as detectable by means of Duplex scanning and digital bloodpressure measurement (Chapter $5)$.

\section{Noninvasive investigation of PTFE graft fistulas}

The value of continuous-wave Doppler analysis and sonography for the diagnosis of stenoses in asymptomatic PTFE ( ${ }^{\circledR} \mathrm{Gore}$-tex) graft fistulas was studied in 23 patients. Of their stenotic lesions $60 \%$ were located at the graft-venous anastomosis, which is comparable to data from the literature. ${ }^{13}$ In the area of the graft anastomoses, continuous-wave Doppler analysis was able to differentiate between arterial and venous anastomotic signals in most patients. However in two graft AV fistulas in a loop configuration with both anastomoses crossing each other at the level of the elbow, it was impossible to screen the anastomoses separately. In the sampling area of continuous-wave Doppler systems, a part of a vessel cross-section or the cross-section of multiple vessels can be present. Therefore, an accurate identification of the vessels may be difficult and even impossible. This is an important drawback of continuous-wave Doppler exam- 
ination. A selective detection and insonation of the anastomoses at the level of the elbow may solve this problem and can be achieved by the use of pulsed Doppler systems in combination with B-mode imaging (Duplex scanning).

Determination of the maximal systolic frequencies in the Doppler signal is an accurate method for the diagnosis of stenoses of $50 \%$ and more and results in a sensitivity of $88 \%$ and a specificity of $89 \%$. These data are not as good as the results of continuous-wave Doppler diagnosis of carotid artery stenoses. The degree of spectral broadening is an important parameter for the detection of carotid artery disease. ${ }^{1,9}$ However its use has less significance in the diagnosis of graft AV fistula stenoses. As the flow velocity increases like in AV fistulas, the regular laminar flow changes to turbulent flow, resulting in spectral broadening of the Doppler signal. The presence of stenoses may therefore be missed, if only spectral broadening is considered.

The application of sonography (B-mode imaging) for the detection of graft fistula stenoses is less sensitive (69\%), but more specific (100\%) compared to Doppler spectral analysis. An additional advantage is the ability to detect perivascular abnormalities like aneurysms and hematoma. The limitations of this method are related to the inability of ultrasound to differentiate between substances of the same acoustic impendance and therefore to distinguish a soft plaque stenosis from a recent thrombus.

Nevertheless, continuous-wave Doppler spectral analysis and sonography are valuable methods for the investigation of graft (PTFE) fistulas. Overlying and crossing vessels can make the interpretation of the Doppler signal more difficult and therefore this method seems to be inappropriate for the examination of AV fistulas with multiple and crossing vessels. The combined use of Doppler spectral analysis and real-time sonography results in a high sensitivity and specificity. With Duplex scanning these two methods can be applied simultanuously.

\section{Duplex ultrasound scanning of Brescia/Cimino and graft AV fistulas}

The accuracy of Duplex scanning in the detection of carotid artery stenoses has been well established. ${ }^{3}$ Only recently Duplex scanning has been introduced for the diagnosis of aortoiliac stenosis, peripheral arterial and venous disease and for the assessment of dialysis fistulas. In these studies on the value of Duplex scanning for the examination of AV fistulas, the outcome of the Duplex scan was compared to intraoperative data and in a few patients only with angiography. ${ }^{6,8,11,18}$ The criteria for the diagnosis of significant stenoses in the fistula 
circuit have not yet been outlined clearly. Therefore, we investigated the accuracy of Duplex scanning of different types of fistulas and correlated the results with the outcome of Digital Subtraction Angiography as the gold standard. Different parameters in the Doppler signal were measured and the accuracy, sensitivity and specificity for the detection of stenoses of $50 \%$ and more in different fistula segments were calculated. The peak systolic and the enddiastolic frequency appeared to be the most accurate parameters. Determination of these values results in sensitivities and specificities well above $90 \%$, in particular in the efferent vein area. It is more difficult to detect accurately stenotic lesions in the anastomotic vessels of Brescia/Cimino fistulas by Duplex scanning, for which several reasons can be mentioned. The anatomical course of the fistula vessels in the anastomotic section of Brescia/Cimino fistulas, may be variable and thus difficult to recognize and to insonate. Moreover, determination of the angle of Doppler insonation may be difficult in extremely curved anastomotic vessels, making determination of the Doppler frequencies inaccurate. Finally, the large intravascular pressure difference across an arteriovenous anastomosis results in acceleration of bloodflow and in an increase of velocity and peak frequencies. As a result a moderate stenosis may be overestimated, comparable to what happens in the diagnosis of carotid artery stenoses in patients with a contralateral carotid occlusion. ${ }^{4,7}$

In our study B-mode imaging was used to detect and recognize arterial and venous vessels and not to measure intravascular diameters. However the Bmode part of Duplex scanning might be of additional value for the assessment of AV fistulas. No studies concerning its use have yet appeared in the literature. Further research on the combined use of B-mode imaging and Doppler spectral analysis for the investigation of AV fistulas seems worthwhile.

Color Doppler sonography is a new noninvasive modality, in which the direction and velocity of the bloodflow are expressed in a wide spectrum of colors from red to blue. Bloodcells moving towards the probe are represented in red on the screen, while bloodflow away from the probe is displayed in a spectrum of blue colors. Preliminary reports on the use of color Doppler imaging in the evaluation of carotid arterial, peripheral arterial and venous disease, are promising. ${ }^{10}$ Recently Middleton et. al. published on color Doppler sonography in hemodialysis vascular access. ${ }^{12}$ They found a positive correlation between DSA examination and color Doppler investigation in $84 \%$ of the patients with synthetic grafts. The results in the evaluation of direct arteriovenous fistulas were less good due to the complex venous runoff and the variability of the anastomoses. 
Further improvements in Duplex and color Doppler sonography technology and increased experience in performing and interpreting the examinations, may result in an improved diagnostic accuracy of these noninvasive diagnostic techniques.

\section{The value of Duplex scanning for the prediction of fistula complications}

Several clinical and patient-linked parameters have been reported to be of prognostic significance for the occurrence of fistula complications. No data are available concerning the prognostic value of noninvasive investigations in predicting complications. In several studies, Diabetes Mellitus and type of fistula have been mentioned as important prognostic parameters of fistula failure. In the underlying study no significant influence of diabetes could be detected on the contrary. Sex, congestive heart failure and type of fistula were of prognostic value. We also found different parameters in the brachial artery Doppler spectrum valuable for the prediction of fistula thrombosis, in particular, the maximal systolic and enddiastolic frequency. From the literature, it is known that in thrombosed fistulas often severe stenoses can be found during surgical exploration. ${ }^{13}$ Moreover, it is likely that venous outflow obstruction is the underlying cause in patients with venous hypertension. Therefore, the noninvasive detection of stenoses may be of importance to select fistulas at risk for thrombosis, allowing the prevention of fistula occlusion by elective revision. In this study, the total number of stenoses in the fistula circuit correlates well with the occurrence of thrombosis. The presence of efferent vein stenoses has a significant effect on the development of venous hypertension.

Furthermore, in a multivariate analysis it became evident that the number of venous stenoses is the most important prognostic factor for flow-related complications, followed by congestive heart failure and the brachial artery Fmax. Sex, age, diabetes, Fdias, total number of stenoses are of no additional prognostic value. This outcome indicates that noninvasive assessment of the fistula vessels and the brachial artery can select patients at risk for complications. 


\section{Hemodynamic sequelae of AV fistulas investigated by Duplex ultrasound scanning and digital bloodpressure measurement}

The fysiology and hemodynamics of arteriovenous fistulas in the forearm have been described extensively by Strandness and Sumner. ${ }^{15}$ Several studies on the changes in the amount and direction of bloodflow in the forearm, caused by AV fistulas and detectable by Doppler examination and digital bloodpressure measurement, have since been reported. In none of these studies distal radial artery steal has been studied directly with a noninvasive method.

In the present study, the type and degree of this steal could be correlated with digital bloodpressures. In patients with permanent steal significant lower thumb pressures were found compared with patients with a transient steal. If the bloodflow and velocity in the distal ulnar artery increase (measured by systolic and enddiastolic frequencies), also the velocity in the palmar arch will increase. As a result, the bloodpressure in the digital arteries will be lowered. We could prove this feature in the group of patients studied. In particular, there was a significant correlation between the ulnar artery Fdias and both the thumb pressure anci thumb/brachial (T/B) pressure index.

The presence of large fistula flows, like in elbow fistulas, may result in peripheral ischemia due to stealing from the peripheral arteries. In the studied patients, no significant correlation was found between brachial artery Fmax or Fdias and digital pressures. However, the brachial artery frequency ratio (Fratio) did correlate with the T/B index. In 2 of the 4 patients with hand ischemia, high brachial artery Doppler frequencies and ratios were found, indicating large volume flows through the fistula.

In vitro studies have shown the theoretical influence of proximal artery obstruction on digital bloodpressures and the chance to develop hand ischemia. ${ }^{5}$ These observations could not be confirmed by the results of our patient study. The presence of radial artery stenoses of $50 \%$ or more, proximal to the arteriovenous anastomosis, did not result in significantly lower thumb pressures and $T / B$ indices. Probably, adequate collateral ulnar artery flow will compensate distal perfusion and pressure.

Duplex scanning and digital bloodpressure measurement are valuable methods for the evaluation of patients with symptoms of hand ischemia. Their application may be particularly useful to discriminate between peripheral neuropathy and ischemia and venous congestion. ${ }^{17}$ Follow-up studies on the altered hemodynamics in the arteries of the forearm and hand after the creation of an arteriovenous fistula, may be of particular interest and might play a role in the prevention of hand ischemia. 


\section{CONCLUSIONS AND FUTURE PERSPECTIVES}

This thesis is a first step in the search for prognostic factors which might lead to less complications and improved patency rates of arteriovenous fistulas for hemodialysis. From the results of this study, it can be concluded that an accurate noninvasive detection of stenoses in the fistula circuit is possible. Furthermore, Duplex scanning can quantify hemodynamic sequelae in the fistula arm and be of value to determine prognostic riskfactors. Regular noninvasive follow-up thus could be useful to detect patients and fistulas at risk for complications.

It seems worthwhile to organize a prospective study to see whether elective intervention (transluminal angioplasty or surgical revision) based on such follow-up might influence complication and patency rates of dialysis fistulas. Furthermore, it may be of interest to study noninvasively the pre- and peroperative hemodynamics in the forearm in order to detect in an early stage correctable flow disturbances which might lead to early fistula occlusion. 


\section{Chapter 7}

\section{Summary}

In this thesis new, noninvasive techniques for the assessment of AV fistulas for hemodialysis are described. Dialysis fistulas have a high rate of complications, which often result in loss of the vascular access site. Therefore accurate diagnosis of fistula complications and a reliable follow-up method may be of importance for the maintenance of the AV fistula. The goal of this study was to determine the accuracy of Doppler examination and sonographic imaging techniques for the diagnosis of stenoses in Brescia/Cimino as well as graft AV fistulas. In addition, the prognostic value of noninvasive ultrasound methods for the detection of complications in AV fistulas and the assessment of hemodynamic changes in the forearm, due to the AV fistula, were studied.

In chapter 1 the different types of vascular access and their complications as well as their (patho)fysiology and methods of investigation are described. Thrombotic occlusion is the major complication and occurs more frequently in graft AV fistulas than in Brescia/Cimino fistulas. Puncture-related and hemodynamic complications will develop in the minority of the patients. The presence of an AV fistula results in a different vascular fysiology of the extremity. Increased bloodflow and decreased resistance may give rise to lowered finger perfusion and bloodpressure, increased cardiac output and venous distension.

Angiography is commonly used for the assessment of complicated fistulas. It can be performed by direct brachial cannulation, fistula punction or intravenous contrast injection in the contralateral arm (Digital Subtraction Angiography). Noninvasive methods of investigation can be either indirect, making use of pulse-volume registration and distal bloodpressure measurement or direct. Direct noninvasive methods of investigation are sonography and Doppler spectral analysis. 
In chapter 2, the results of continuous-wave (CW) Doppler spectral analysis and sonography for the detection of stenoses in PTFE graft AV fistulas are described. Conventional angiography was used as a reference method for the noninvasive examinations. Sufficient information was obtained with sonography in all patients. Doppler analysis was not able to discriminate between arterial and venous anastomoses in 2 patients. The sensitivity of sonography to detect stenoses of $50 \%$ and more, was $69 \%$ and the specificity $100 \%$. Determination of the maximal systolic frequency in the Doppler signal resulted in a sensitivity of $88 \%$ and a specificity of $89 \%$. The use of severe spectral broadening with negative reflections in the Doppler signal had a sensitivity of $86 \%$ and a specificity of $87 \%$.

It could be concluded that the noninvasive examination of PTFE graft fistulas with CW Doppler and sonography, is accurate in the detection of stenoses of $50 \%$ or more.

In chapter 3 the results of Duplex scanning for the assessment of Brescia/Cimino fistulas and graft AV fistulas, are presented. Digital subtraction angiography served as the reference method. The best parameter for detection of stenotic lesions of $50 \%$ or more was the maximal systolic frequency (Fmax). Determination of enddiastolic frequencies (Fdias) and Resistance Index (RI) had no additional value. The ratio of maximal systolic frequencies, measured over stenotic and nonstenotic vessels (Fratio), led to an increase of accuracy in the diagnosis of stenoses in graft fistulas only. In Brescia/Cimino fistulas the sensitivity was $79 \%$ and the specificity $84 \%$ in the detection of stenoses in the anastomotic area. For graft fistulas the sensitivity was $92 \%$ and the specificity $84 \%$. Efferent vein stenoses could be detected with a sensitivity of $95 \%$ and a specificity of $97 \%$.

The relatively low sensitivity and specificity in the anastomotic vessels of Brescia/Cimino fistulas is due to the high flow over the anastomosis and the difficulty to recognize the anatomy of the fistula.

In chapter 4 the value of clinical and Duplex parameters for the prediction of fistula complications is described. Sex, type of fistula, previous access surgery and congestive heart failure were significant clinical riskfactors for the occurrence of flow-related complications (fistula thrombosis and low flow). Peripheral arterial disease was the only risk factor for the development of hemodynamic complications (ischemia and venous hypertension). Brachial artery Fmax, Fdias and Fratio were important determinants for the development of thrombosis. The total number of stenoses of $50 \%$ and more, detected by the 
Duplex scan, was significantly related to fistula thrombosis. In patients with venous hypertension, the number of venous stenoses is significantly greater than in patients without venous hypertension. In a multivariate analysis, sex, congestive heart failure and brachial artery Fmax were significantly correlated to the later development of flow-related complications. The number of venous stenoses had a significant relationship with the chance on hemodynamic complications.

Chapter $\mathbf{5}$ describes the changes in local hemodynamics in the arteries of the forearm and hand, evaluated by Duplex scanning and digital bloodpressure measurement. Low thumb pressure and thumb-to-brachial pressure index (T/B index) were found in patients with a Brescia/Cimino fistula and patients with a permanent steal in the distal radial artery. Radial artery stenoses, proximal or distal to the anastomosis in Brescia/Cimino and straight graft fistulas, did not result in significantly lower $\mathrm{T} / \mathrm{B}$ indices. Fistulas with large volume flows, documented by spectral analysis of the brachial artery Doppler spectrum, had relatively low T/B indices. In patients with symptoms of hand ischemia, significant lower thumb pressures and $\mathrm{T} / \mathrm{B}$ indices were measured compared to asymptomatic patients.

The peripheral resistance, as it could be determined by Doppler spectral analysis of the distal ulnar artery, directly correlated with the T/B index. A decrease in peripheral resistance, documented by an increase in enddiastolic flow in the ulnar artery, resulted in lowering of the T/B index.

Chapter 6 provides a general discussion on the different methods of examination. The methods are compared as far as their accuracy and limitations are concerned. The local hemodynamic circulation in the arteries of forearm and hand, in patients with AV fistulas, is discussed.

Conclusions and future perspectives on the use of noninvasive diagnostic techniques of $\mathrm{AV}$ fistulas are outlined. 



\section{Chapter 8}

\section{Samenvatting}

In dit proefschrift worden nieuwe, niet-invasieve technieken voor het onderzoek van AV fistels voor hemodialyse, beschreven. Dialysefistels hebben een grote kans op complicaties, welke vaak het verlies van de toegang tot de bloedbaan tot gevolg hebben. Daarom is een betrouwbare diagnose van gecompliceerde fistels en een goede follow-up van belang voor het behoud van de AV fistel. Het doel van deze studie is bepaling van de betrouwbaarheid van Doppler onderzoek en echografische technieken voor de diagnose van stenosen in Brescia/Cimino en graft AV fistels. Tevens wordt de voorspellende waarde van niet-invasieve ultrageluidsmethoden, voor het ontstaan van complicaties in AV fistels onderzocht en de veranderingen in de bloedsomloop in de onderarm, veroorzaakt door de AV fistel, worden bestudeerd.

In hoofdstuk 1 worden de verschillende methoden van toegangschirurgie en hun complicaties, alsmede de (patho) fysiologie en onderzoeksmethoden beschreven. Occlusie door trombose is de belangrijkste complicatie en komt meer voor in graft AV fistels dan in Brescia/Cimino fistels. Complicaties, die het gevolg zijn van punctie, en hemodynamische complicaties zullen bij een minderheid van de patienten ontstaan. De aanwezigheid van een AV fistel in de arm resulteert in een verandering van de bloedstroom. Een toename van de bloedstroom en een vermindering van de perifere weerstand leidt tot verlaging van de vinger perfusie en bloeddruk, toename in hartminuutvolume en uitzetting van de venen.

Angiografie wordt in het algemeen gebruikt voor het onderzoek van AV fistels met complicaties. Angiografie kan worden verricht door middel van punctie van de a. brachialis, punctie van de fistel met een proximale stuwband of via intraveneuze contrast toediening in de contralaterale arm (Digitale Subtractie Angiografie). Niet-invasieve methoden van onderzoek kunnen zowel indirect zijn, gebruik makend van polsvolume registratie en vinger bloeddruk meting, dan wel direct. Directe niet-invasieve onderzoeksmethoden zijn echografie en Doppler spectraal analyse. 
In hoofdstuk 2 worden de resultaten van continuous-wave (CW) Doppler spectraal analyse en echografie voor de detectie van stenosen in PTFE graft AV fistels beschreven. Conventionele angiografie werd gebruikt als de gouden standaard, waarmee de uitkomsten van de niet-invasieve onderzoeken werden vergeleken. Echografie gaf voldoende informatie over de fistels in alle gevallen. Daarentegen was Doppler analyse niet in staat om de arteriele en veneuze anastomoses in 2 patienten van elkaar te onderscheiden. De sensitiviteit van echografie om stenosen van $50 \%$ en meer te ontdekken, was $69 \%$ en de specificiteit was $100 \%$. De bepaling van de maximale systolische frequentie in het Doppler signaal resulteerde in een sensitiviteit van $88 \%$ en een specificiteit van $89 \%$. De toepassing van spectraal verbreding met negatieve frequenties in het Doppler signaal had een sensitiviteit van $86 \%$ en een specificiteit van $87 \%$.

Concluderend kan worden gezegd, dat niet-invasief onderzoek van PTFE graft fistels met behulp van continuous-wave Doppler en echografie, betrouwbaar is voor de diagnostiek van stenosen van $50 \%$ en meer.

In hoofdstuk 3 worden de resultaten van Duplex onderzoek van Brescia/Cimino en graft AV fistells, gepresenteerd. Digitale Subtractie Angiografie fungeerde als de referentie methode. De beste parameter om lesies van $50 \%$ en meer te ontdekken, was de maximale systolische frequentie (Fmax). Bepaling van de einddiastolische frequentie (Fdias) en de Resistance Index (RI) had geen additionele waarde. Gebruik van de ratio van maximale systolische frequenties over een stenotisch segment met een normaal segment (Fratio), gaf alleen bij graft fistels een toename van de betrouwbaarheid voor de diagnose van stenosen. Voor Brescia/Cimino fistels was de sensitiviteit $79 \%$ en de specificiteit $84 \%$ voor het ontdekken van stenosen in de vaten van de arterioveneuze anastomose. Voor graft fistels was de sensitiviteit $92 \%$ en de specificiteit $84 \%$. Stenosen in de afvoerende vene konden worden ontdekt met een sensitiviteit van $95 \%$ en een specificiteit $\operatorname{van} 97 \%$.

De relatief lage sensitiviteit en specificiteit, behaald bij onderzoek van de vaten van de AV anastomose van Brescia/Cimino fistels, is waarschijnlijk het gevolg van de hoge stroomsnelheden in de anastomose en de moeilijkheid om de fistel anatomie te herkennen.

In hoofdstuk 4 wordt de waarde van klinische en Duplex variabelen om fistel complicaties te voorspellen, beschreven. Geslacht, fistel type, eerdere fistel operaties en decompensatio cordis waren belangrijke klinische risicofactoren voor het ontstaan van flow-gerelateerde complicaties (trombose van de fistel en onvoldoende flow). Perifere vaatziekte was de enige risicofactor voor het ontwikkelen 
van hemodynamische complicaties (ischemie en veneuze hypertensie). De maximale systolische frequentie, einddiastolische frequentie en frequentie ratio (quotient van maximale systolische frequenties met open en gecomprimeerde fistel) in de a. brachialis, waren belangrijke parameters voor het ontstaan van flow-gerelateerde complicaties. Het totaal aantal stenosen van $50 \%$ en meer, ontdekt door de Duplex scan, was significant gerelateerd aan het optreden van trombosering. Bij patienten met een veneuze hypertensie, was het aantal stenosen in de efferente vene belangrijk groter dan in patienten zonder een veneuze hypertensie. Met behulp van multivariant analyse bleken geslacht, decompensatio cordis en de maximale systolische frequentie in de a. brachialis, statistisch significant te correleren met het optreden van flow-gerelateerde complicaties. Het aantal stenosen in de afvoerende vene had een belangrijk relatie met de kans op hemodynamische complicaties.

Hoofdstuk 5 beschrijft de veranderingen in locale hemodynamiek in de slagaderen van de onderarm en hand, onderzocht met behulp van Duplex scanning en vinger bloeddruk meting. Een lage duimdruk en duim/brachialis $(D / B)$ index werden gevonden bij patienten met een Brescia/Cimino fistel en patienten met een permanente steal in de distale a.radialis. Stenosen in de a. radialis, proximaal of distaal van de anastomose in Brescia/Cimino fistels en rechte graft interposities, hadden geen invloed op de D/B index. Fistels waardoor een groot volume aan bloedstroom gaat, gedocumenteerd door spectraal analyse van het Doppler signaal van de a. brachialis, hadden relatief lage $\mathrm{D} / \mathrm{B}$ indices. Bij patienten met klachten van hand ischemie werden belangrijk lagere duimdrukken en $D / B$ indices gemeten, vergeleken met asymptomatische patienten.

De perifere weerstand, zoals die bepaald kon worden door spectraal analyse van het Doppler signaal van de distale a. ulnaris, correleerde rechtstreeks met de D/B index. Een vermindering in de perifere weerstand, gedocumenteerd door een toename van de einddiastolische bloedstroom in de a. ulnaris, resulteerde in een verlaging van de $\mathrm{D} / \mathrm{B}$ index.

In hoofdstuk 6 wordt een algemene beschouwing over de verschillende methoden van onderzoek gehouden. De methoden worden vergeleken wat betreft hun betrouwbaarheid en beperkingen. De in de inleiding gestelde vragen worden beantwoord.

De locale hemodynamiek in de bloedvaten van de onderarm en hand, bij patienten met een AV fistel, worden besproken. 
Conclusies en toekomstverwachtingen betreffende het gebruik van niet-invasieve diagnostische technieken voor het onderzoek van AV fistels, worden uitgesproken. 


\section{Dankwoord}

Het schrijven van een proefschrift is geen "one man show". Zonder de hulp en inzet van vele personen is het niet mogelijk om dit tot een goed einde te brengen. De chirurgen van de maatschap Heelkunde van het Catharina ziekenhuis stelden $\mathrm{mij}$ in de gelegenheid om onderzoek te verrichten in het vaatlab. De secretaresse en verpleegkundigen van de dialyse afdeling waren behulpzaam bij het maken van afspraken en het begeleiden van de dialyse patienten.

Herman Pieterman had een groot aandeel in de studie door het echografisch en angiografisch onderzoek uit te voeren.

In het St. Antonius ziekenhuis waren de chirurgen van de maatschap direct bereid om te helpen bij het opzetten van het onderzoek. Vooral de interesse en adviezen van Bert Eikelboom waren een enorme stimulans. In het bijzonder wil ik Hans Hoeneveld bedanken die alle Duplex onderzoeken op de zijn bekende zorgvuldige wijze uitvoerde.

Hein de Bruin verrichtte en perfectioneerde het merendeel van de Digitale Subtractie Angiografieën en was behulpzaam bij het nakijken van de foto's.

Dr. P. van der Zouwen stelde mij in de gelegenheid om de patienten van zijn dialyse afdeling te onderzoeken. Op de Kunstnier afdeling waren de verpleegkundigen en de secretaressen behulpzaam bij het maken van de juiste afspraken. David Batchelor controleerde en corrigeerde de Engelse tekst.

In Maastricht was Prof.dr. Gauke Kootstra bereid om als promotor op te treden. In het bijzonder dank ik mijn co-promoter en huidige collega Peter Kitslaar, voor zijn belangrijke adviezen en aandeel in de statistische verwerking van alle gegevens op snelle wijze. Tenslotte wil ik Luci bedanken, die mij tijdens de steeds vaker terugkerende periodes van totale wanhoop weer motiveerde om toch door te zetten. 



\section{Curriculum vitae}

\section{5 april 1952:}

september 1964 - juni 1969:

september 1969 - november 1975

februari 1976 - november 1976 :

januari 1977 - december 1978:

januari 1979 - december 1982:

1 januari 1983 :

januari 1983 - november 1985 :
januari 1984 - maart 1984: Stage afdeling Heelkunde Canisius-Wilhelmina Ziekenhuis, Nijmegen.

september 1984 - november 1984: Waarneming matschap chirurgie van het R.K.Z. te Groningen.

februari 1986 - januari 1988: Opleiding Vaatchirurgie in het St. Antonius ziekenhuis, Nieuwegein (opleiders: dr. B.C. Eikelboom; F.E.E. Vermeulen).

mei $1988 \quad-$ februari 1989:

maart 1989 - heden:
Geboren te Rotterdam

HBS-B , St. Franciscuscollege Rotterdam.

Gynaecologie en Verloskunde, St. Clara Ziekenhuis Rotterdam. (opleiders: dr. Q.A.M. Eysbouts; dr. J.G. Prins).

Inschrijving in het Specialisten Register als Algemeen Chirurg.

Chef de Clinique Heelkunde, Catharina Ziekenhuis Eindhoven.

Staflid Algemene Heelkunde van het Slotervaart ziekenhuis, Amsterdan.

Staflid Algemene Heelkunde met aandachtsgebied

Vaatchirurgie, Academisch Ziekenhuis Maastricht. 